\title{
Influence of Quinoidal Distortion on the Electronic Properties of Oxidized Divinylarylene-Bridged Diruthenium Complexes
}

\author{
Nils Rotthowe, Jakob Zwicker and Rainer F. Winter* \\ Fachbereich Chemie, Universität Konstanz, Universitätsstraße 10, D-78453 Konstanz, Germany
}

\section{Supporting Information}

\section{Table of Contents}

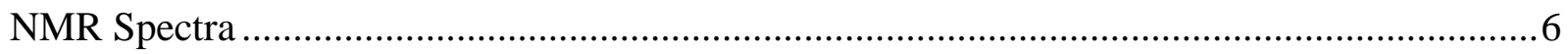

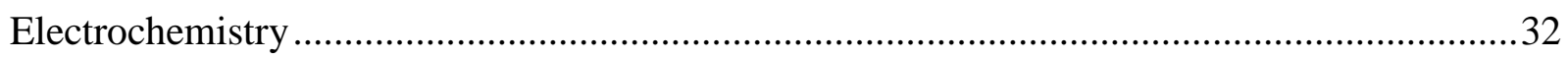

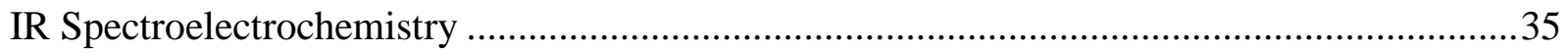

UV/Vis/NIR Spectroelectrochemistry, Solvatochromism and TD-DFT computed spectra......42

\section{List of Figures}

Figure S1. ${ }^{1} \mathrm{H}$ NMR spectrum of $\left[\left\{\mathrm{Ru}(\mathrm{CO}) \mathrm{Cl}\left(\mathrm{P}^{i} \mathrm{Pr}_{3}\right)_{2}\right\}_{2}(\mu-1,4-\mathrm{CH}=\mathrm{CH}-\right.$ naphthalene-CH=CH$\left.)\right]$ $\left(\mathrm{Ru}_{2} \mathrm{NA}\right)$ in $\mathrm{CD}_{2} \mathrm{Cl}_{2}$.

Figure S2. ${ }^{13} \mathrm{C}\left\{{ }^{1} \mathrm{H}\right\}$ NMR spectrum of $\left[\left\{\mathrm{Ru}(\mathrm{CO}) \mathrm{Cl}\left(\mathrm{P}^{i} \mathrm{Pr}_{3}\right)_{2}\right\}_{2}(\mu-1,4-\mathrm{CH}=\mathrm{CH}\right.$-naphthalene$\mathrm{CH}=\mathrm{CH})]\left(\mathrm{Ru}_{2} \mathrm{NA}\right)$ in $\mathrm{CD}_{2} \mathrm{Cl}_{2}$.

Figure S3. ${ }^{31} \mathrm{P}\left\{{ }^{1} \mathrm{H}\right\}$ NMR spectrum of $\left[\left\{\mathrm{Ru}(\mathrm{CO}) \mathrm{Cl}\left(\mathrm{P}^{i} \mathrm{Pr}_{3}\right)_{2}\right\}_{2}(\mu-1,4-\mathrm{CH}=\mathrm{CH}\right.$-naphthalene$\mathrm{CH}=\mathrm{CH})]\left(\mathrm{Ru}_{2} \mathrm{NA}\right)$ in $\mathrm{CD}_{2} \mathrm{Cl}_{2}$.

Figure S4. ${ }^{1} \mathrm{H}$ NMR spectrum of $\left[\left\{\mathrm{Ru}(\mathrm{CO}) \mathrm{Cl}\left(\mathrm{P}^{i} \mathrm{Pr}_{3}\right)_{2}\right\}_{2}(\mu-4,7-\mathrm{CH}=\mathrm{CH}-\mathrm{BTD}-\mathrm{CH}=\mathrm{CH})\right]$ $\left(\mathrm{Ru}_{2} \mathrm{BTD}\right)$ in $\mathrm{CD}_{2} \mathrm{Cl}_{2}$.

Figure S5. ${ }^{13} \mathrm{C}\left\{{ }^{1} \mathrm{H}\right\} \mathrm{NMR}$ spectrum of $\left[\left\{\mathrm{Ru}(\mathrm{CO}) \mathrm{Cl}\left(\mathrm{P}^{i} \mathrm{Pr}_{3}\right)_{2}\right\}_{2}(\mu-4,7-\mathrm{CH}=\mathrm{CH}-\mathrm{BTD}-\mathrm{CH}=\mathrm{CH})\right]$

$\left(\mathrm{Ru}_{2} \mathrm{BTD}\right)$ in $\mathrm{CD}_{2} \mathrm{Cl}_{2}$.

Figure S6. ${ }^{31} \mathrm{P}\left\{{ }^{1} \mathrm{H}\right\} \mathrm{NMR}$ spectrum of $\left[\left\{\mathrm{Ru}(\mathrm{CO}) \mathrm{Cl}\left(\mathrm{P}^{i} \mathrm{Pr}_{3}\right)_{2}\right\}_{2}(\mu-4,7-\mathrm{CH}=\mathrm{CH}-\mathrm{BTD}-\mathrm{CH}=\mathrm{CH})\right]$

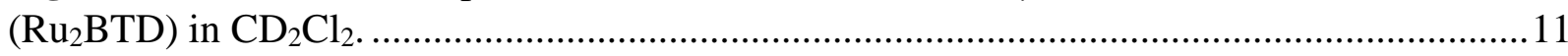

Figure S7. ${ }^{1} \mathrm{H}$ NMR spectrum of 4-bromo-7-(2-methyl-3-butyn-2-ol)-BTD (2) in $\mathrm{CDCl}_{3} \ldots . . .12$ Figure S8. ${ }^{13} \mathrm{C}\left\{{ }^{1} \mathrm{H}\right\}$ NMR spectrum of 4-bromo-7-(2-methyl-3-butyn-2-ol)-BTD (2) in $\mathrm{CDCl}_{3}$.

Figure S9. ${ }^{1} \mathrm{H}$ NMR spectrum of 4-trimethylsilylethynyl-7-(2-methyl-3-butyn-2-ol)-BTD (3) in $\mathrm{CDCl}_{3}$.

Figure S10. ${ }^{13} \mathrm{C}\left\{{ }^{1} \mathrm{H}\right\}$ NMR spectrum of 4-trimethylsilylethynyl-7-(2-methyl-3-butyn-2-ol)$\mathrm{BTD}(3)$ in $\mathrm{CDCl}_{3}$..... 
Figure S11. ${ }^{1} \mathrm{H}$ NMR spectrum of 4-ethynyl-7-(2-methyl-3-butyn-2-ol)-BTD (4) in $\mathrm{CDCl}_{3} \ldots 16$

Figure S12. ${ }^{13} \mathrm{C}\left\{{ }^{1} \mathrm{H}\right\}$ NMR spectrum of 4-ethynyl-7-(2-methyl-3-butyn-2-ol)-BTD (4) in $\mathrm{CDCl}_{3}$.

Figure S13. ${ }^{1} \mathrm{H}$ NMR spectrum of bis[7-(2-methyl-3-butyn-2-ol)-4,4'-BTD]-1,2-acetylene (5) in $\mathrm{CDCl}_{3}$.

Figure S14. ${ }^{13} \mathrm{C}\left\{{ }^{1} \mathrm{H}\right\}$ NMR spectrum of bis[7-(2-methyl-3-butyn-2-ol)-4,4'-BTD]-1,2acetylene (5) in $\mathrm{CDCl}_{3}$.

Figure S15. ${ }^{1} \mathrm{H}$ NMR spectrum of bis[7-(ethynyl)-4,4'-BTD]-1,2-acetylene $\left({ }^{\mathrm{e}} \mathrm{BTD}_{2}, 6\right)$ in $\mathrm{CDCl}_{3}$.

Figure S16. ${ }^{13} \mathrm{C}\left\{{ }^{1} \mathrm{H}\right\}$ NMR spectrum of bis[7-(ethynyl)-4,4'-BTD]-1,2-acetylene ( ${ }^{\mathrm{e}} \mathrm{BTD}, \mathrm{6}$ ) in $\mathrm{CDCl}_{3}$.

Figure S17. ${ }^{1} \mathrm{H}$ NMR spectrum of bis[7- $\left.\left\{\mathrm{Ru}(\mathrm{CO}) \mathrm{Cl}\left(\mathrm{P}^{i} \mathrm{Pr}_{3}\right)_{2}(\mathrm{CH}=\mathrm{CH})\right\}-4,4^{\prime}-\mathrm{BTD}\right]-1,2-$ acetylene $\left(\mathrm{Ru}_{2}{ }^{\mathrm{e}} \mathrm{BTD}_{2}\right)$ in $\mathrm{CD}_{2} \mathrm{Cl}_{2}$.

Figure S18. ${ }^{13} \mathrm{C}\left\{{ }^{1} \mathrm{H}\right\}$ NMR spectrum of bis[7- $\left.\left\{\mathrm{Ru}(\mathrm{CO}) \mathrm{Cl}\left(\mathrm{P}^{i} \mathrm{Pr}_{3}\right)_{2}(\mathrm{CH}=\mathrm{CH})\right\}-4,4^{\prime}-\mathrm{BTD}\right]-1,2-$ acetylene $\left(\mathrm{Ru}_{2}{ }^{\mathrm{e}} \mathrm{BTD}_{2}\right)$ in $\mathrm{CD}_{2} \mathrm{Cl}_{2}$.

Figure S19. ${ }^{31} \mathrm{P}\left\{{ }^{1} \mathrm{H}\right\}$ NMR spectrum of bis[7- $\left\{\mathrm{Ru}(\mathrm{CO}) \mathrm{Cl}\left(\mathrm{P}^{i} \operatorname{Pr}_{3}\right)_{2}(\mathrm{CH}=\mathrm{CH})\right\}-4,4$ '-BTD $]-1,2-$

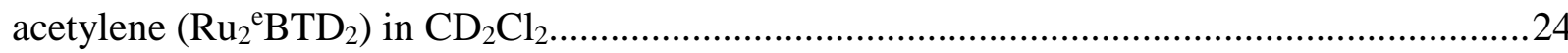

Figure S20. ${ }^{1} \mathrm{H}$ NMR spectrum of bis[7-(2-methyl-3-butyn-2-ol)-4,4'-BTD]-1,2-ethylene (7) in $\mathrm{CDCl}_{3}$.

Figure S21. ${ }^{13} \mathrm{C}\left\{{ }^{1} \mathrm{H}\right\}$ NMR spectrum of bis[7-(2-methyl-3-butyn-2-ol)-4,4'-BTD]-1,2-ethylene (7) in $\mathrm{CDCl}_{3}$

Figure S22. ${ }^{1} \mathrm{H}$ NMR spectrum of bis[7-(ethynyl)-4,4'-BTD]-1,2-ethylene ( $\left.{ }^{\mathrm{v}} \mathrm{BTD}_{2}, 8\right)$ in $\mathrm{CDCl}_{3}$.

Figure S23. ${ }^{13} \mathrm{C}\left\{{ }^{1} \mathrm{H}\right\}$ NMR spectrum of bis[7-(ethynyl)-4,4'-BTD]-1,2-ethylene ( ${ }^{\text {BTD }} 2,8$ ) in $\mathrm{CDCl}_{3}$.

Figure S24. ${ }^{1} \mathrm{H}$ NMR spectrum of bis $\left[7-\left\{\mathrm{Ru}(\mathrm{CO}) \mathrm{Cl}\left(\mathrm{P}^{i} \mathrm{Pr}_{3}\right)_{2}(\mathrm{CH}=\mathrm{CH})\right\}-4,4\right.$ '-BTD]-1,2ethylene $\left(\mathrm{Ru}_{2}{ }^{\mathrm{v}} \mathrm{BTD}_{2}\right)$ in $\mathrm{CD}_{2} \mathrm{Cl}_{2}$.

Figure S25. ${ }^{13} \mathrm{C}\left\{{ }^{1} \mathrm{H}\right\}$ NMR spectrum of bis[7- $\left\{\mathrm{Ru}(\mathrm{CO}) \mathrm{Cl}\left(\mathrm{P}^{i} \operatorname{Pr}_{3}\right)_{2}(\mathrm{CH}=\mathrm{CH})\right\}-4,4$ '-BTD $]-1,2-$ ethylene $\left(\mathrm{Ru}_{2}{ }^{\mathrm{v}} \mathrm{BTD}_{2}\right)$ in $\mathrm{CD}_{2} \mathrm{Cl}_{2}$.

Figure S26. ${ }^{31} \mathrm{P}\left\{{ }^{1} \mathrm{H}\right\}$ NMR spectrum of bis[7- $\left\{\mathrm{Ru}(\mathrm{CO}) \mathrm{Cl}\left(\mathrm{P}^{i} \mathrm{Pr}_{3}\right)_{2}(\mathrm{CH}=\mathrm{CH})\right\}-4,4$ '-BTD $]-1,2-$ ethylene $\left(\mathrm{Ru}_{2}{ }^{\mathrm{v}} \mathrm{BTD}_{2}\right)$ in $\mathrm{CD}_{2} \mathrm{Cl}_{2}$.

Figure S27. Cyclic voltammograms of $\mathrm{Ru}_{2} \mathrm{NA}$ at $v=100 \mathrm{mV} / \mathrm{s}$ with $\mathrm{NBu}_{4} \mathrm{PF}_{6}$ as supporting electrolyte (top, left), at $v=400 \mathrm{mV} / \mathrm{s}$ with $\mathrm{NBu}_{4} \mathrm{PF}_{6}$ as supporting electrolyte with complementary simulation (top, right) and at $v=100 \mathrm{mV} / \mathrm{s}$ with $\mathrm{NBu}_{4} \mathrm{BAr}^{\mathrm{F}}$ as supporting electrolyte (bottom, left). General conditions: $\mathrm{T}=293 \mathrm{~K}, \mathrm{CH}_{2} \mathrm{Cl}_{2}$ as the solvent.

Figure S28. Cyclic voltammograms of $\mathrm{Ru}_{2} \mathrm{BTD}$ at $v=100 \mathrm{mV} / \mathrm{s}$ with $\mathrm{NBu}_{4} \mathrm{PF}_{6}$ as supporting electrolyte (top, left), at $v=600 \mathrm{mV} / \mathrm{s}$ with $\mathrm{NBu}_{4} \mathrm{PF}_{6}$ as supporting electrolyte with 
complementary simulation (top, right) and at $v=100 \mathrm{mV} / \mathrm{s}$ with $\mathrm{NBu}_{4} \mathrm{BAr}^{\mathrm{F}}$ as supporting electrolyte (bottom, left). General conditions: $\mathrm{T}=293 \mathrm{~K}, \mathrm{CH}_{2} \mathrm{Cl}_{2}$ as the solvent.

Figure S29. Cyclic voltammograms of $\mathrm{Ru}_{2}{ }^{\mathrm{e}} \mathrm{BTD}_{2}$ at $v=100 \mathrm{mV} / \mathrm{s}$ with $\mathrm{NBu}_{4} \mathrm{BAr}{ }^{\mathrm{F}}$ as supporting electrolyte (left) and at $v=800 \mathrm{mV} / \mathrm{s}$ with $\mathrm{NBu}_{4} \mathrm{BAr}^{\mathrm{F}}$ as supporting electrolyte with complementary simulation (right). General conditions: $\mathrm{T}=293 \mathrm{~K}, \mathrm{CH}_{2} \mathrm{Cl}_{2}$ as the solvent. .....33

Figure S30. Cyclic voltammograms of $\mathrm{Ru}_{2}{ }^{\mathrm{v}} \mathrm{BTD}_{2}$ at $v=100 \mathrm{mV} / \mathrm{s}$ with $\mathrm{NBu}_{4} \mathrm{BAr}^{\mathrm{F}}$ as supporting electrolyte (left) and at $v=800 \mathrm{mV} / \mathrm{s}$ with $\mathrm{NBu}_{4} \mathrm{BAr}^{\mathrm{F}}$ as supporting electrolyte with complementary simulation (right). General conditions: $\mathrm{T}=293 \mathrm{~K}, \mathrm{CH}_{2} \mathrm{Cl}_{2}$ as the solvent. .....34

Figure S31. Changes in the IR spectrum $\left(\mathrm{CH}_{2} \mathrm{Cl}_{2}, \mathrm{NBu}_{4} \mathrm{PF}_{6}, \mathrm{~T}=293 \mathrm{~K}\right)$ of $\mathrm{Ru}_{2} \mathrm{NA}$ during the first oxidation in the $\mathrm{CO}$ stretch region (top, left), NIR region (top, right), second oxidation in the $\mathrm{CO}$ stretch region (bottom, left) and NIR region (bottom, right).

Figure S32. Changes in the IR spectrum $\left(\mathrm{CH}_{2} \mathrm{Cl}_{2}, \mathrm{NBu}_{4} \mathrm{PF}_{6}, \mathrm{~T}=293 \mathrm{~K}\right)$ of $\mathrm{Ru}_{2} \mathrm{BTD}$ during the first oxidation in the $\mathrm{CO}$ stretch region (top, left), NIR region (top, right), second oxidation in the $\mathrm{CO}$ stretch region (bottom, left) and NIR region (bottom, right).

Figure S33. Changes in the IR spectrum $\left(\mathrm{CH}_{2} \mathrm{Cl}_{2}, \mathrm{NBu}_{4} \mathrm{BAr}{ }^{\mathrm{F}}, \mathrm{T}=293 \mathrm{~K}\right)$ of $\mathrm{Ru}_{2}{ }^{\mathrm{e}} \mathrm{BTD}_{2}$ during the first oxidation in the $\mathrm{CO} / \mathrm{CC}$ stretch region (top, left), NIR region (top, right), second oxidation in the $\mathrm{CO} / \mathrm{CC}$ stretch region (bottom, left) and NIR region (bottom, right).

Deconvoluted IR spectrum of the $\mathrm{CO}$ region at point of maximum monocation concentration (bottom, left).

Figure S34. Changes in the IR spectrum $\left(\mathrm{CH}_{2} \mathrm{Cl}_{2}, \mathrm{NBu}_{4} \mathrm{BAr}{ }^{\mathrm{F}}, \mathrm{T}=293 \mathrm{~K}\right)$ of $\mathrm{Ru}_{2}{ }^{\mathrm{v}} \mathrm{BTD}_{2}$ during the first oxidation in the $\mathrm{CO}$ stretch region (top, left), NIR region (top, right), second oxidation in the CO stretch region (mid, left) and NIR region (mid, right). Deconvoluted IR spectrum of the $\mathrm{CO}$ region at point of maximum monocation concentration (bottom, left)..... 38

Figure S35. Experimental (top curve) and simulated (bottom curve) EPR spectra of the radical cation $\mathrm{Ru}_{2} \mathrm{NA}^{++}$(top left) and $\mathrm{Ru}_{2} \mathrm{BTD}^{++}$(bottom left) in $\mathrm{CH}_{2} \mathrm{Cl}_{2}$ at $293 \mathrm{~K}$ with calculated spin density plots (right). Oxidizing agent $\mathrm{FcPF}_{6}$.

Figure S36. Experimental (top curve) and simulated (bottom curve) EPR spectra of the radical cation $\mathrm{Ru}_{2}{ }^{\mathrm{e}} \mathrm{BTD}_{2}{ }^{++}$(top left) and the paramagnetic dication $\mathrm{Ru}_{2}{ }^{\mathrm{e}} \mathrm{BTD}_{2}{ }^{2+}$ (bottom left) in $\mathrm{CH}_{2} \mathrm{Cl}_{2}$ at $293 \mathrm{~K}$ with calculated spin density plots (right). The monocation was generated with 20 eq. of $\mathrm{FcBAr}^{\mathrm{F}}$. The dication was generated with a 10 -fold excess $\mathrm{AcFcSbF}_{6}$ in $\mathrm{CH}_{2} \mathrm{Cl}_{2} \ldots \ldots \ldots \ldots . . . .40$

Figure S37. Experimental (top curve) and simulated (bottom curve) EPR spectra of the radical cation $\mathrm{Ru}_{2}{ }^{\mathrm{v}} \mathrm{BTD}_{2}{ }^{++}$(top left) and radical dication $\mathrm{Ru}_{2}{ }^{\mathrm{V}} \mathrm{BTD}_{2}{ }^{2+}$ (bottom left) in $\mathrm{CH}_{2} \mathrm{Cl}_{2}$ at $293 \mathrm{~K}$ with calculated spin density plots (right). Monocation was generated with 20 eq. of $\mathrm{FcBAr}^{\mathrm{F}}$. Dication was generated to relative concentration of around $99 \%$ with $\mathrm{AcFcSbF}_{6}$ in 10 -fold excess.

Figure S38. Difference in signal intensities at $T=273 \mathrm{~K}$ and $T=253,233$ and $213 \mathrm{~K}$ for dicationic $\mathrm{Ru}_{2}{ }^{\mathrm{v}} \mathrm{p}$-phen ${ }_{2}{ }^{2+}$ The dication was generated by electrolysis in $\mathrm{DCM} / \mathrm{NBu}_{4} \mathrm{PF}_{6} \ldots \ldots . . .41$

Figure S39. Changes in the UV/Vis/NIR spectrum $\left(\mathrm{CH}_{2} \mathrm{Cl}_{2}, \mathrm{NBu}_{4} \mathrm{PF}_{6}, \mathrm{~T}=293 \mathrm{~K}\right)$ of $\mathrm{Ru}_{2} \mathrm{NA}$ during the first oxidation (left) and the second oxidation (right). 
Figure S40. TD-DFT calculated UV/Vis/NIR absorption spectrum of neutral $\mathrm{Ru}_{2} \mathrm{NA}$ and graphical representation of MOs with the largest contribution to the relevant transitions. Color coding for Electron Density Difference Maps (EDDMs); blue: electron density loss, red: electron density gain.

Figure S41. TD-DFT calculated UV/Vis/NIR absorption spectrum of the radical cation $\mathrm{Ru}_{2} \mathrm{NA}^{+}$and graphical representation of MOs with the largest contribution to the relevant transitions. Color coding for Electron Density Difference Maps (EDDMs); blue: electron density loss, red: electron density gain.

Figure S42. TD-DFT calculated UV/Vis/NIR absorption spectrum of the dication $\mathbf{R} \mathbf{u}_{2} \mathbf{N A}{ }^{2+}$ in the singlet state (bottom, left) and the triplet state (top, left) and graphical representation of MOs with the largest contribution to the relevant transitions (singlet state assumed). Color coding for Electron Density Difference Maps (EDDMs); blue: electron density loss, red: electron density gain.

Figure S43. Changes in the UV/Vis/NIR spectrum $\left(\mathrm{CH}_{2} \mathrm{Cl}_{2}, \mathrm{NBu}_{4} \mathrm{PF}_{6}, \mathrm{~T}=293 \mathrm{~K}\right)$ of $\mathrm{Ru}_{2} \mathrm{BTD}$ during the first oxidation (left) and the second oxidation (right).

Figure S44. TD-DFT calculated UV/Vis/NIR absorption spectrum of neutral Ru2BTD and graphical representation of MOs with the largest contribution to the relevant transitions. Color coding for Electron Density Difference Maps (EDDMs); blue: electron density loss, red: electron density gain.

Figure S45. TD-DFT calculated UV/Vis/NIR absorption spectra for different rotamers of the radical cation $\mathrm{Ru}_{2} \mathrm{BTD}^{+}$and graphical representation of MOs with the largest contribution to the relevant transitions (configuration assumed where vinyl ruthenium units are in a cisoid orientation to the thiadiazol heterocycle $\mathrm{Ru}_{2} \mathrm{BTD}^{+}$cis-TD). Color coding for Electron Density Difference Maps (EDDMs); blue: electron density loss, red: electron density gain. 45

Figure S46. TD-DFT calculated UV/Vis/NIR absorption spectrum of the dication $\mathbf{R} \mathbf{u}_{2} \mathbf{B T D}^{\mathbf{2 +}}$ in the singlet state (bottom, left) and the triplet state (top, left) and graphical representation of MOs with the largest contribution to the relevant transitions (singlet state assumed). Color coding for Electron Density Difference Maps (EDDMs); blue: electron density loss, red: electron density gain.

Figure S47. Changes in the UV/Vis/NIR spectrum $\left(\mathrm{CH}_{2} \mathrm{Cl}_{2}, \mathrm{NBu}_{4} \mathrm{BAr}{ }^{\mathrm{F}}, \mathrm{T}=293 \mathrm{~K}\right)$ of $\mathrm{Ru}_{2}{ }^{\mathrm{e}} \mathrm{BTD} \mathrm{D}_{2}$ during the first oxidation (left) and the second oxidation (right).

Figure S48. Changes in the UV/Vis/NIR spectrum $\left(\mathrm{CH}_{2} \mathrm{Cl}_{2}, \mathrm{NBu}_{4} \mathrm{BAr}{ }^{\mathrm{F}}, \mathrm{T}=293 \mathrm{~K}\right)$ of $\mathrm{Ru}_{2}{ }^{\mathrm{v}} \mathrm{BTD} 2$ during the first oxidation (left) and the second oxidation (right).

Figure S49. TD-DFT calculated UV/Vis/NIR absorption spectrum of neutral $\mathrm{Ru}_{2}{ }^{\mathrm{e}} \mathrm{BTD}_{2}$ and graphical representation of MOs with the largest contribution to the relevant transitions. Color coding for Electron Density Difference Maps (EDDMs); blue: electron density loss, red: electron density gain.

Figure S50. TD-DFT calculated UV/Vis/NIR absorption spectrum of neutral $\mathrm{Ru}_{2}{ }^{\mathrm{v}} \mathrm{BTD}_{2}$ and graphical representation of MOs with the largest contribution to the relevant transitions. Color 
coding for Electron Density Difference Maps (EDDMs); blue: electron density loss, red: electron density gain.

Figure S51. TD-DFT calculated UV/Vis/NIR absorption spectrum of the monocation $\mathrm{Ru}_{2}{ }^{\mathrm{e}} \mathrm{BTD}_{2}{ }^{+}$and graphical representation of MOs with the largest contribution to the relevant transitions. Color coding for Electron Density Difference Maps (EDDMs); blue: electron density loss, red: electron density gain.

Figure S52. TD-DFT calculated UV/Vis/NIR absorption spectrum of the monocation $\mathbf{R u}_{2}{ }^{\mathbf{v}} \mathbf{B T D}_{2}{ }^{+}$and graphical representation of MOs with the largest contribution to the relevant transitions. Color coding for Electron Density Difference Maps (EDDMs); blue: electron density loss, red: electron density gain.

Figure S53. Vis/NIR absorption characteristics of the radical cation $\mathrm{Ru}_{2}{ }^{\mathrm{e}} \mathrm{BTD}_{2}{ }^{+}$(left) and $\mathrm{Ru}_{2}{ }^{\mathrm{v}} \mathrm{BTD}_{2}{ }^{+}$(right) in three solvents of different polarity.

Figure S54. TD-DFT calculated UV/Vis/NIR absorption spectrum of the dication $\mathrm{Ru}_{2}{ }^{\mathrm{e}} \mathrm{BTD}_{2}{ }^{2+}$ in the singlet state (bottom, left) and the triplet state (top, left) and graphical representation of MOs with the largest contribution to the relevant transitions (singlet state assumed). Color coding for Electron Density Difference Maps (EDDMs); blue: electron density loss, red: electron density gain.

Figure S55. TD-DFT calculated UV/Vis/NIR absorption spectrum of the dication $\mathrm{Ru}_{2}{ }^{\mathrm{V}} \mathrm{BTD}_{2}{ }^{2+}$ in the singlet state (bottom, left) and the triplet state (top, left) and graphical representation of MOs with the largest contribution to the relevant transitions (singlet state assumed). Color coding for Electron Density Difference Maps (EDDMs); blue: electron density loss, red: electron density gain. 


\section{NMR Spectra}
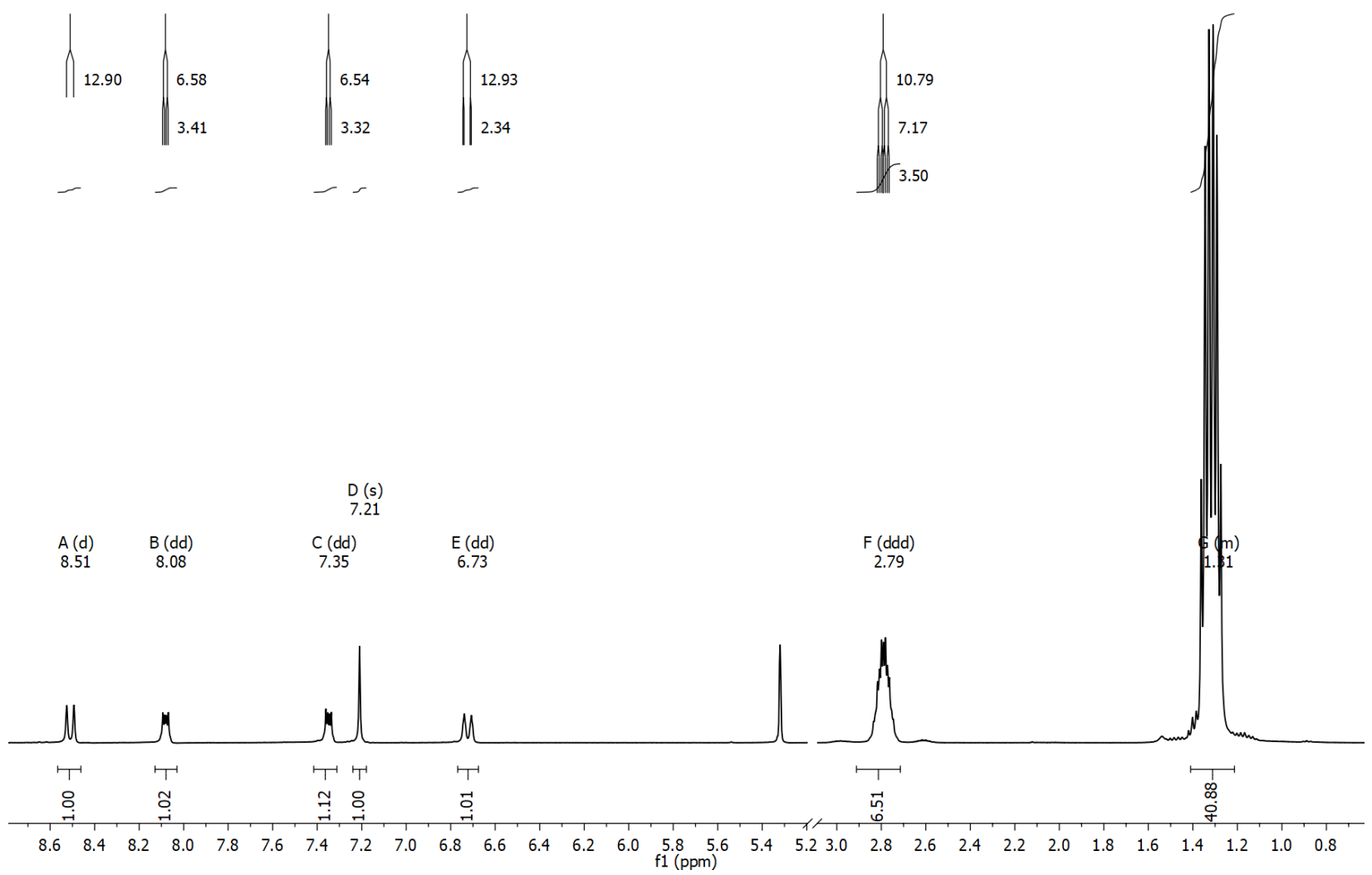

Figure S1. ${ }^{1} \mathrm{H}$ NMR spectrum of $\left[\left\{\mathrm{Ru}(\mathrm{CO}) \mathrm{Cl}\left(\mathrm{P}^{i} \mathrm{Pr}_{3}\right)_{2}\right\}_{2}(\mu-1,4-\mathrm{CH}=\mathrm{CH}\right.$-naphthalene- $\left.\mathrm{CH}=\mathrm{CH})\right]\left(\mathbf{R u} \mathbf{u}_{2} \mathbf{N A}\right)$ in $\mathrm{CD}_{2} \mathrm{Cl}_{2}$. 


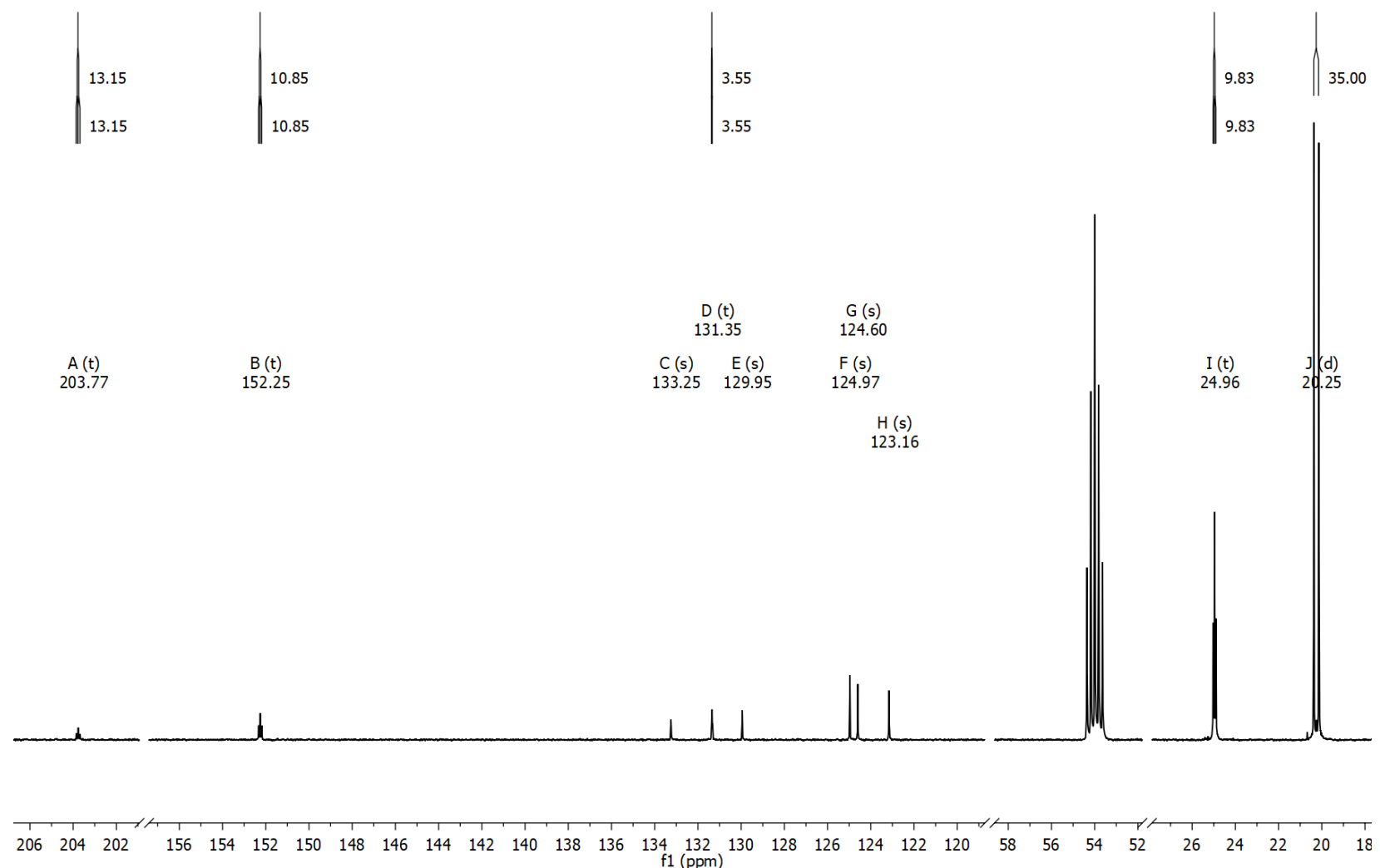

Figure S2. ${ }^{13} \mathrm{C}\left\{{ }^{1} \mathrm{H}\right\}$ NMR spectrum of $\left[\left\{\mathrm{Ru}(\mathrm{CO}) \mathrm{Cl}\left(\mathrm{P}^{\mathrm{i}} \mathrm{Pr}_{3}\right)_{2}\right\}_{2}(\mu-1,4-\mathrm{CH}=\mathrm{CH}-\right.$ naphthalene-CH=CH$\left.)\right]\left(\mathbf{R u}_{2} \mathbf{N A}\right)$ in $\mathrm{CD}_{2} \mathrm{Cl}_{2}$. 


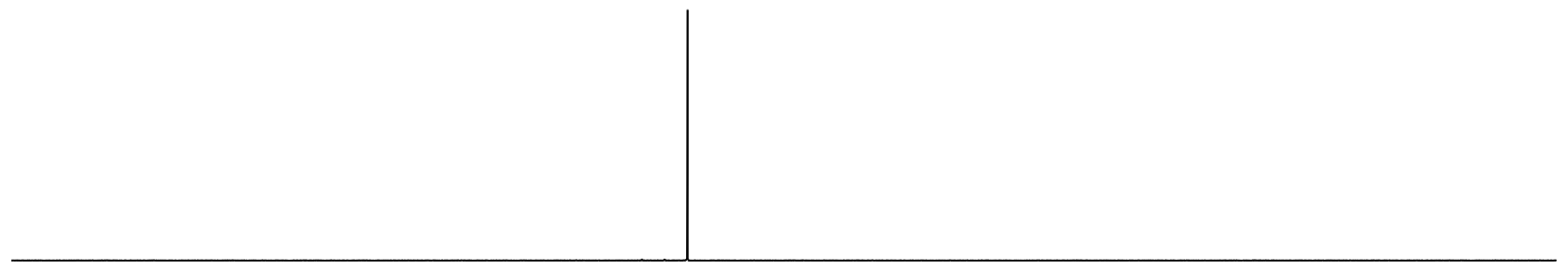

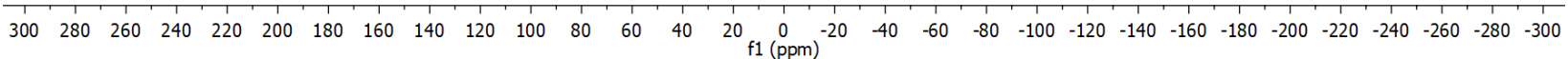

Figure S3. ${ }^{31} \mathrm{P}\left\{{ }^{1} \mathrm{H}\right\}$ NMR spectrum of $\left[\left\{\mathrm{Ru}(\mathrm{CO}) \mathrm{Cl}\left(\mathrm{P}^{i} \mathrm{Pr}_{3}\right)_{2}\right\}_{2}(\mu-1,4-\mathrm{CH}=\mathrm{CH}-\right.$ naphthalene-CH=CH$\left.)\right]\left(\mathbf{R u}_{2} \mathbf{N A}\right)$ in $\mathrm{CD}_{2} \mathrm{Cl}_{2}$. 


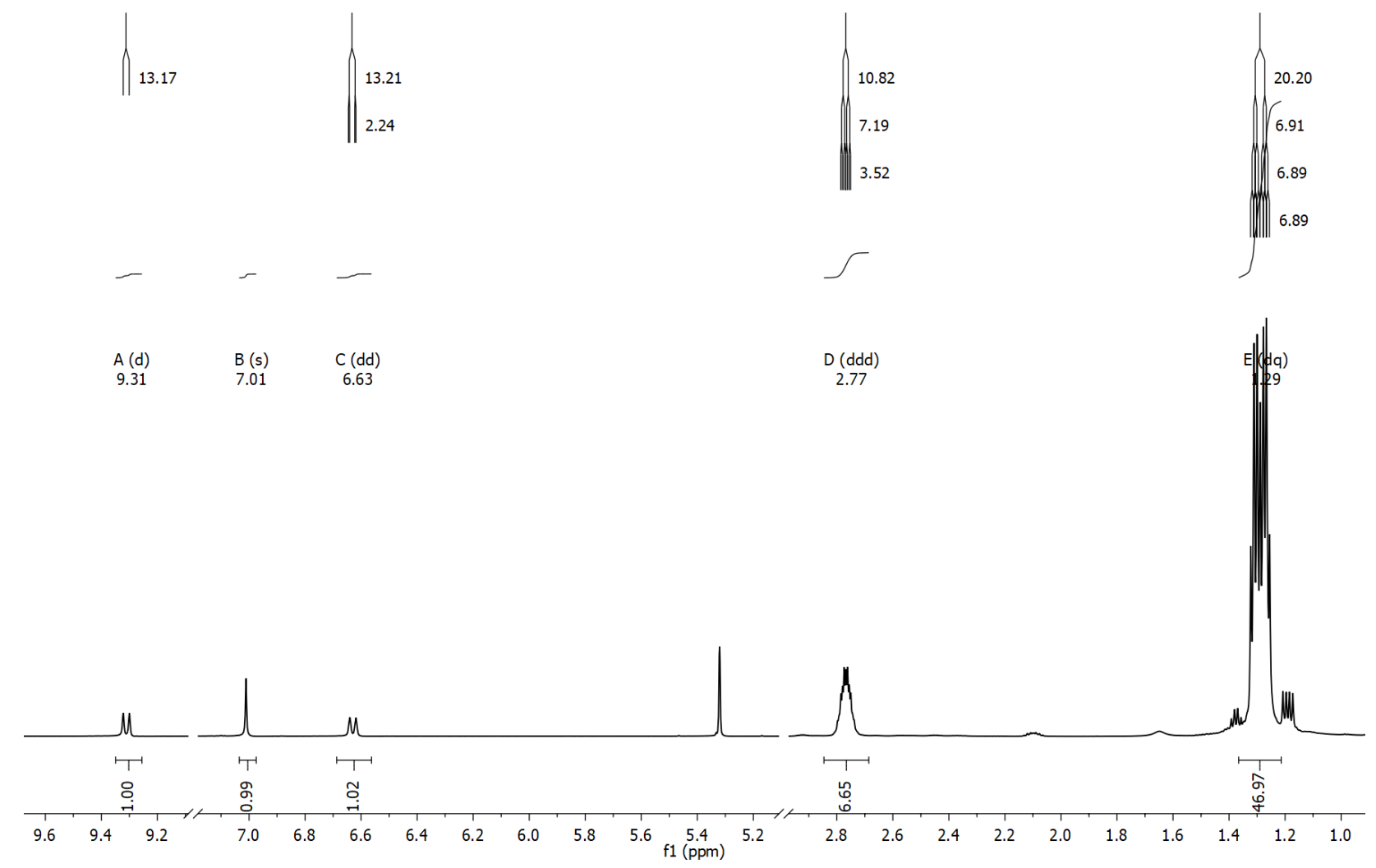

Figure S4. ${ }^{1} \mathrm{H}$ NMR spectrum of $\left[\left\{\mathrm{Ru}(\mathrm{CO}) \mathrm{Cl}\left(\mathrm{P}^{i} \operatorname{Pr}_{3}\right)_{2}\right\}_{2}(\mu-4,7-\mathrm{CH}=\mathrm{CH}-\mathrm{BTD}-\mathrm{CH}=\mathrm{CH})\right]\left(\mathbf{R u}_{2} \mathbf{B T D}\right)$ in $\mathrm{CD}_{2} \mathrm{Cl}_{2}$. 


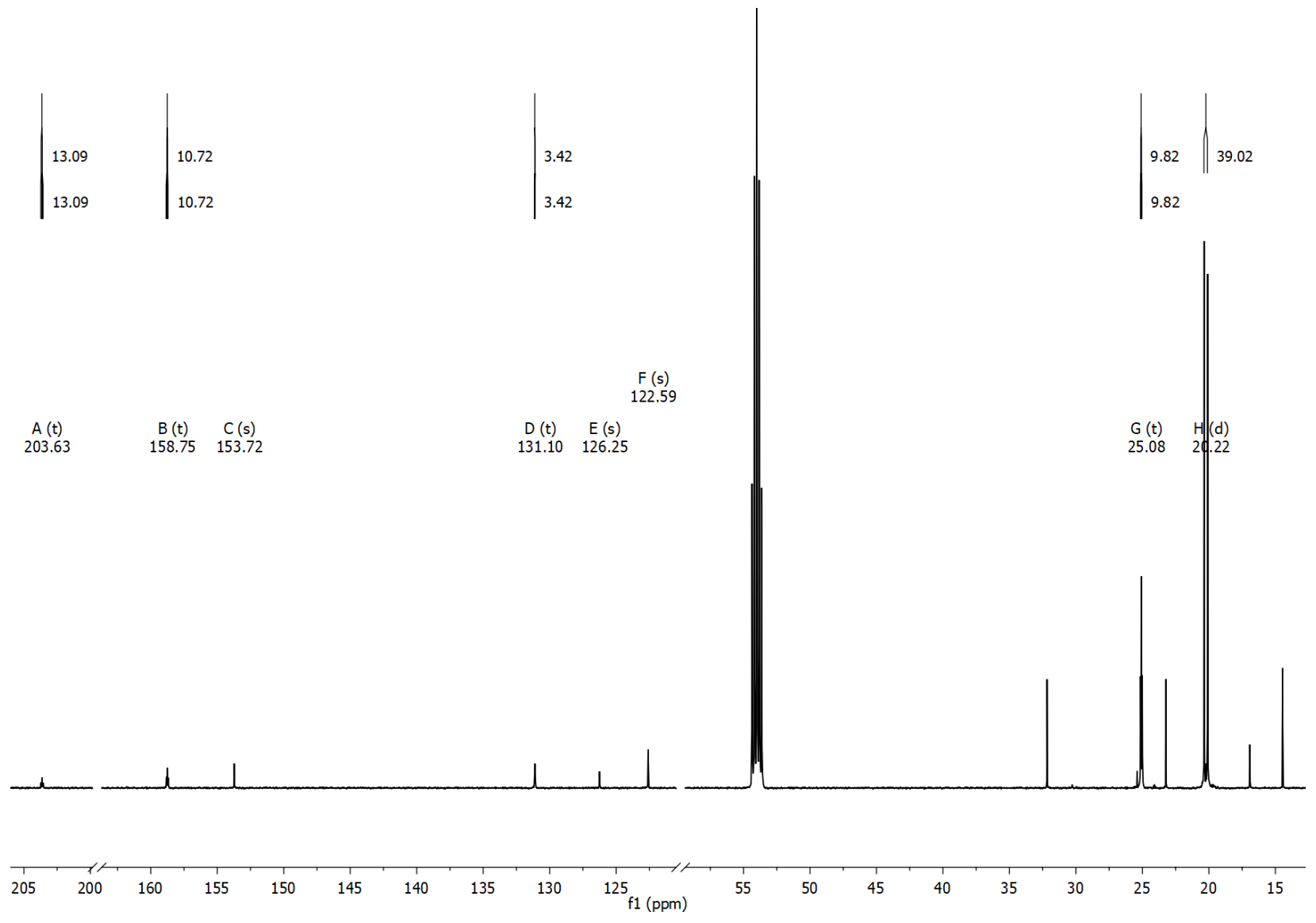

Figure S5. ${ }^{13} \mathrm{C}\left\{{ }^{1} \mathrm{H}\right\} \mathrm{NMR}$ spectrum of $\left[\left\{\mathrm{Ru}(\mathrm{CO}) \mathrm{Cl}\left(\mathrm{P}^{i} \mathrm{Pr}_{3}\right)_{2}\right\}_{2}(\mu-4,7-\mathrm{CH}=\mathrm{CH}-\mathrm{BTD}-\mathrm{CH}=\mathrm{CH})\right]\left(\mathbf{R u}_{2} \mathbf{B T D}\right)$ in $\mathrm{CD}_{2} \mathrm{Cl}_{2}$. 


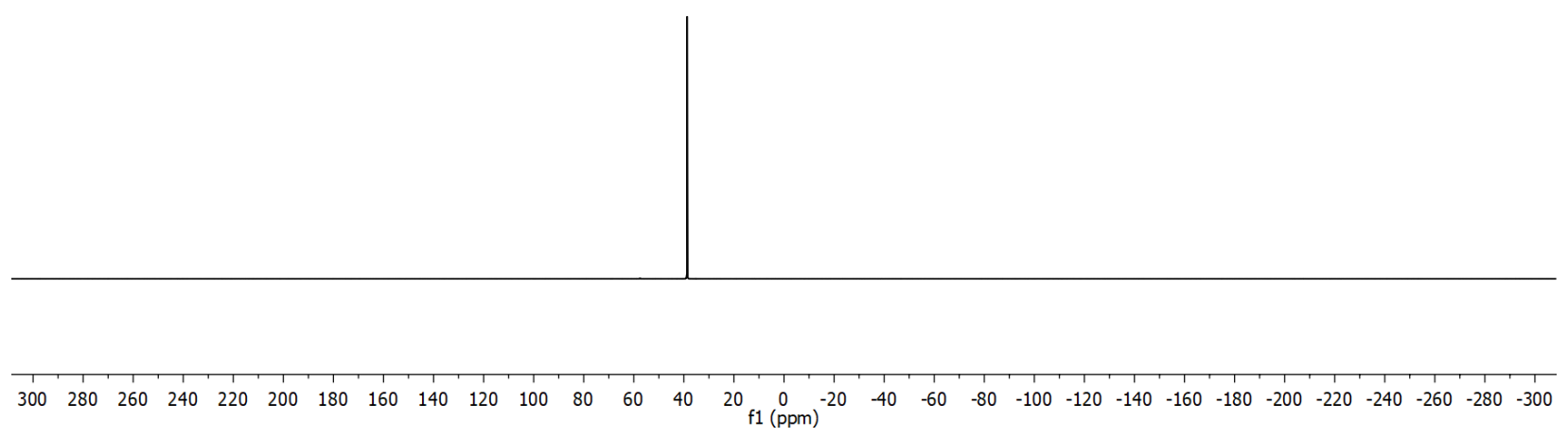

Figure S6. ${ }^{31} \mathrm{P}\left\{{ }^{1} \mathrm{H}\right\}$ NMR spectrum of $\left[\left\{\mathrm{Ru}(\mathrm{CO}) \mathrm{Cl}\left(\mathrm{P}^{i} \mathrm{Pr}_{3}\right)_{2}\right\}_{2}(\mu-4,7-\mathrm{CH}=\mathrm{CH}-\mathrm{BTD}-\mathrm{CH}=\mathrm{CH})\right]\left(\mathbf{R u}_{2} \mathbf{B T D}\right)$ in $\mathrm{CD}_{2} \mathrm{Cl}_{2}$. 


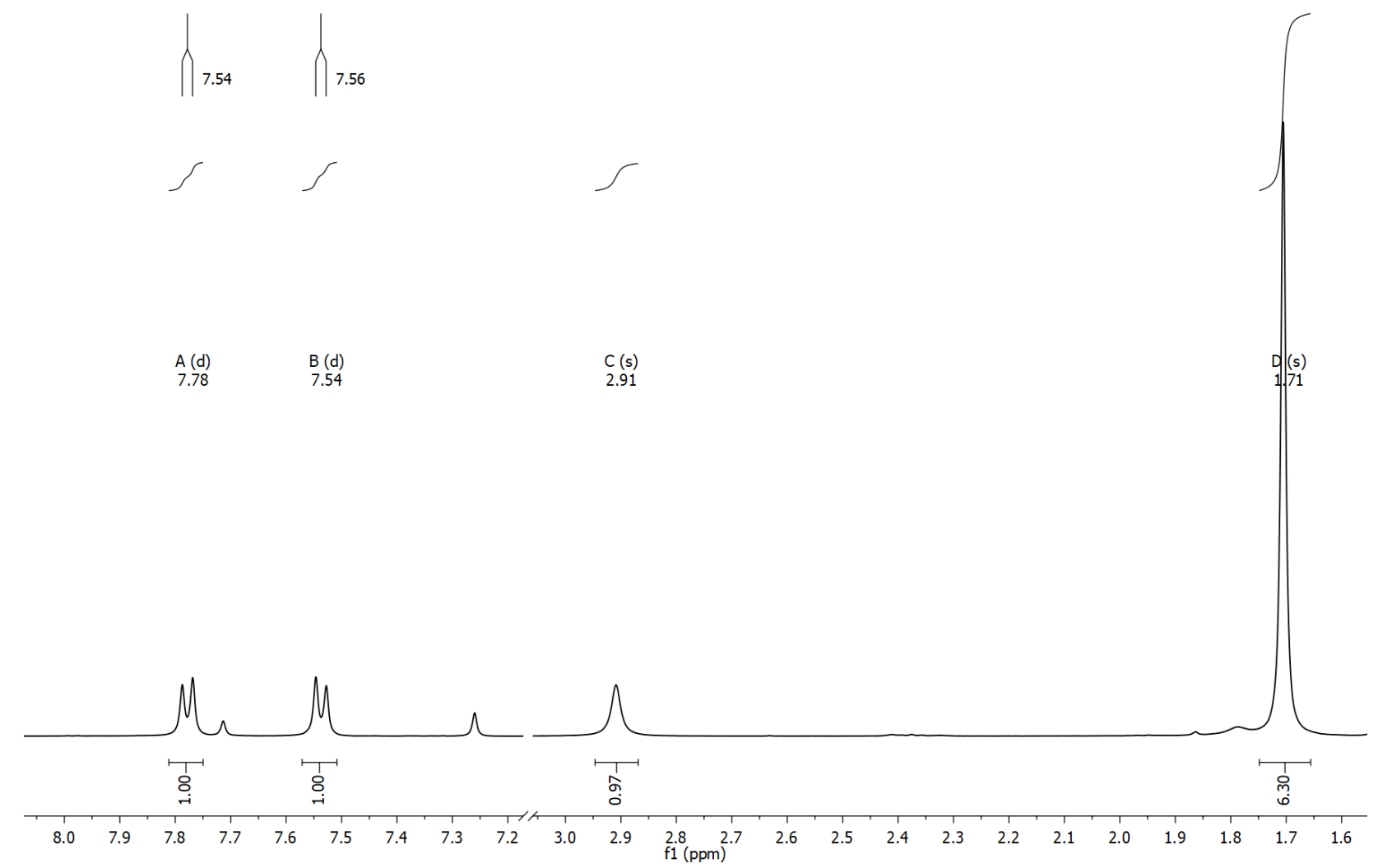

Figure S7. ${ }^{1} \mathrm{H}$ NMR spectrum of 4-bromo-7-(2-methyl-3-butyn-2-ol)-BTD (2) in $\mathrm{CDCl}_{3}$. 


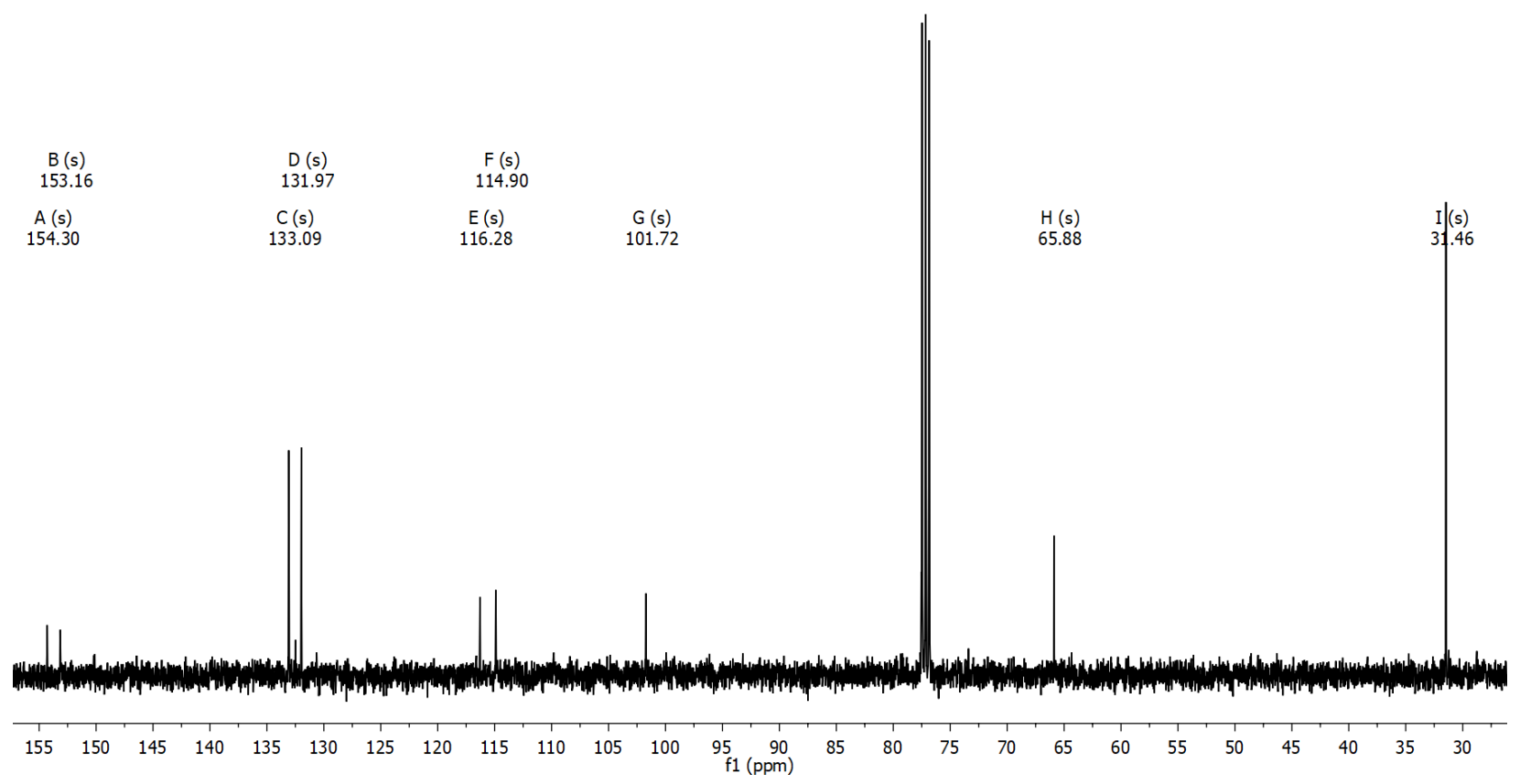

Figure S8. ${ }^{13} \mathrm{C}\left\{{ }^{1} \mathrm{H}\right\}$ NMR spectrum of 4-bromo-7-(2-methyl-3-butyn-2-ol)-BTD (2) in $\mathrm{CDCl}_{3}$. 


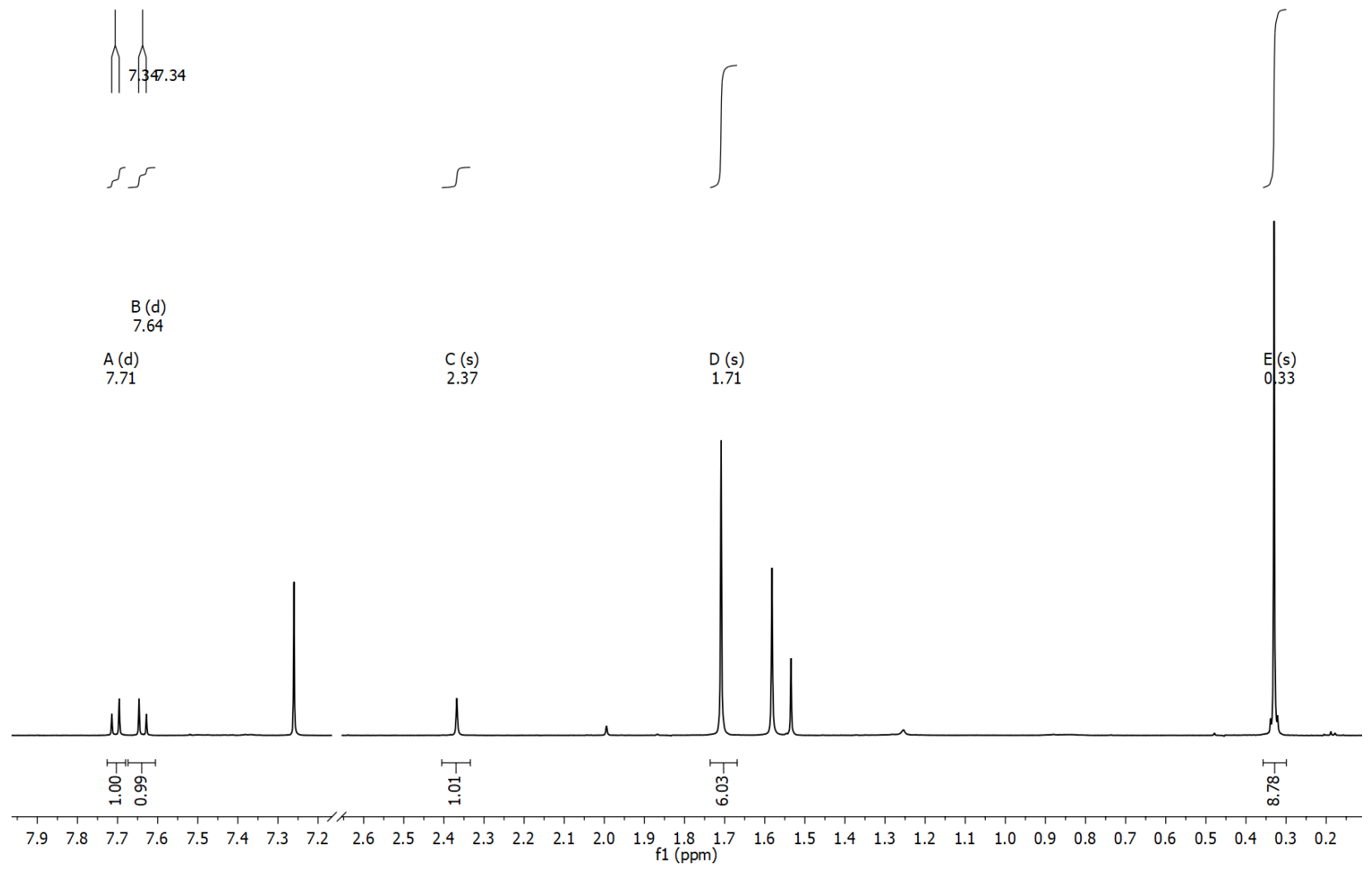

Figure S9. ${ }^{1} \mathrm{H}$ NMR spectrum of 4-trimethylsilylethynyl-7-(2-methyl-3-butyn-2-ol)-BTD (3) in $\mathrm{CDCl}_{3}$. 


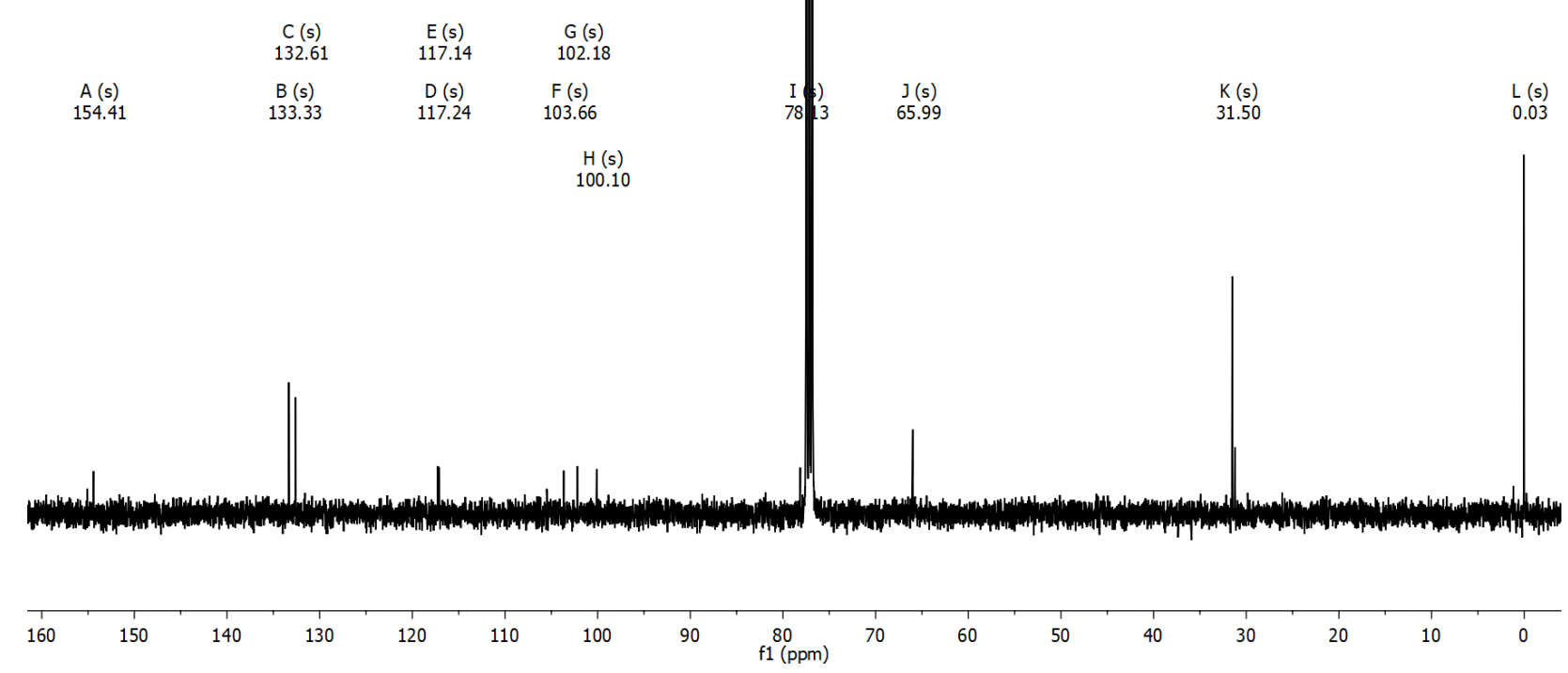

Figure S10. ${ }^{13} \mathrm{C}\left\{{ }^{1} \mathrm{H}\right\}$ NMR spectrum of 4-trimethylsilylethynyl-7-(2-methyl-3-butyn-2-ol)-BTD (3) in $\mathrm{CDCl}_{3}$. 


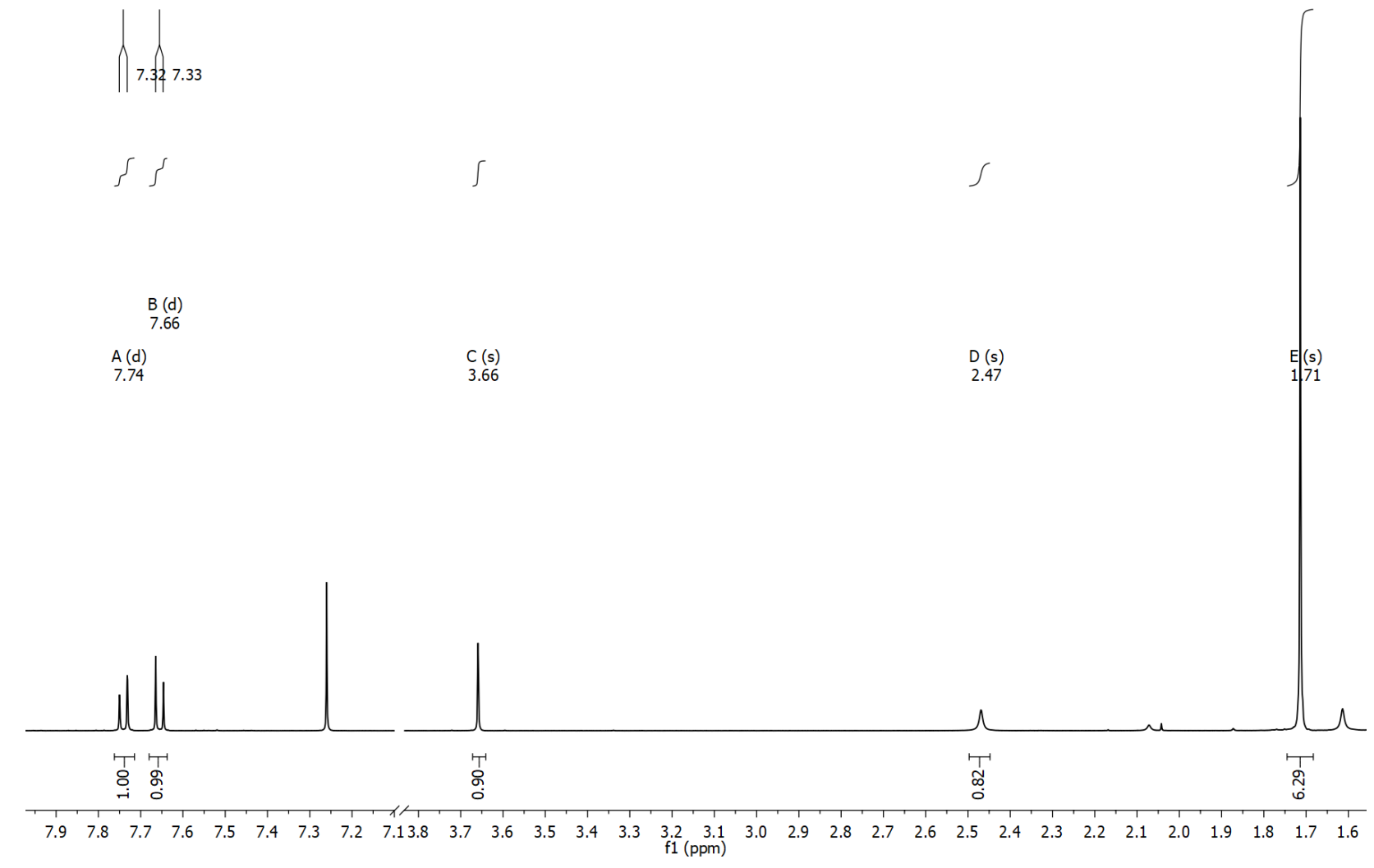

Figure S11. ${ }^{1} \mathrm{H}$ NMR spectrum of 4-ethynyl-7-(2-methyl-3-butyn-2-ol)-BTD (4) in $\mathrm{CDCl}_{3}$. 


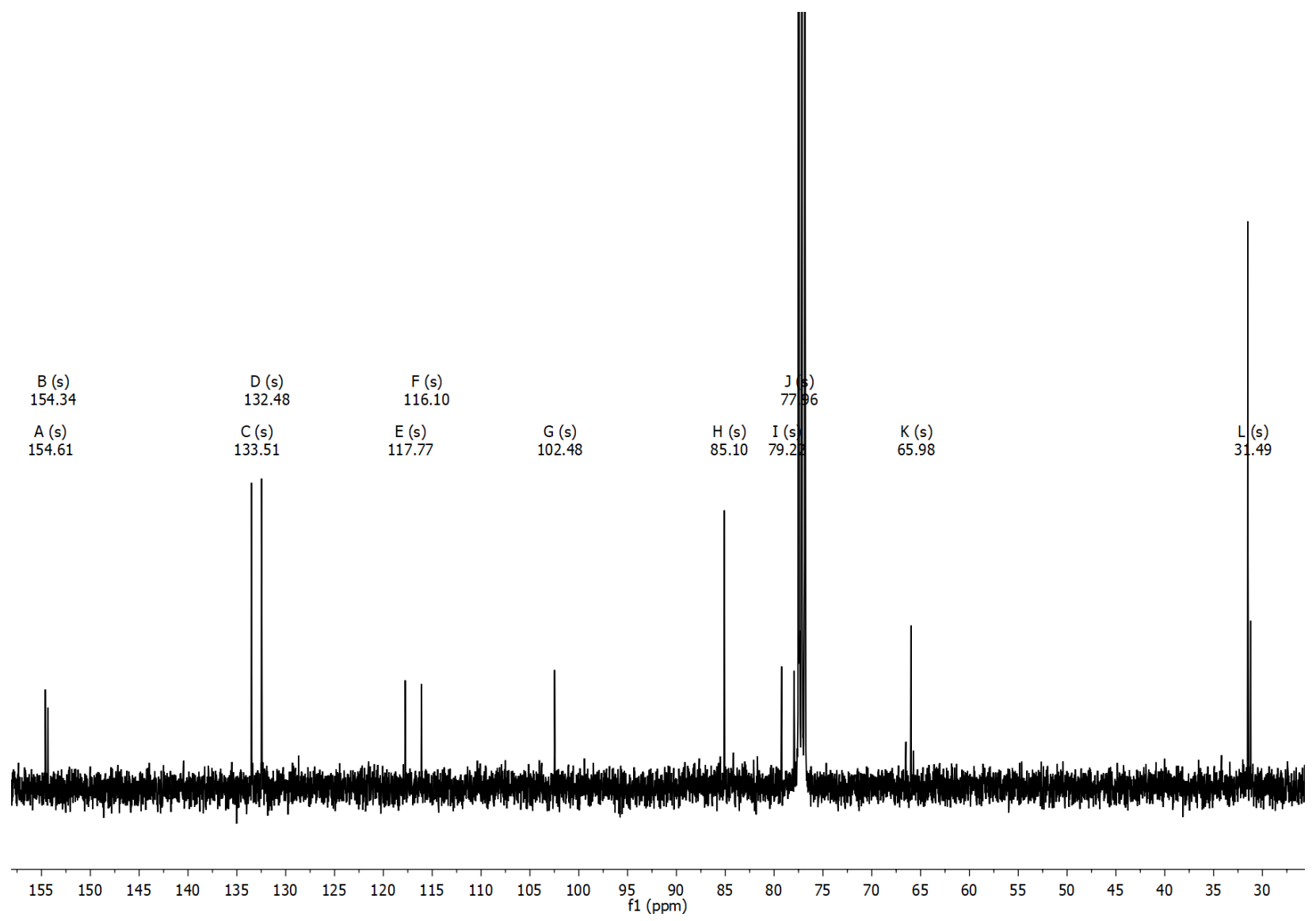

Figure S12. ${ }^{13} \mathrm{C}\left\{{ }^{1} \mathrm{H}\right\}$ NMR spectrum of 4-ethynyl-7-(2-methyl-3-butyn-2-ol)-BTD (4) in $\mathrm{CDCl}_{3}$. 


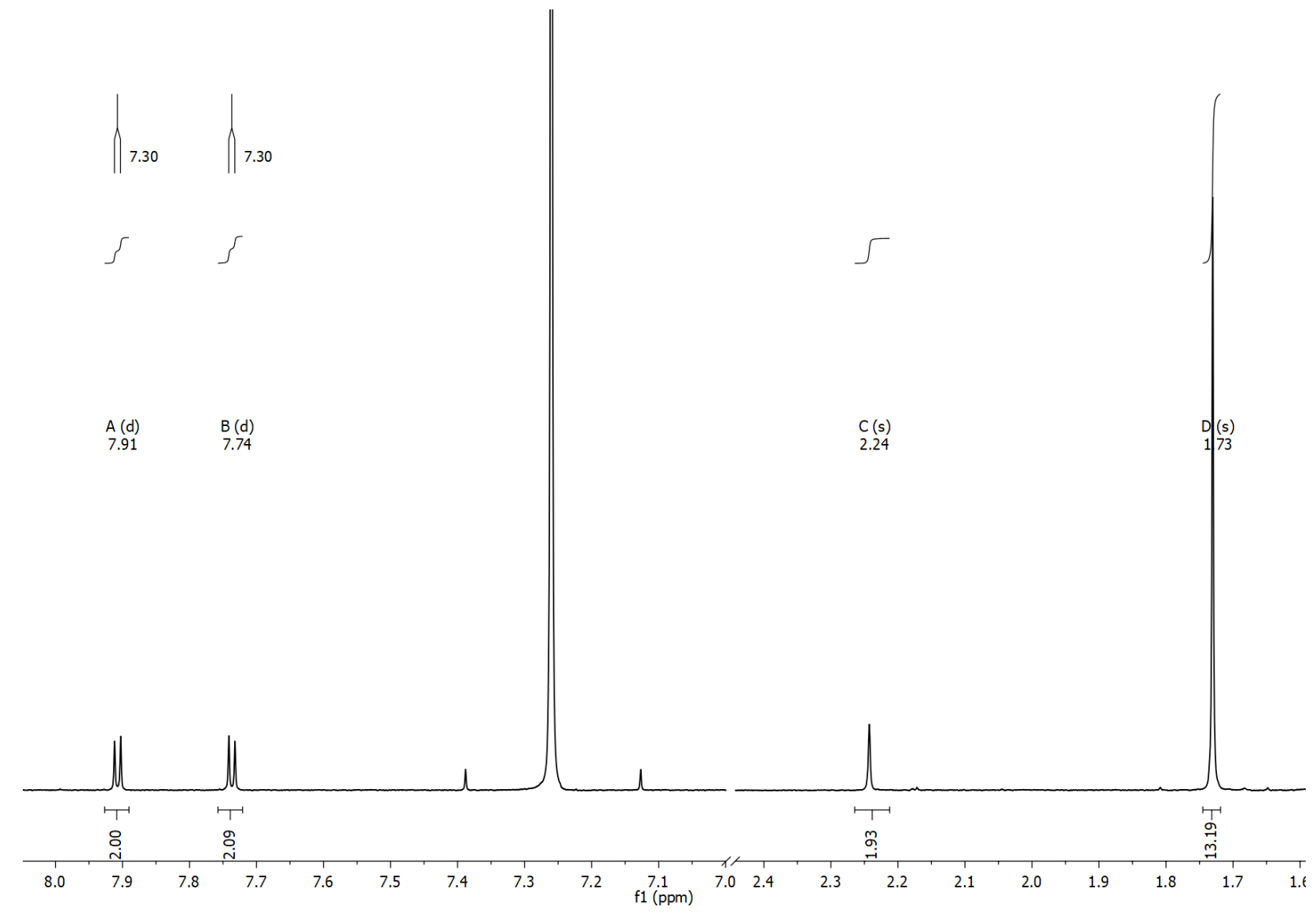

Figure S13. ${ }^{1} \mathrm{H}$ NMR spectrum of bis[7-(2-methyl-3-butyn-2-ol)-4,4'-BTD]-1,2-acetylene (5) in $\mathrm{CDCl}_{3}$. 


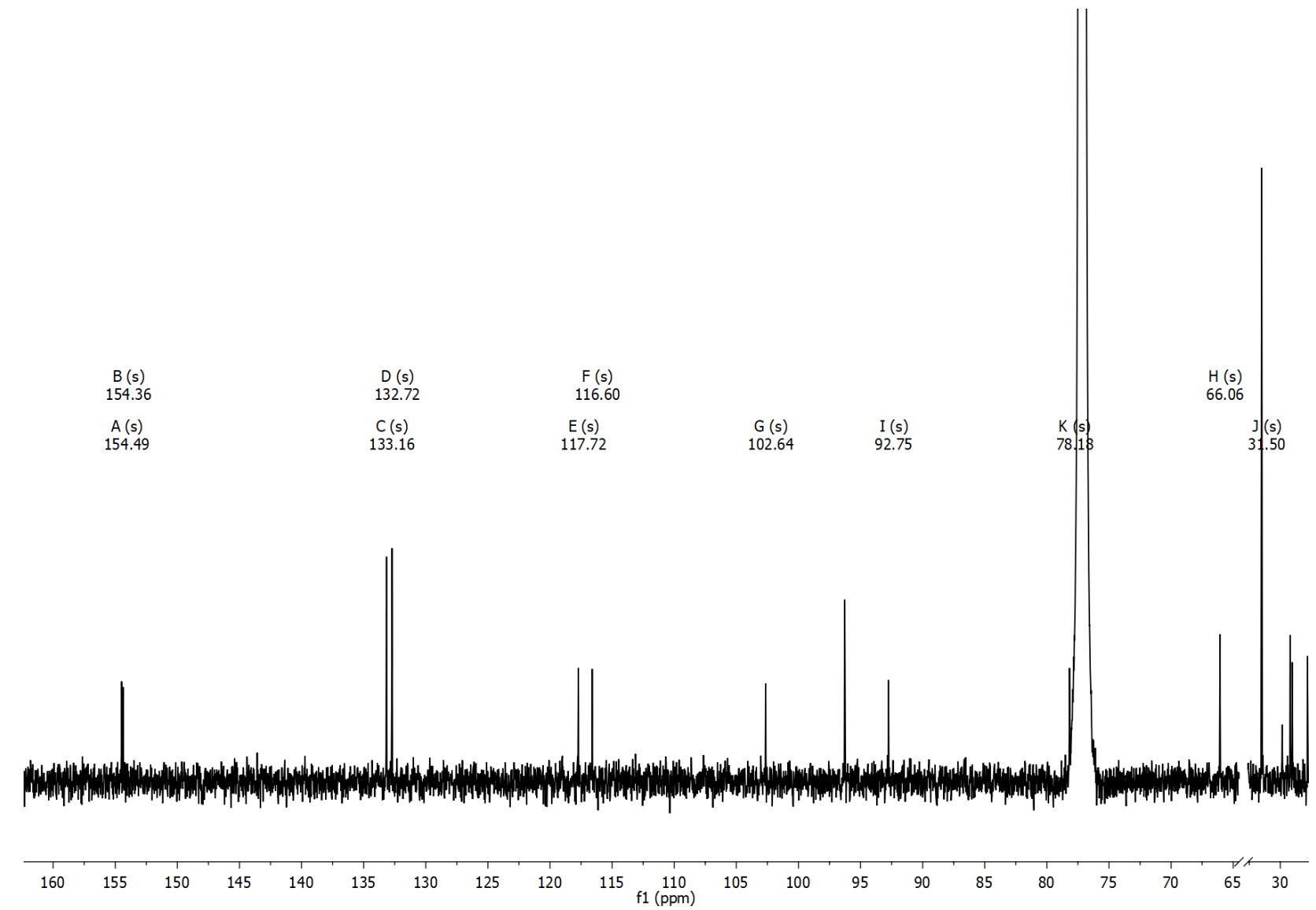

Figure S14. ${ }^{13} \mathrm{C}\left\{{ }^{1} \mathrm{H}\right\}$ NMR spectrum of bis[7-(2-methyl-3-butyn-2-ol)-4,4'-BTD]-1,2-acetylene (5) in $\mathrm{CDCl}_{3}$. 


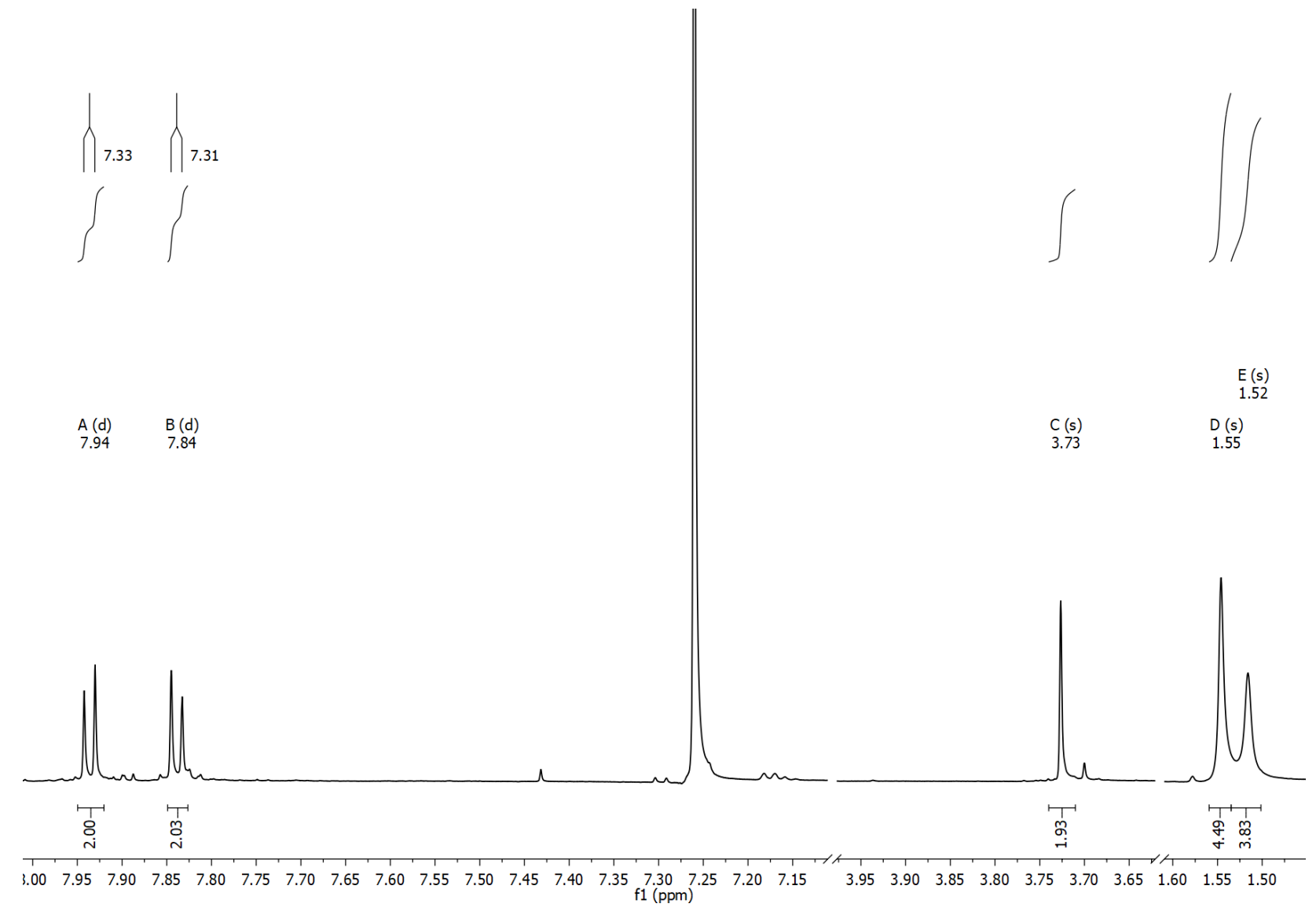

Figure S15. ${ }^{1} \mathrm{H}$ NMR spectrum of bis[7-(ethynyl)-4,4'-BTD]-1,2-acetylene ( $\left.{ }^{\mathbf{e}} \mathbf{B} \mathbf{T D}_{2}, \mathbf{6}\right)$ in $\mathrm{CDCl}_{3}$. 


$\begin{array}{ccc}B(s) & D(s) & F(s) \\ 154.23 & 133.11 & 116.95 \\ A(s) & C(s) & E(s) \\ 154.66 & 133.55 & 117.30\end{array}$
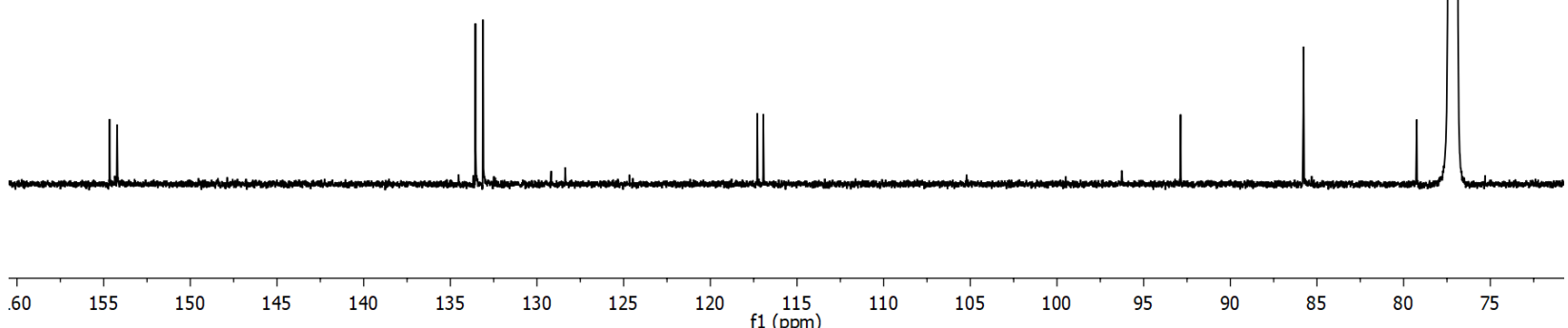

Figure S16. ${ }^{13} \mathrm{C}\left\{{ }^{1} \mathrm{H}\right\}$ NMR spectrum of bis[7-(ethynyl)-4,4'-BTD]-1,2-acetylene ( $\left.{ }^{\mathbf{B}} \mathbf{T D} 2, \mathbf{6}\right)$ in $\mathrm{CDCl}_{3}$. 


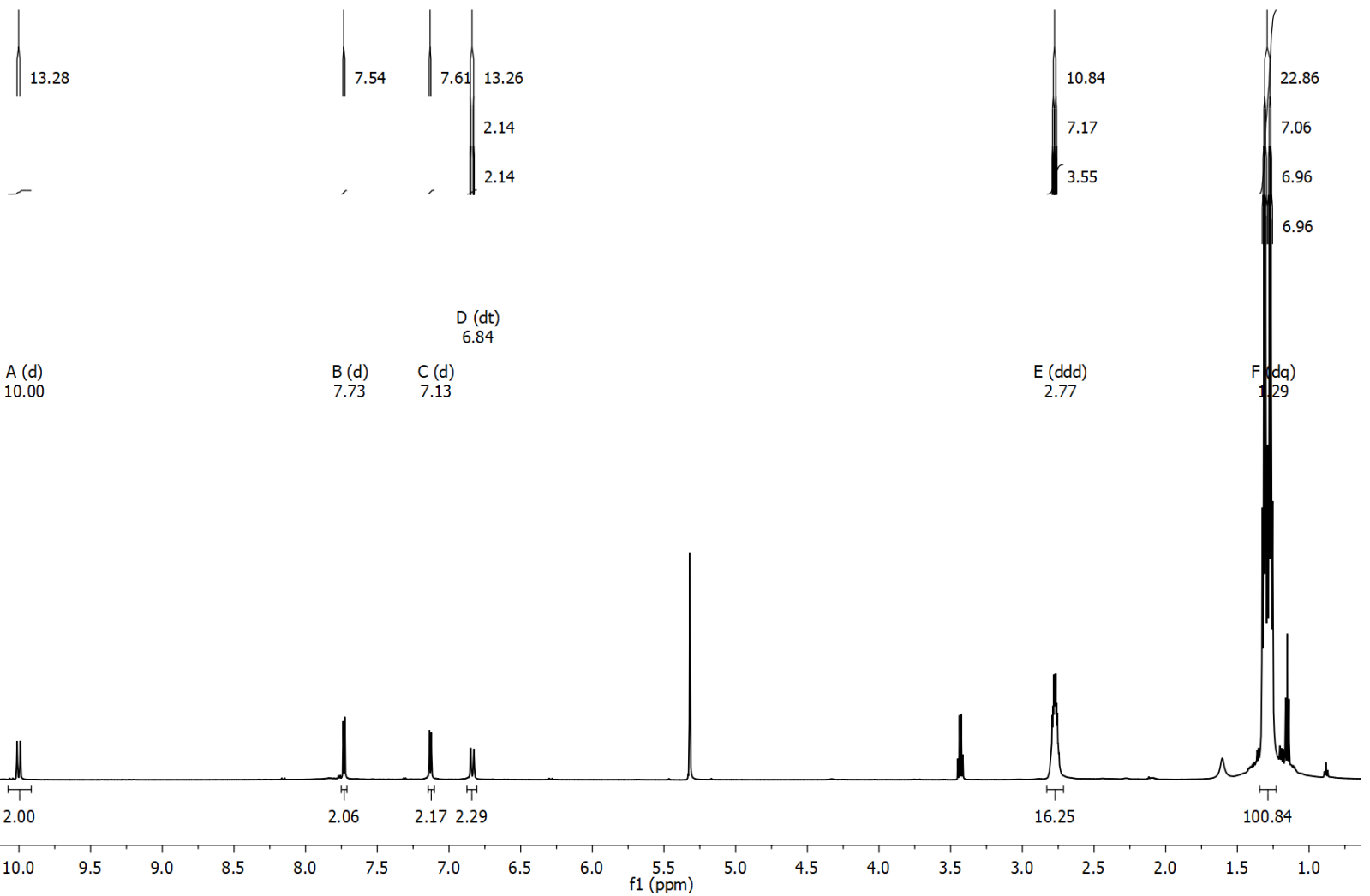

Figure S17. ${ }^{1} \mathrm{H}$ NMR spectrum of bis $\left[7-\left\{\mathrm{Ru}(\mathrm{CO}) \mathrm{Cl}\left(\mathrm{P}^{i} \mathrm{Pr}_{3}\right)_{2}(\mathrm{CH}=\mathrm{CH})\right\}-4,4\right.$ '-BTD]-1,2-acetylene $\left(\mathbf{R u}_{2}{ }^{\mathrm{e}} \mathbf{B T D}_{2}\right)$ in $\mathrm{CD}_{2} \mathrm{Cl}_{2}$. 


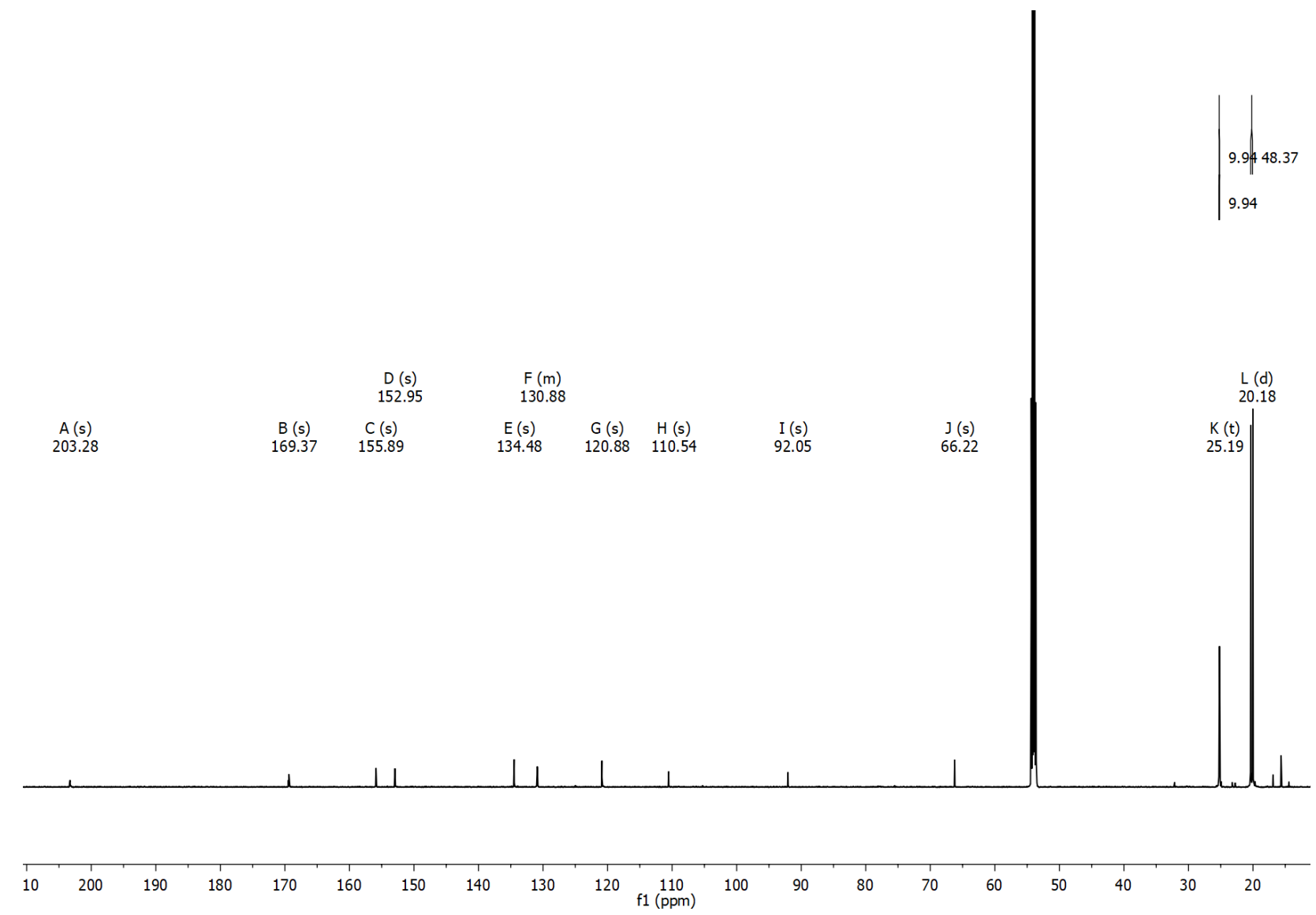

Figure S18. ${ }^{13} \mathrm{C}\left\{{ }^{1} \mathrm{H}\right\}$ NMR spectrum of bis $\left[7-\left\{\operatorname{Ru}(\mathrm{CO}) \mathrm{Cl}\left(\mathrm{P}^{i} \mathrm{Pr}_{3}\right)_{2}(\mathrm{CH}=\mathrm{CH})\right\}-4,4^{\prime}-\mathrm{BTD}\right]-1,2$-acetylene $\left(\mathbf{R u}_{2}{ }^{\mathbf{e}} \mathbf{B T D}_{2}\right)$ in $\mathrm{CD}_{2} \mathrm{Cl}_{2}$. 


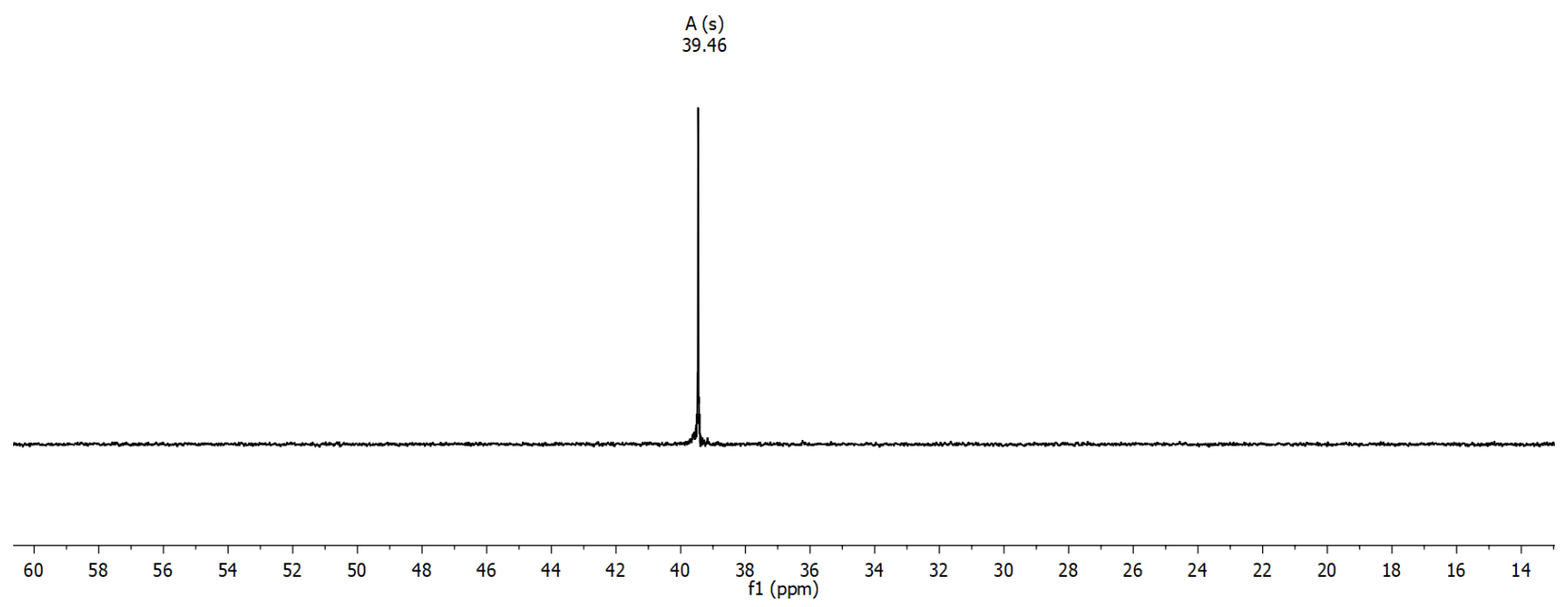

Figure S19. ${ }^{31} \mathrm{P}\left\{{ }^{1} \mathrm{H}\right\}$ NMR spectrum of bis $\left[7-\left\{\operatorname{Ru}(\mathrm{CO}) \mathrm{Cl}\left(\mathrm{P}^{i} \mathrm{Pr}_{3}\right)_{2}(\mathrm{CH}=\mathrm{CH})\right\}-4,4\right.$ '-BTD]-1,2-acetylene $\left(\mathbf{R u}_{2}{ }^{\mathbf{e}} \mathbf{B T D}_{2}\right)$ in $\mathrm{CD}_{2} \mathrm{Cl}_{2}$. 


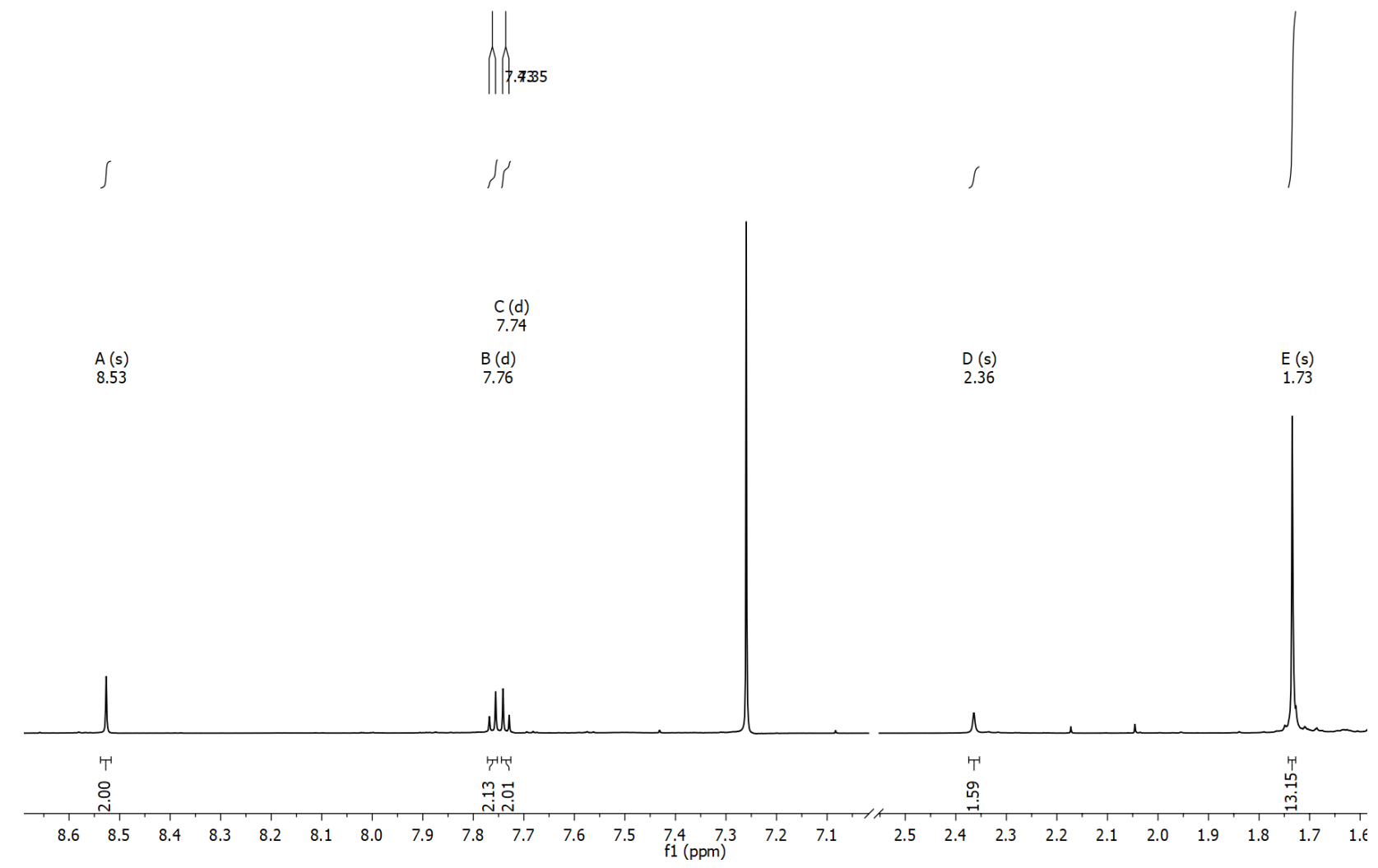

Figure S20. ${ }^{1} \mathrm{H}$ NMR spectrum of bis[7-(2-methyl-3-butyn-2-ol)-4,4'-BTD]-1,2-ethylene (7) in $\mathrm{CDCl}_{3}$. 


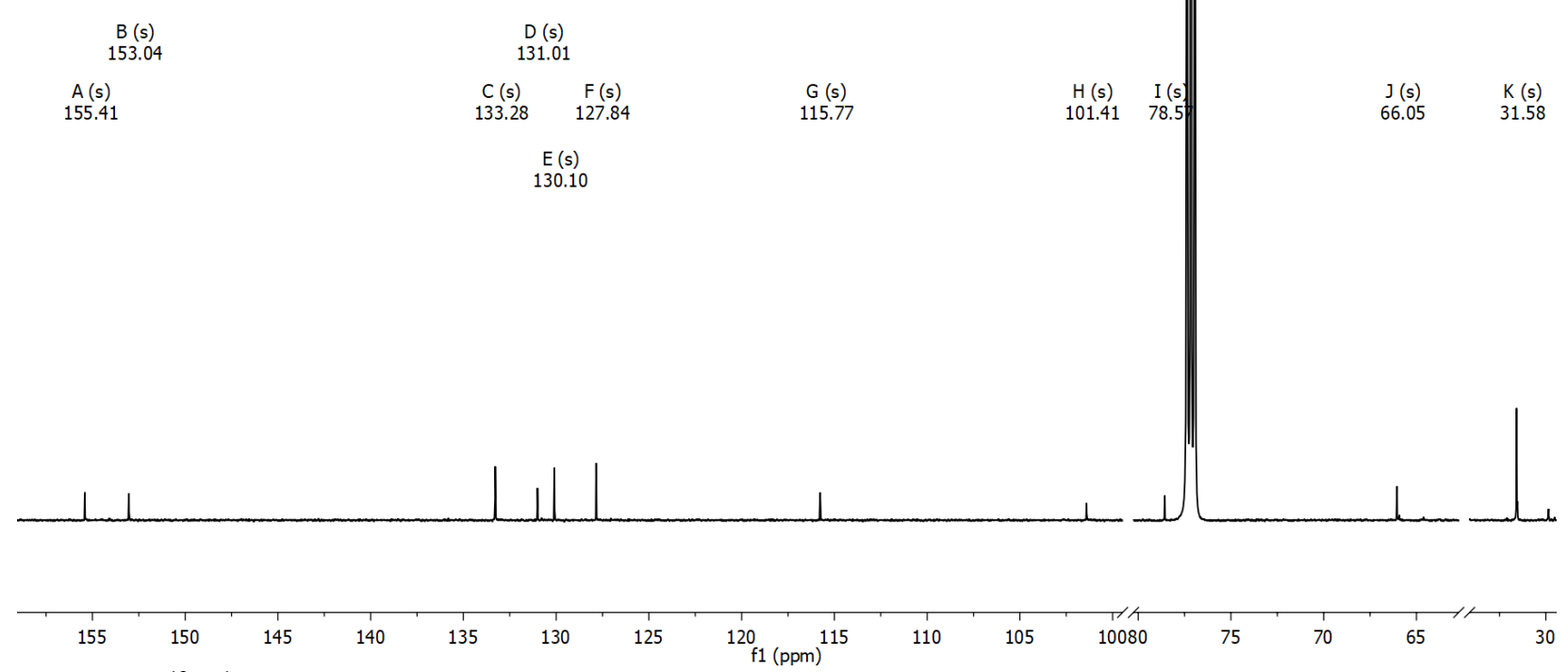

Figure S21. ${ }^{13} \mathrm{C}\left\{{ }^{1} \mathrm{H}\right\}$ NMR spectrum of bis[7-(2-methyl-3-butyn-2-ol)-4,4'-BTD]-1,2-ethylene (7) in $\mathrm{CDCl}_{3}$. 


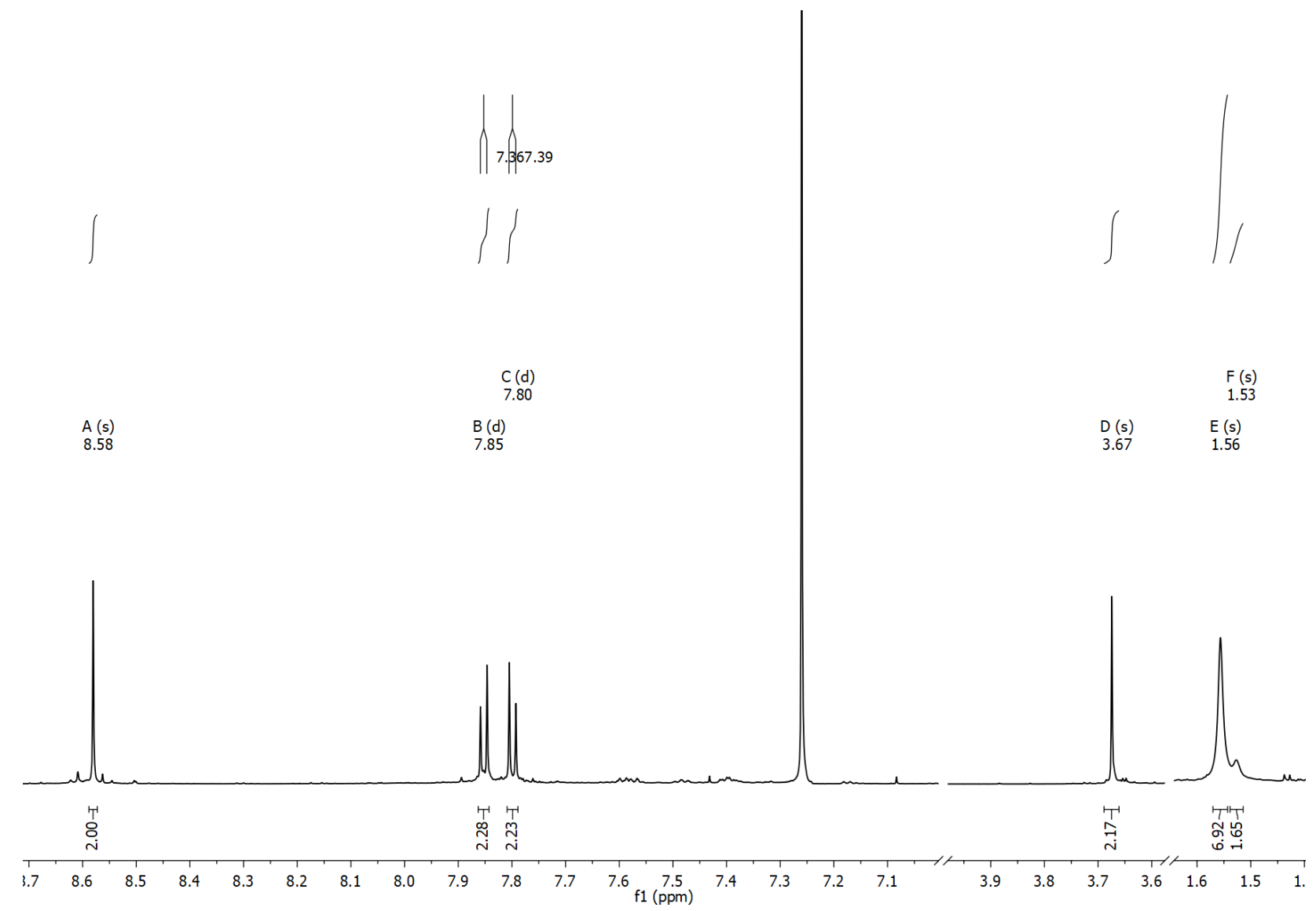

Figure S22. ${ }^{1} \mathrm{H}$ NMR spectrum of bis[7-(ethynyl)-4,4'-BTD]-1,2-ethylene ('BTD2, 8) in $\mathrm{CDCl}_{3}$. 


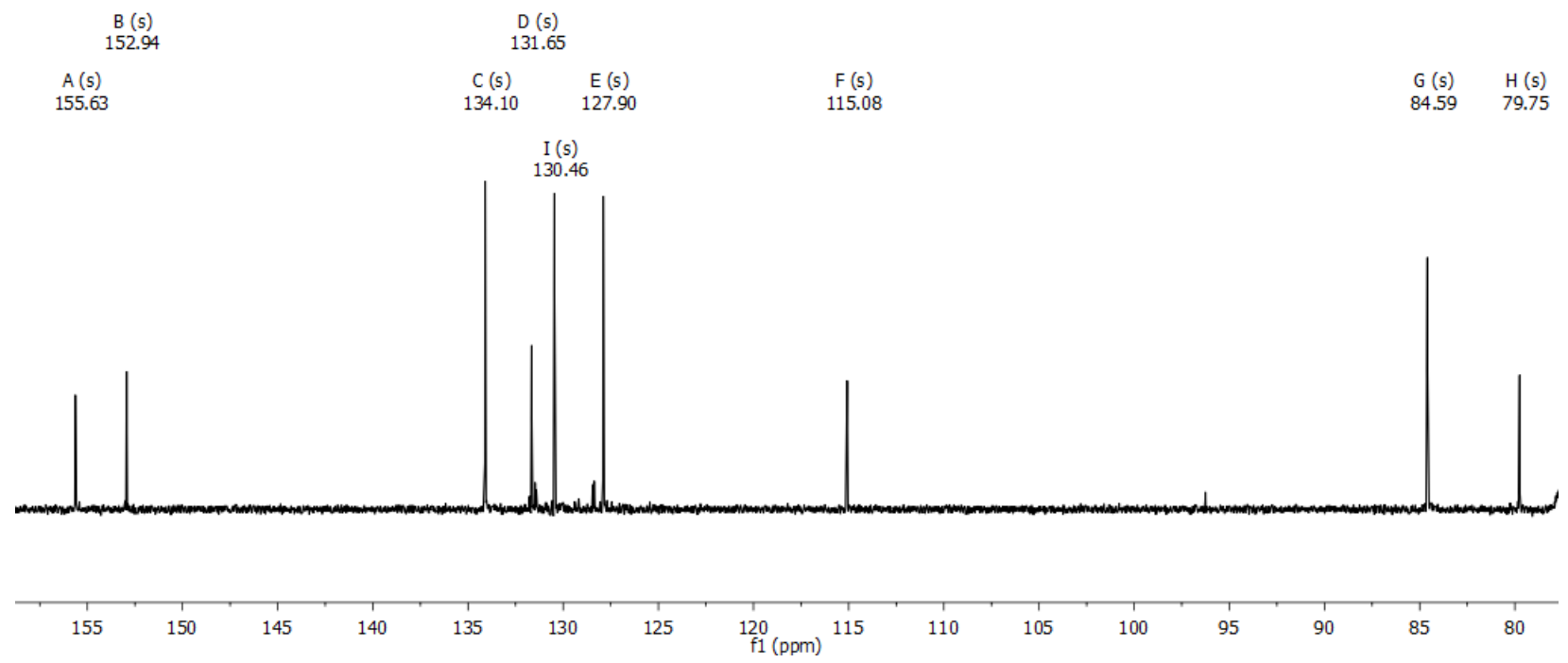

Figure S23. ${ }^{13} \mathrm{C}\left\{{ }^{1} \mathrm{H}\right\}$ NMR spectrum of bis[7-(ethynyl)-4,4'-BTD]-1,2-ethylene ('BTD2, 8) in $\mathrm{CDCl}_{3}$. 


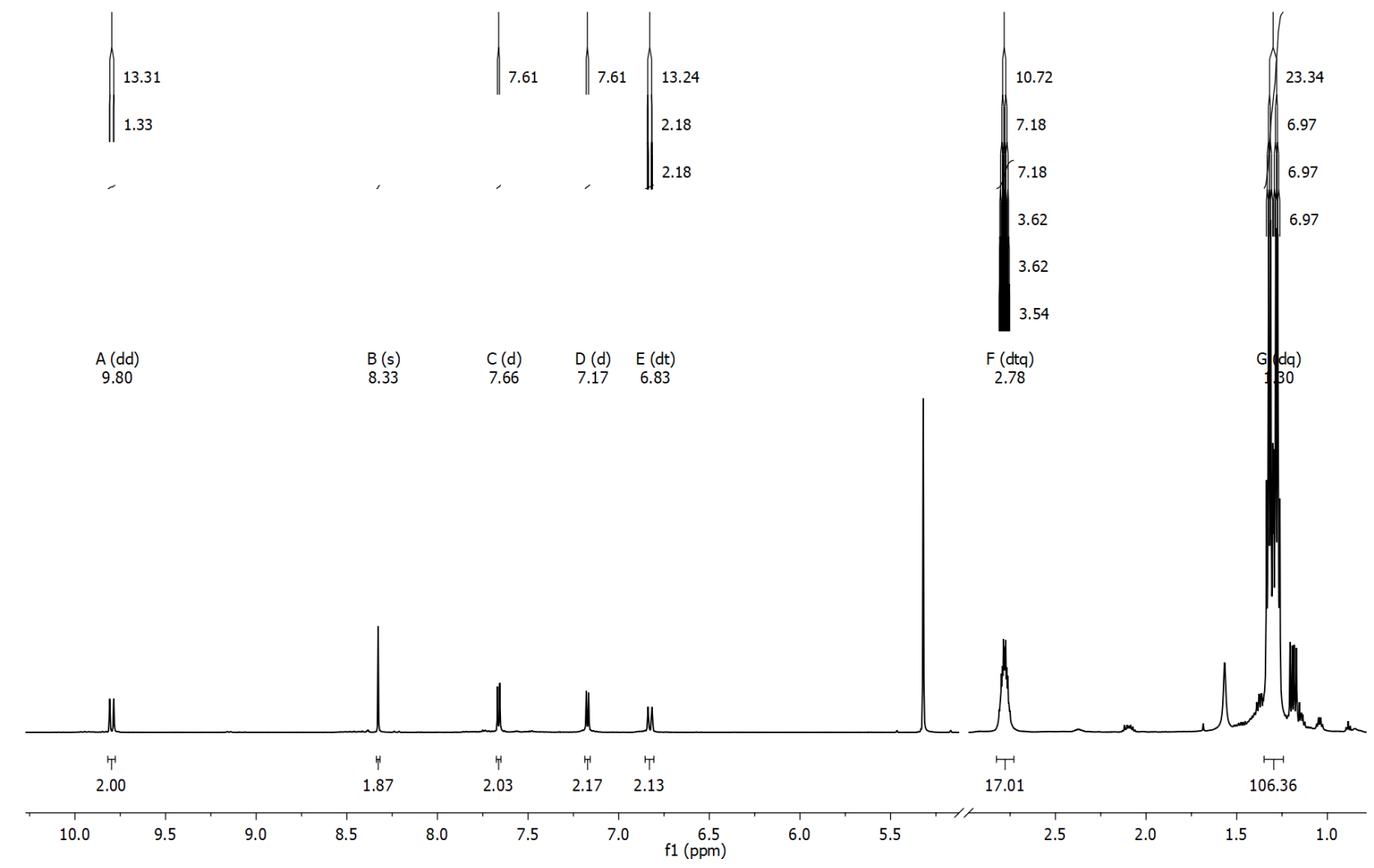

Figure S24. ${ }^{1} \mathrm{H}$ NMR spectrum of bis[7- $\left\{\mathrm{Ru}(\mathrm{CO}) \mathrm{Cl}\left(\mathrm{P}^{i} \mathrm{Pr}_{3}\right)_{2}(\mathrm{CH}=\mathrm{CH})\right\}-4,4$ '-BTD]-1,2-ethylene $\left(\mathbf{R u}_{2}{ }^{\mathbf{v}} \mathbf{B T D}_{2}\right)$ in $\mathrm{CD}_{2} \mathrm{Cl}_{2}$. 


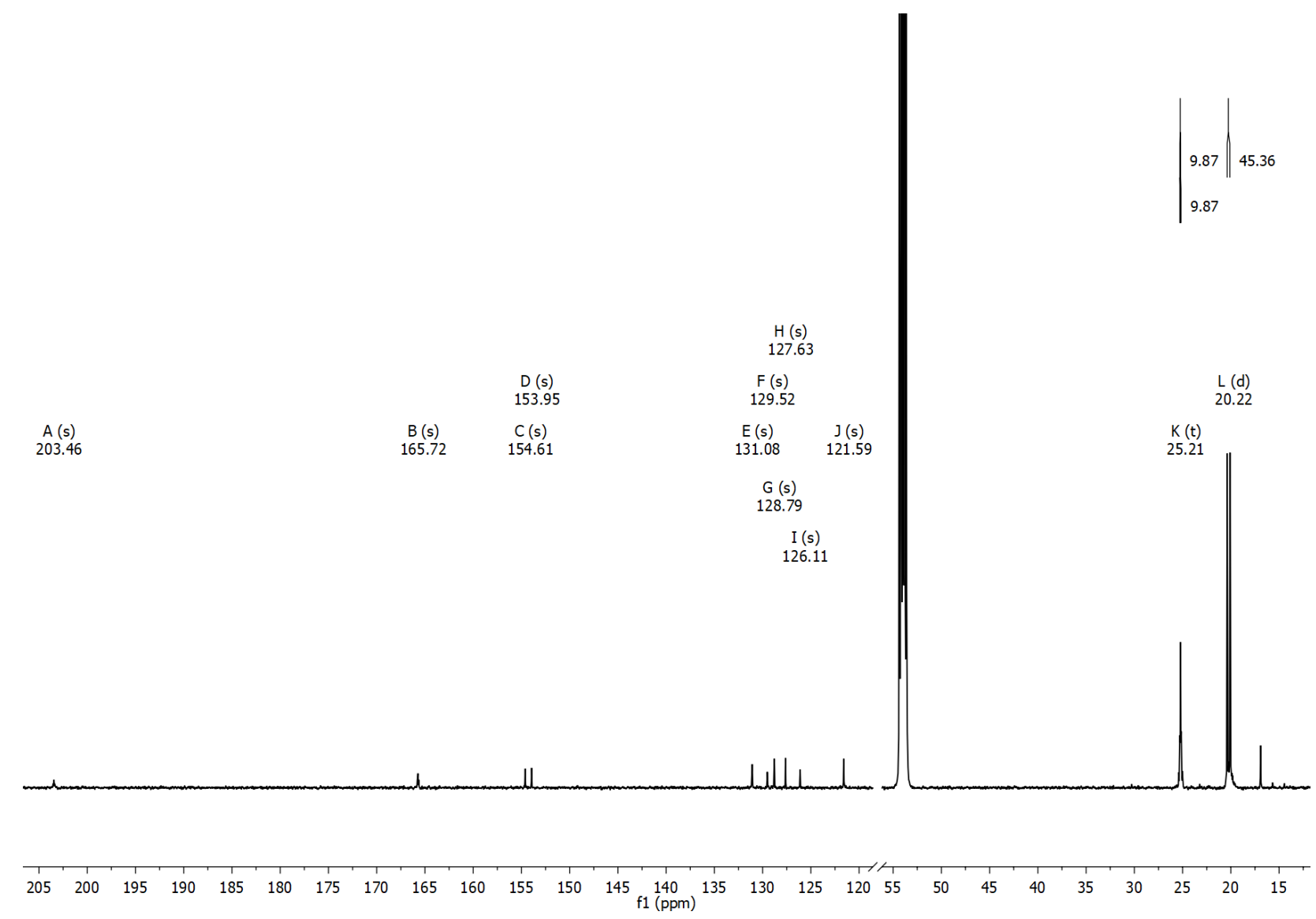

Figure S25. ${ }^{13} \mathrm{C}\left\{{ }^{1} \mathrm{H}\right\}$ NMR spectrum of bis $\left[7-\left\{\operatorname{Ru}(\mathrm{CO}) \mathrm{Cl}\left(\mathrm{P}^{i} \mathrm{Pr}_{3}\right)_{2}(\mathrm{CH}=\mathrm{CH})\right\}-4,4^{\prime}-\mathrm{BTD}\right]-1,2$-ethylene $\left(\mathbf{R u}_{2} \mathbf{B}^{\mathbf{B}} \mathbf{T D}_{2}\right)$ in $\mathrm{CD}_{2} \mathrm{Cl}_{2}$. 


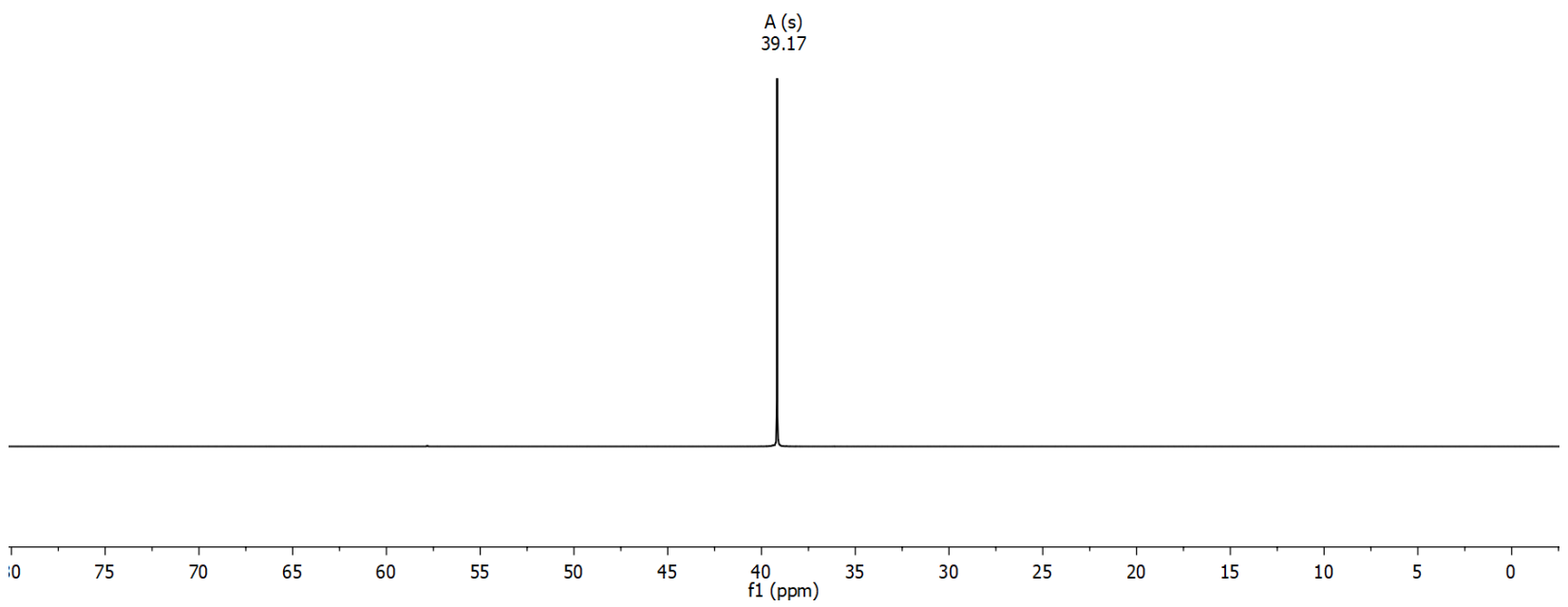

Figure S26. ${ }^{31} \mathrm{P}\left\{{ }^{1} \mathrm{H}\right\}$ NMR spectrum of bis $\left[7-\left\{\operatorname{Ru}(\mathrm{CO}) \mathrm{Cl}\left(\mathrm{P}^{i} \mathrm{Pr}\right)_{2}(\mathrm{CH}=\mathrm{CH})\right\}-4,4{ }^{\prime}-\mathrm{BTD}\right]-1,2$-ethylene $\left(\mathbf{R u}_{2}{ }^{\mathbf{v}} \mathbf{B T D}_{2}\right)$ in $\mathrm{CD}_{2} \mathrm{Cl}_{2}$. 


\section{Electrochemistry}
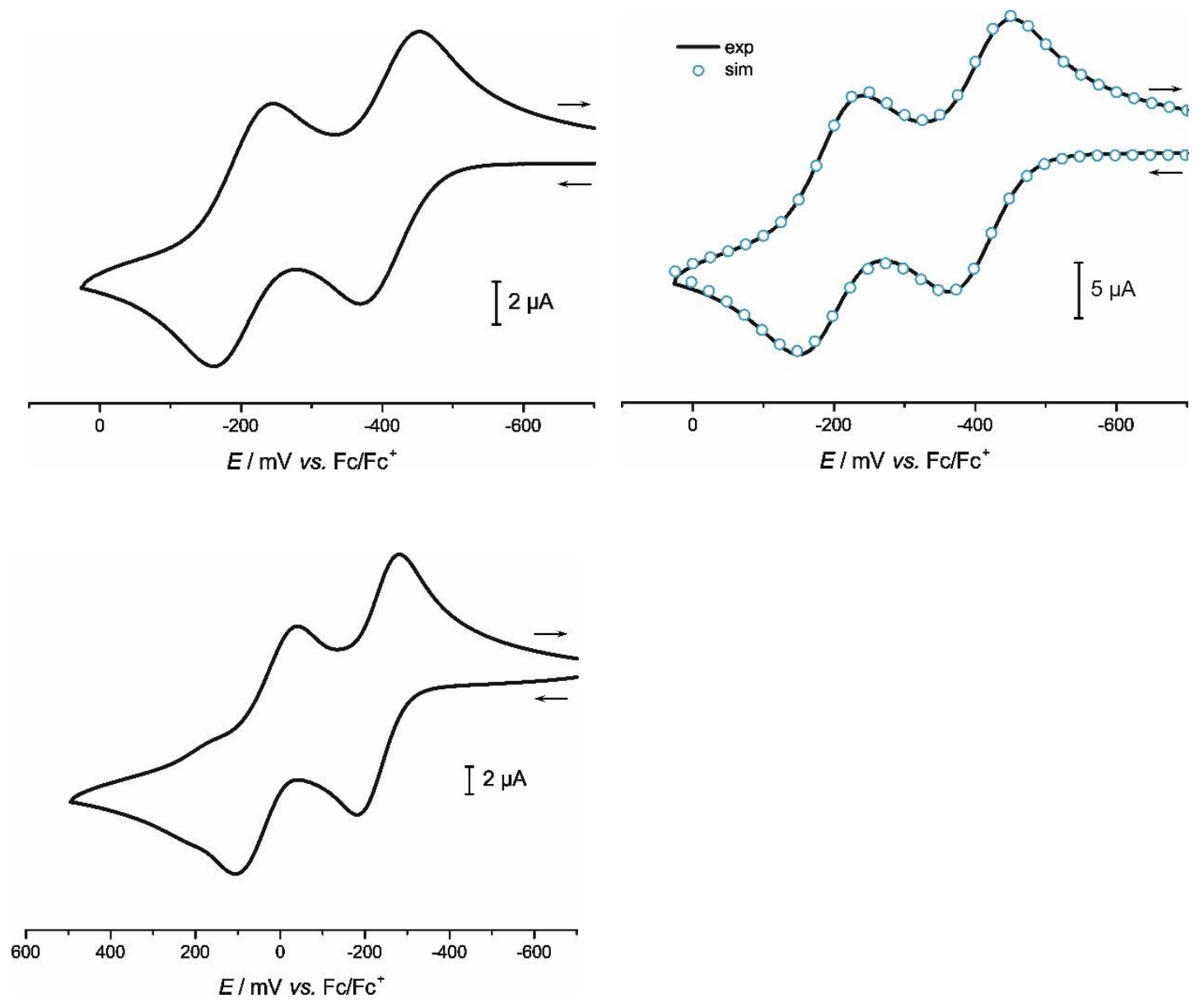

Figure S27. Cyclic voltammograms of $\mathbf{R u}_{2} \mathbf{N A}$ at $v=100 \mathrm{mV} / \mathrm{s}$ with $\mathrm{NBu}_{4} \mathrm{PF}_{6}$ as supporting electrolyte (top, left), at $v=400$ $\mathrm{mV} / \mathrm{s}$ with $\mathrm{NBu}_{4} \mathrm{PF}_{6}$ as supporting electrolyte with complementary simulation (top, right) and at $v=100 \mathrm{mV} / \mathrm{s} \mathrm{with} \mathrm{NBu} 4 \mathrm{BAr}^{\mathrm{F}}$ as supporting electrolyte (bottom, left). General conditions: $\mathrm{T}=293 \mathrm{~K}, \mathrm{CH}_{2} \mathrm{Cl}_{2}$ as the solvent. 

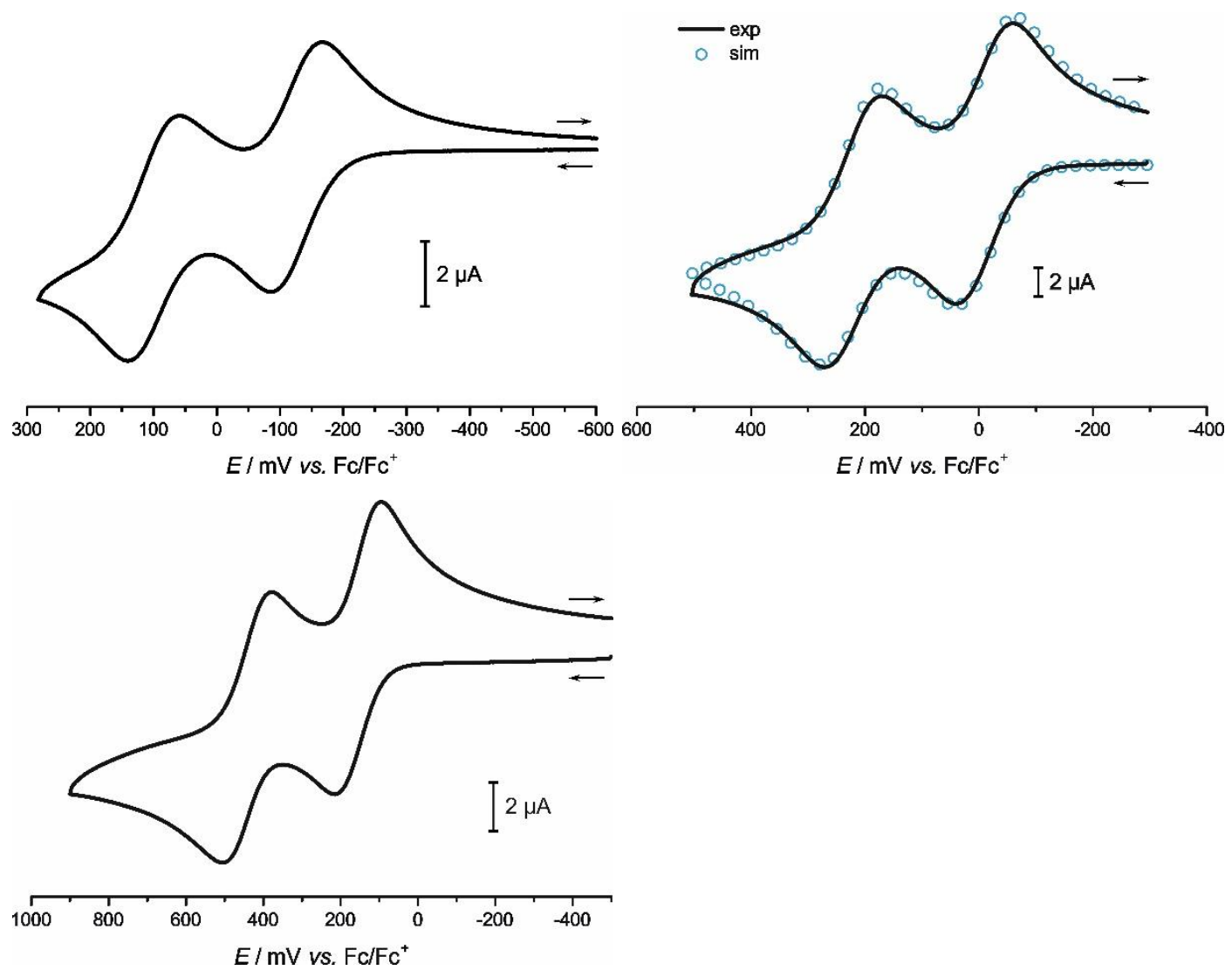

Figure S28. Cyclic voltammograms of $\mathbf{R u}_{2} \mathbf{B T D}$ at $v=100 \mathrm{mV} / \mathrm{s}$ with $\mathrm{NBu}_{4} \mathrm{PF}_{6}$ as supporting electrolyte (top, left), at $v=600$

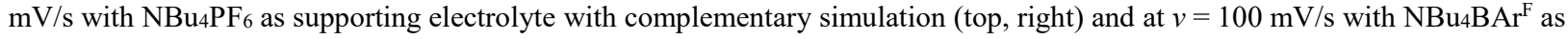
supporting electrolyte (bottom, left). General conditions: $\mathrm{T}=293 \mathrm{~K}, \mathrm{CH}_{2} \mathrm{Cl}_{2}$ as the solvent.
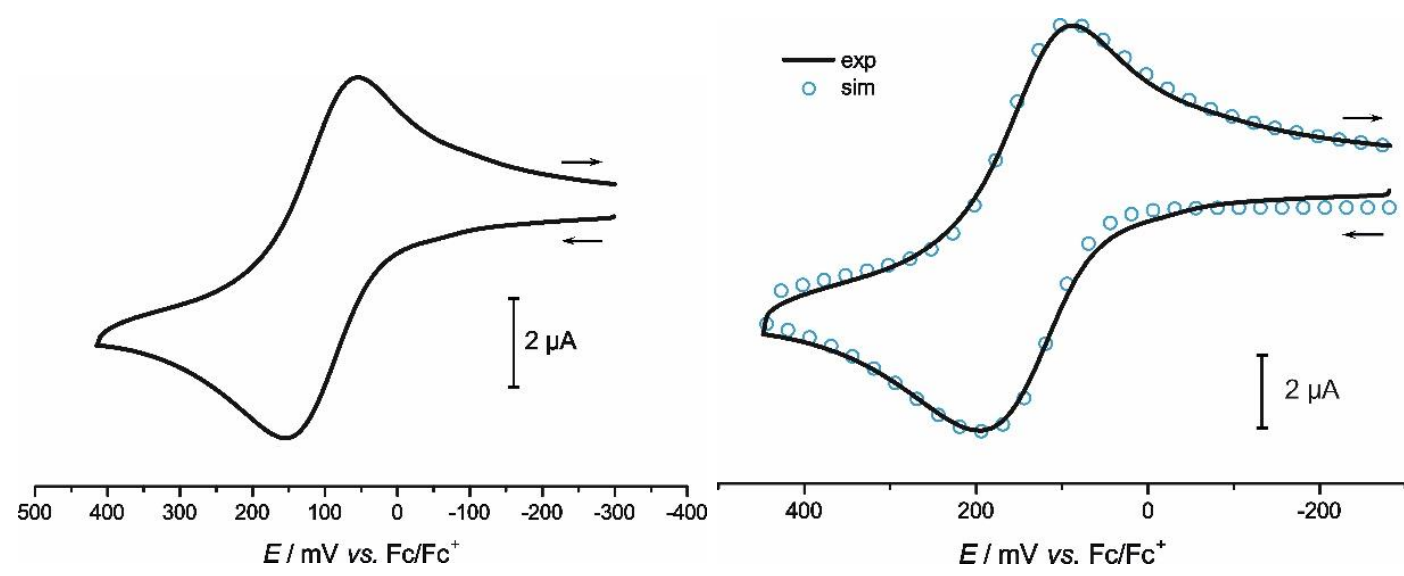

Figure S29. Cyclic voltammograms of $\mathbf{R u}_{2}{ }^{\mathrm{e}} \mathbf{B T D}_{2}$ at $v=100 \mathrm{mV} / \mathrm{s}$ with $\mathrm{NBu}_{4} \mathrm{BAr}^{\mathrm{F}}$ as supporting electrolyte (left) and at $v=800$ $\mathrm{mV} / \mathrm{s}$ with $\mathrm{NBu}_{4} \mathrm{BAr}^{\mathrm{F}}$ as supporting electrolyte with complementary simulation (right). General conditions: $\mathrm{T}=293 \mathrm{~K}, \mathrm{CH}_{2} \mathrm{Cl}_{2}$ as the solvent. 

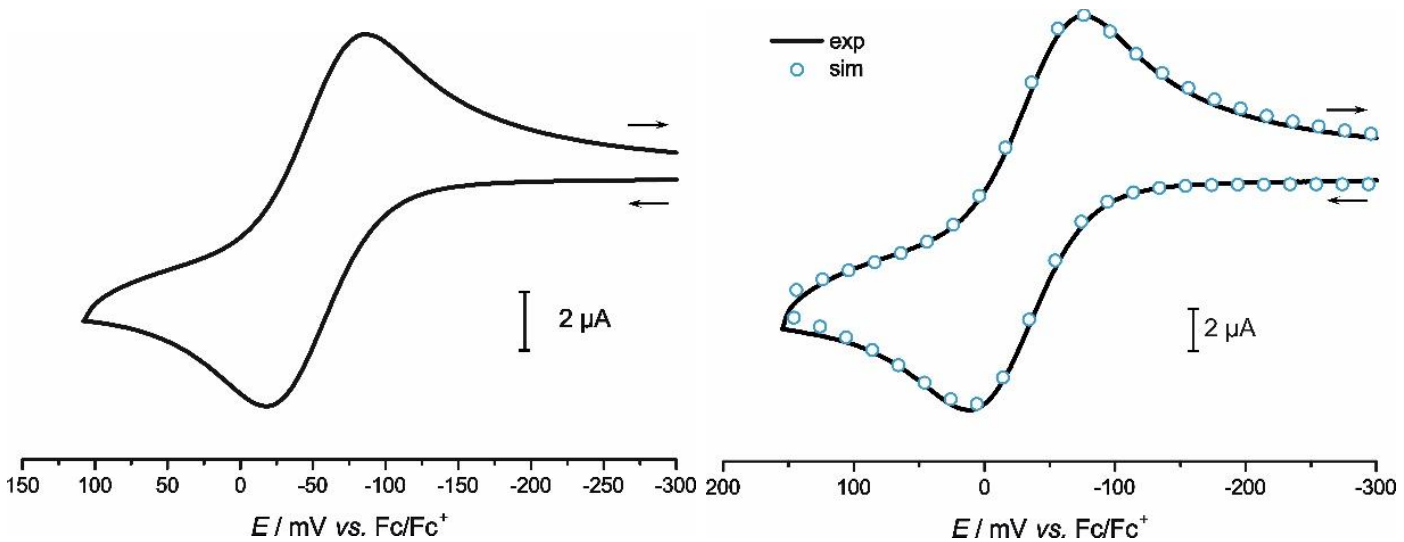

Figure S30. Cyclic voltammograms of $\mathbf{R u}_{2}{ }^{\mathbf{}} \mathbf{B T D}_{\mathbf{2}}$ at $v=100 \mathrm{mV} / \mathrm{s}$ with $\mathrm{NBu}_{4} \mathrm{BAr}{ }^{\mathrm{F}}$ as supporting electrolyte (left) and at $v=800$ $\mathrm{mV} / \mathrm{s}$ with $\mathrm{NBu}_{4} \mathrm{BAr}^{\mathrm{F}}$ as supporting electrolyte with complementary simulation (right). General conditions: $\mathrm{T}=293 \mathrm{~K}, \mathrm{CH}_{2} \mathrm{Cl}_{2}$ as the solvent. 


\section{IR Spectroelectrochemistry}
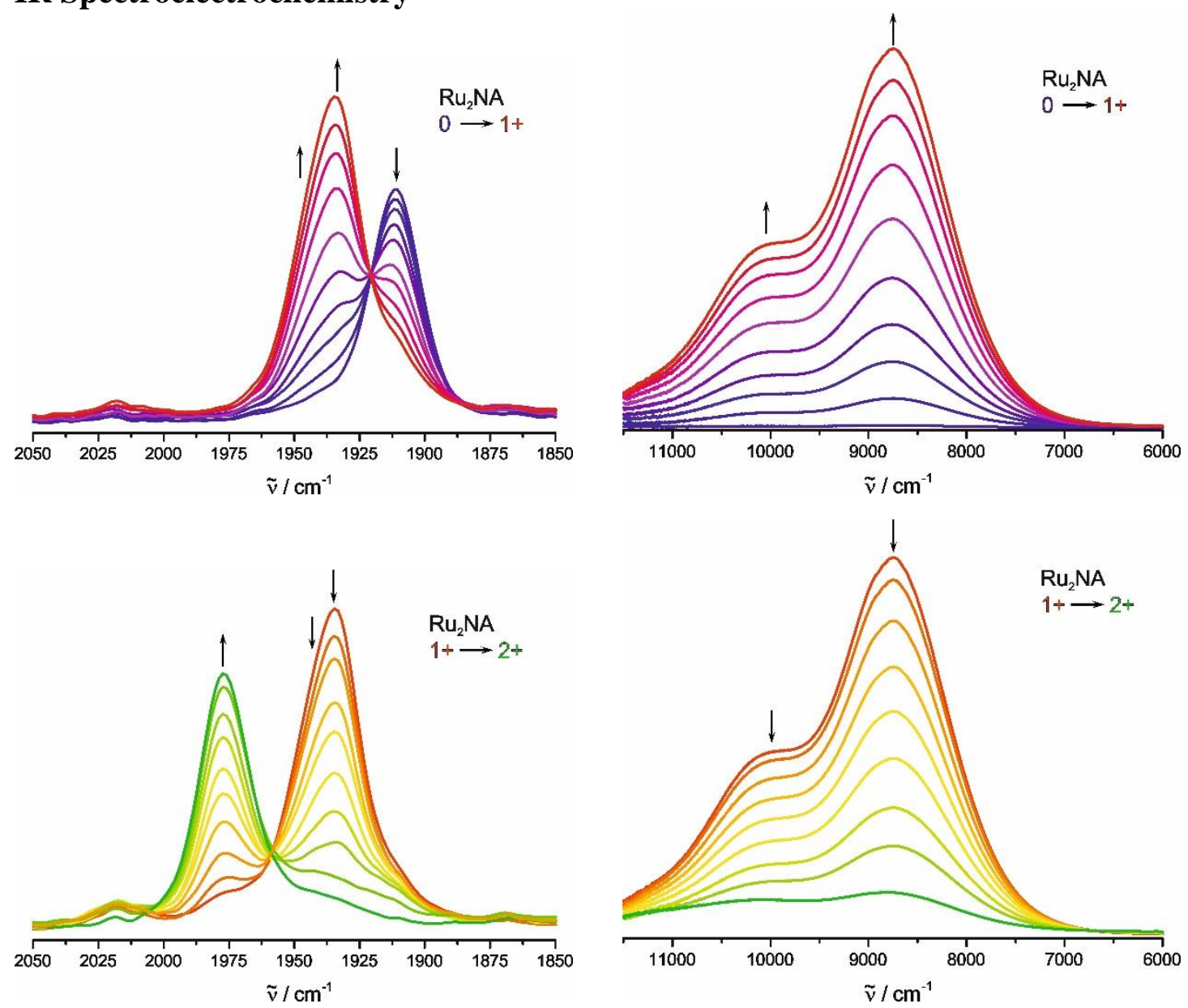

Figure S31. Changes in the IR spectrum $\left(\mathrm{CH}_{2} \mathrm{Cl}_{2}, \mathrm{NBu}_{4} \mathrm{PF}_{6}, \mathrm{~T}=293 \mathrm{~K}\right)$ of $\mathbf{R u}_{2} \mathbf{N A}$ during the first oxidation in the $\mathrm{CO}$ stretch region (top, left), NIR region (top, right), second oxidation in the CO stretch region (bottom, left) and NIR region (bottom, right). 

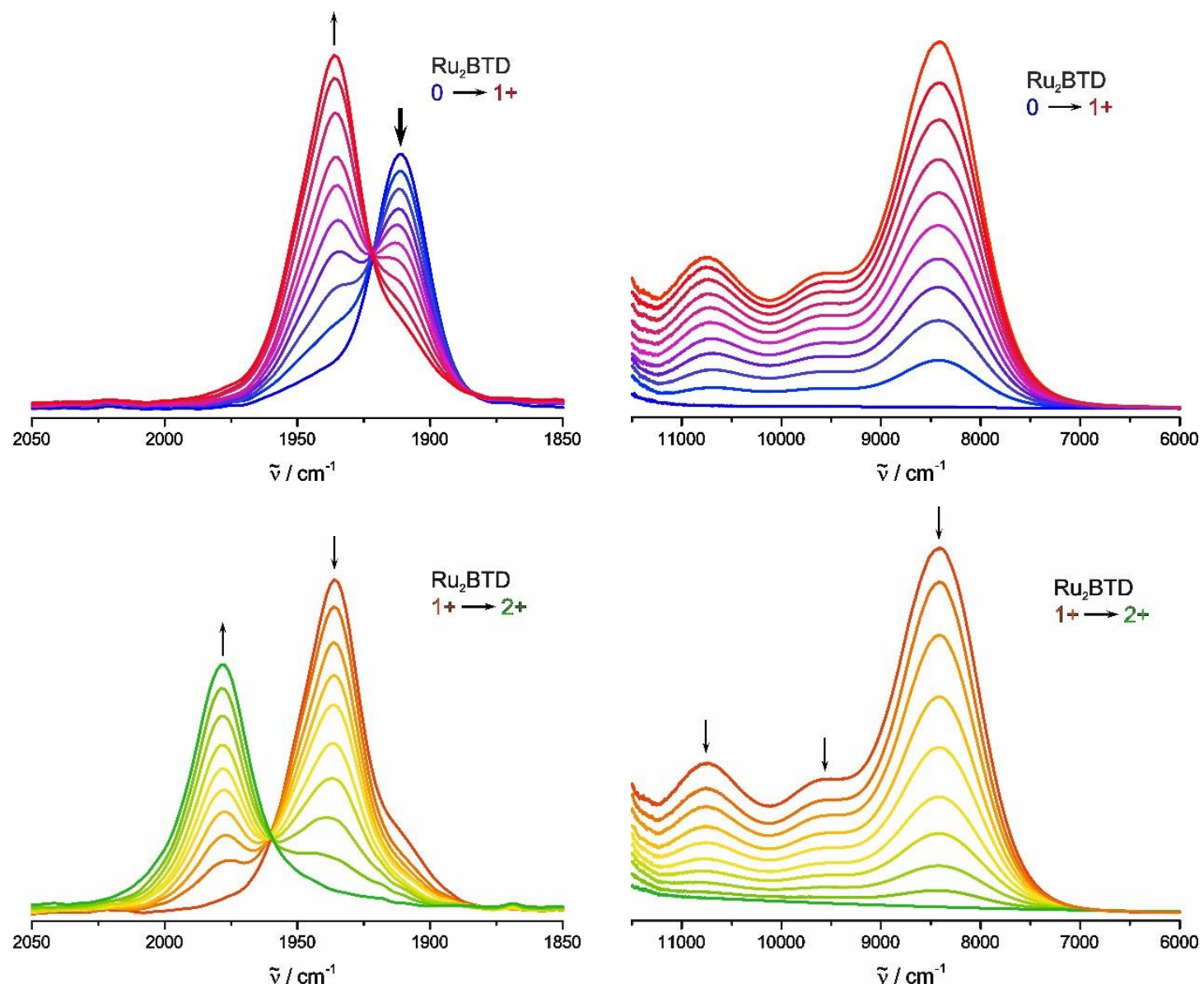

Figure S32. Changes in the IR spectrum $\left(\mathrm{CH}_{2} \mathrm{Cl}_{2}, \mathrm{NBu}_{4} \mathrm{PF}_{6}, \mathrm{~T}=293 \mathrm{~K}\right)$ of $\mathbf{R u}_{2} \mathbf{B T D}$ during the first oxidation in the $\mathrm{CO}$ stretch region (top, left), NIR region (top, right), second oxidation in the $\mathrm{CO}$ stretch region (bottom, left) and NIR region (bottom, right). 


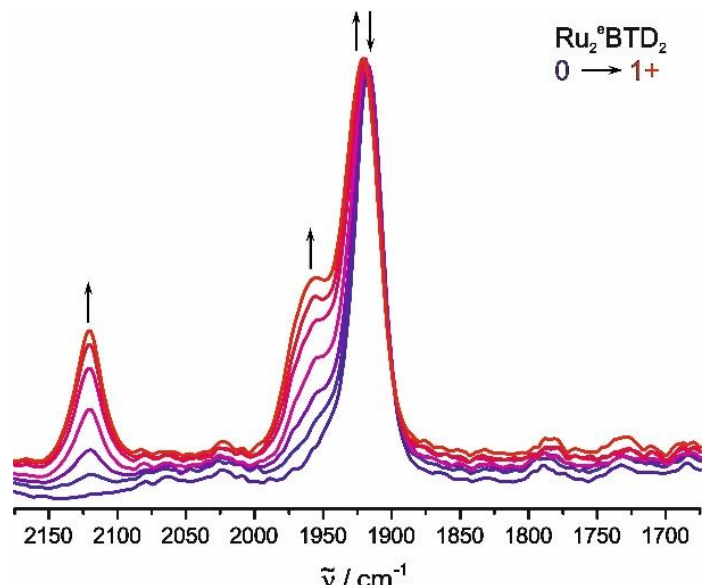

$\tilde{v} / \mathrm{cm}^{-1}$

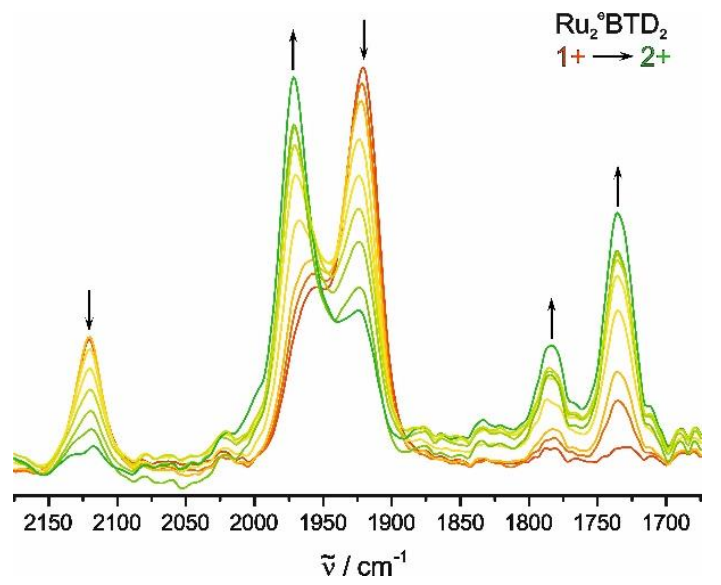

$\mathrm{Ru}_{2}{ }^{8} \mathrm{BTD} \mathrm{D}_{2}$

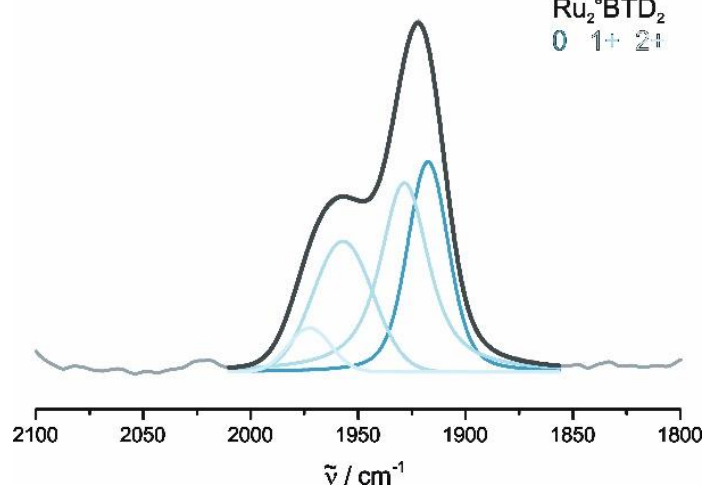

$\mathrm{Ru}_{2}{ }^{\circ} \mathrm{BTD}$

$0 \longrightarrow 1+$
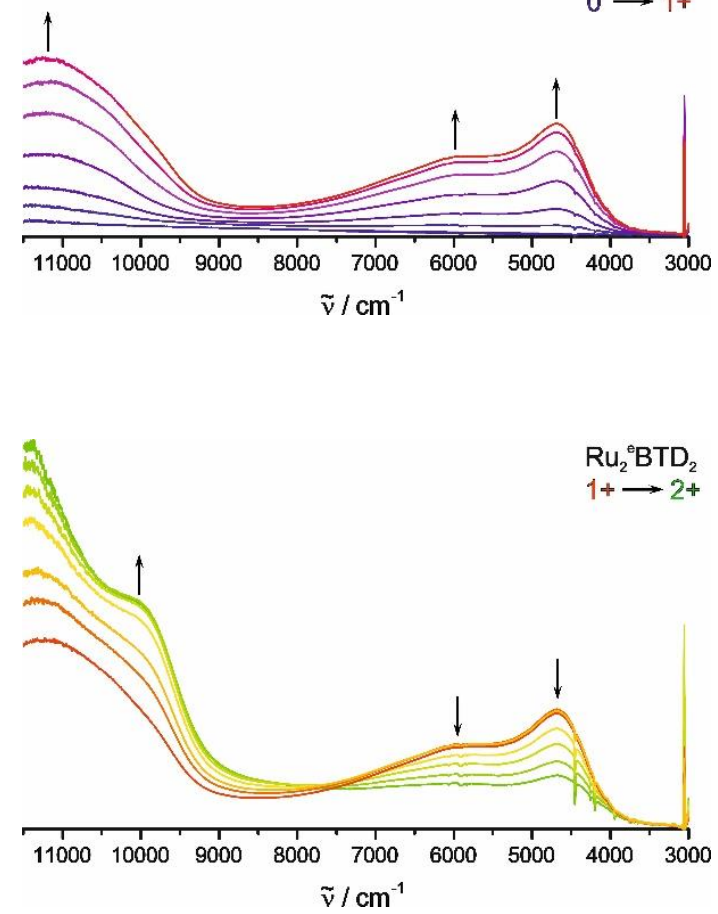

Figure S33. Changes in the IR spectrum $\left(\mathrm{CH}_{2} \mathrm{Cl}_{2}, \mathrm{NBu}_{4} \mathrm{BAr}{ }^{\mathrm{F}}, \mathrm{T}=293 \mathrm{~K}\right)$ of $\mathbf{R u}_{2}{ }^{\mathrm{e}} \mathbf{B} \mathbf{T D}_{2}$ during the first oxidation in the $\mathrm{CO} / \mathrm{CC}$ stretch region (top, left), NIR region (top, right), second oxidation in the CO/CC stretch region (bottom, left) and NIR region (bottom, right). Deconvoluted IR spectrum of the CO region at point of maximum monocation concentration (bottom, left). 

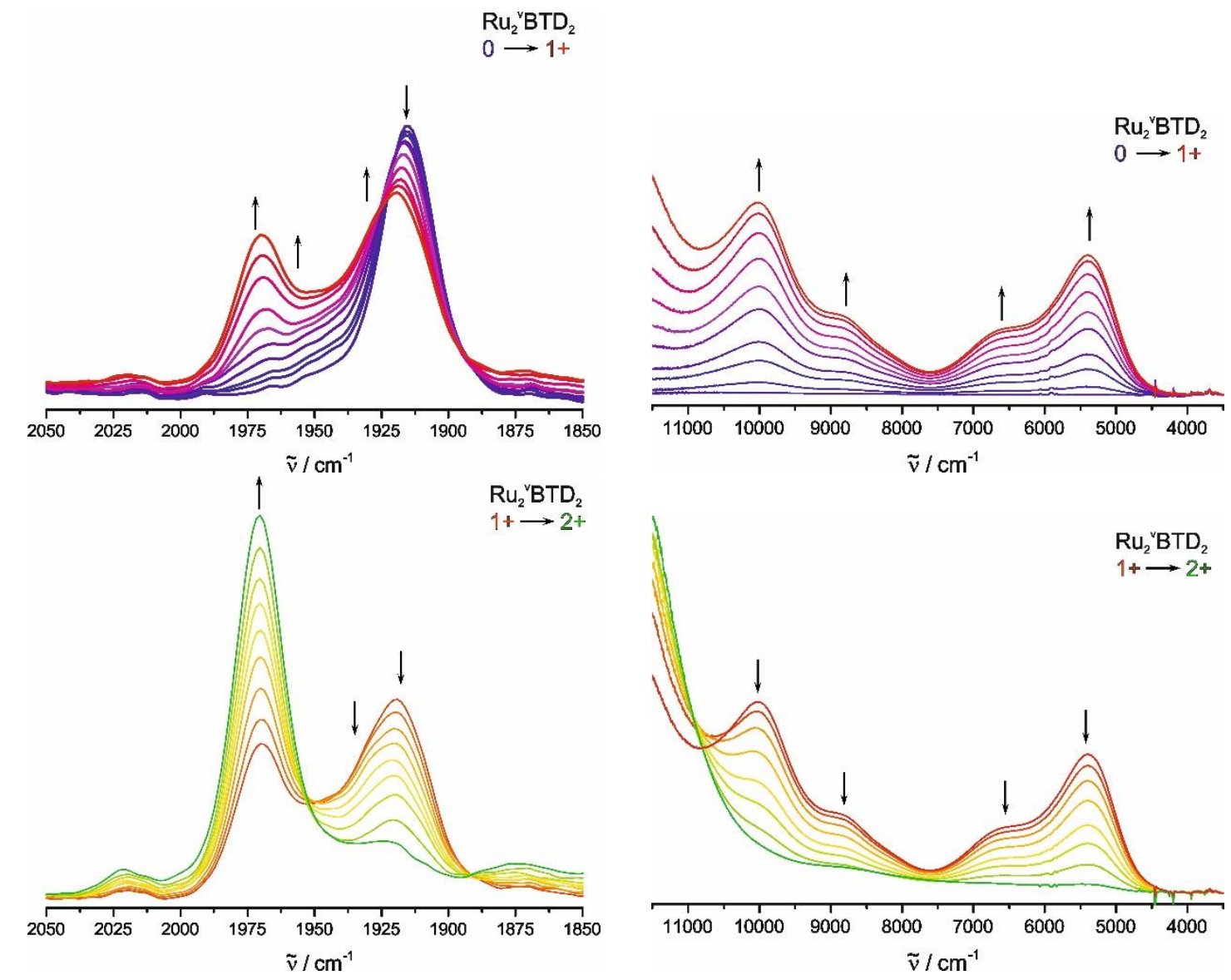

$\mathrm{Ru}_{2}{ }^{\mathrm{B}} \mathrm{BTD}$

$0 \quad 1+\underline{2}: 4$

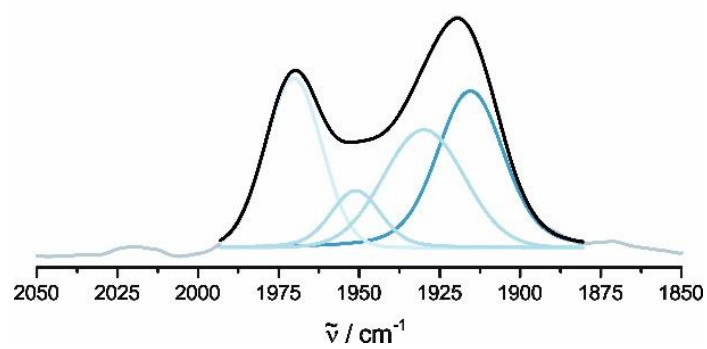

Figure S34. Changes in the IR spectrum $\left(\mathrm{CH}_{2} \mathrm{Cl}_{2}, \mathrm{NBu}_{4} \mathrm{BAr}{ }^{\mathrm{F}}, \mathrm{T}=293 \mathrm{~K}\right)$ of $\mathbf{R u}_{2}{ }^{\mathbf{v}} \mathbf{B T D} \mathbf{D}_{2}$ during the first oxidation in the CO stretch region (top, left), NIR region (top, right), second oxidation in the CO stretch region (mid, left) and NIR region (mid, right). Deconvoluted IR spectrum of the CO region at point of maximum monocation concentration (bottom, left). 


\section{EPR Spectroscopy}
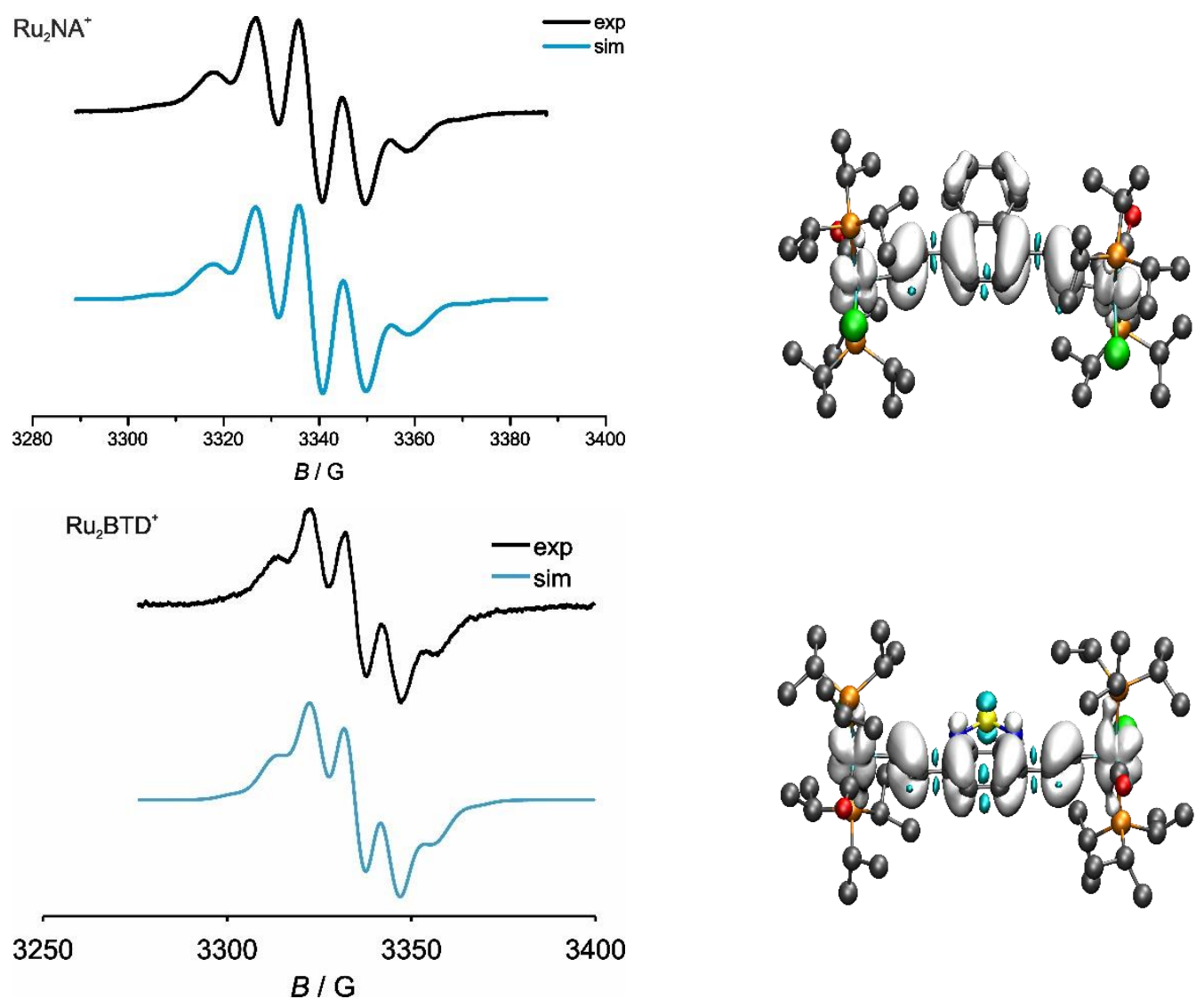

Figure S35. Experimental (top curve) and simulated (bottom curve) EPR spectra of the radical cation Ru2NA $\mathbf{N A}^{++}$(top left) and $\mathbf{R u}_{2} \mathbf{B T D}^{++}$(bottom left) in $\mathrm{CH}_{2} \mathrm{Cl}_{2}$ at $293 \mathrm{~K}$ with calculated spin density plots (right). Oxidizing agent $\mathrm{FcPF}_{6}$. 

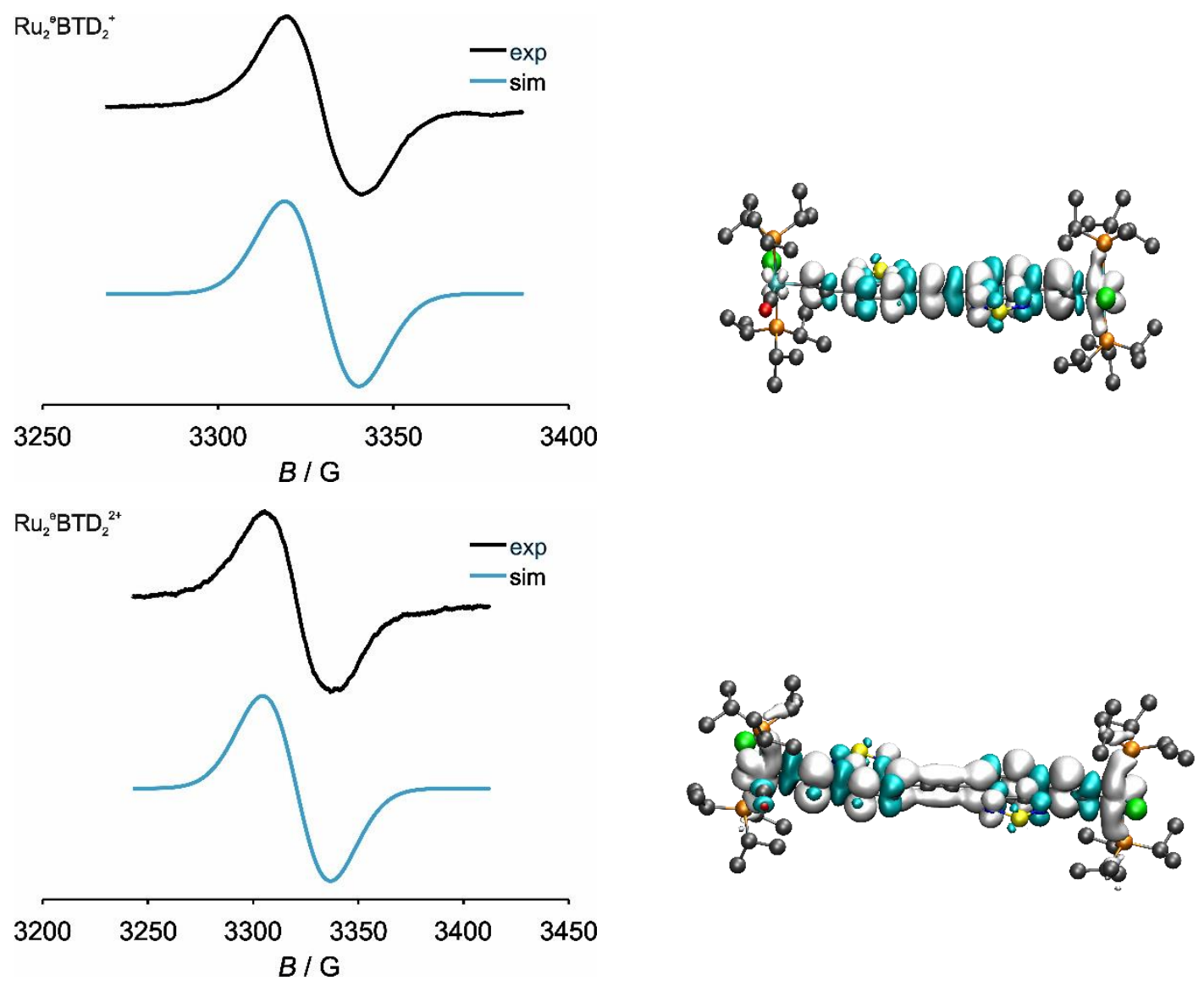

Figure S36. Experimental (top curve) and simulated (bottom curve) EPR spectra of the radical cation $\mathbf{R u}_{2}{ }^{{ }} \mathbf{B} \mathbf{B D}_{2}{ }^{++}$(top left) and the paramagnetic dication $\mathbf{R} \mathbf{u}_{2}{ }^{\mathrm{e}} \mathbf{B T D}_{2}{ }^{2+}$ (bottom left) in $\mathrm{CH}_{2} \mathrm{Cl}_{2}$ at $293 \mathrm{~K}$ with calculated spin density plots (right). The monocation was generated with 20 eq. of $\mathrm{FcBAr}^{\mathrm{F}}$. The dication was generated with a 10 -fold excess $\mathrm{AcFcSbF}_{6}$ in $\mathrm{CH}_{2} \mathrm{Cl}_{2}$. 


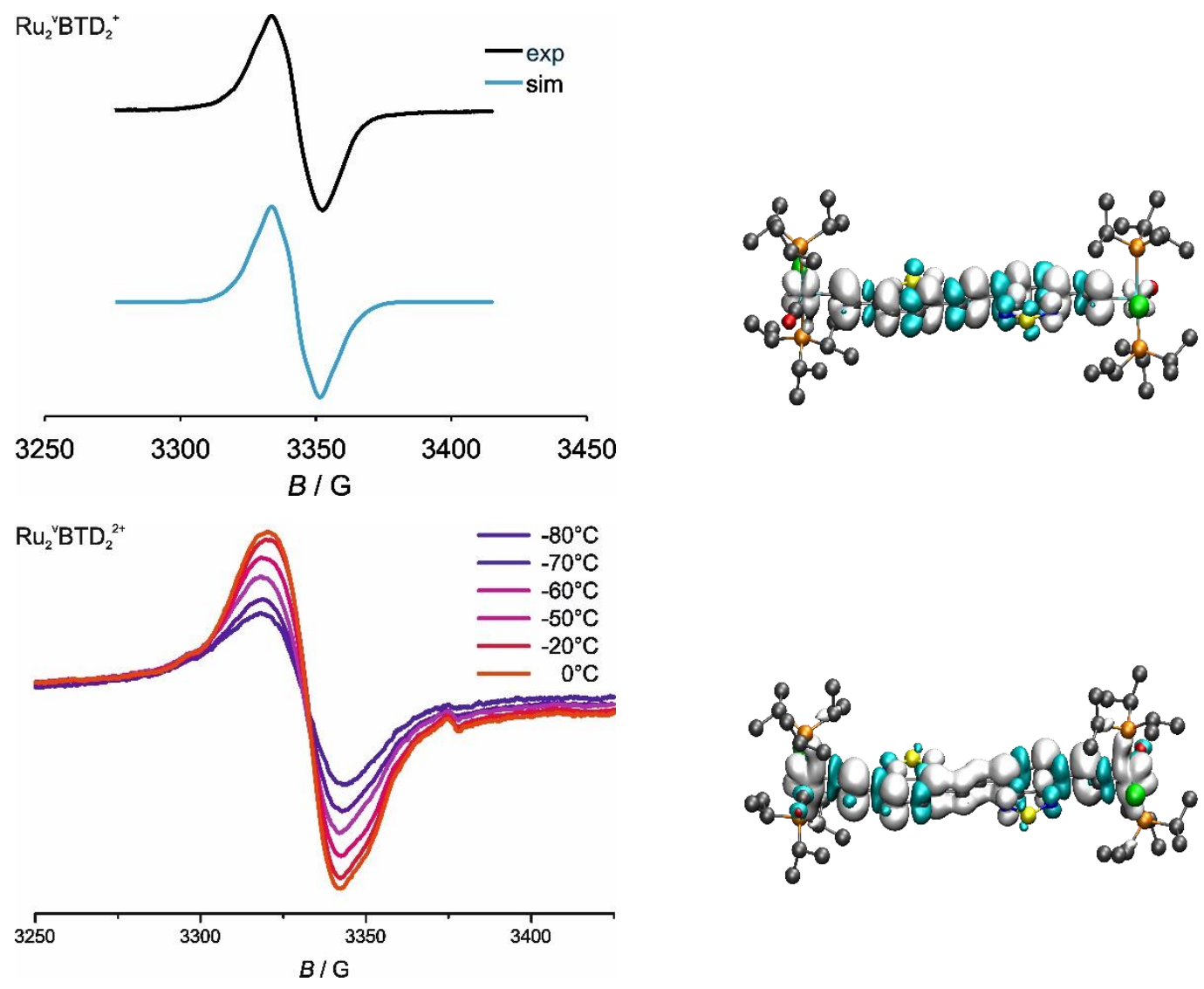

Figure S37. Experimental (top curve) and simulated (bottom curve) EPR spectra of the radical cation $\mathbf{R u}_{2}{ }^{\mathbf{v}} \mathbf{B T D}_{2}{ }^{++}$(top left) and radical dication $\mathbf{R u}_{2}{ }^{\mathbf{}} \mathbf{B T D}_{2}{ }^{2+}$ (bottom left) in $\mathrm{CH}_{2} \mathrm{Cl}_{2}$ at $293 \mathrm{~K}$ with calculated spin density plots (right). Monocation was generated with 20 eq. of FcBArF. Dication was generated to relative concentration of around $99 \%$ with $\mathrm{AcFcSbF}_{6}$ in $10-$ fold excess.
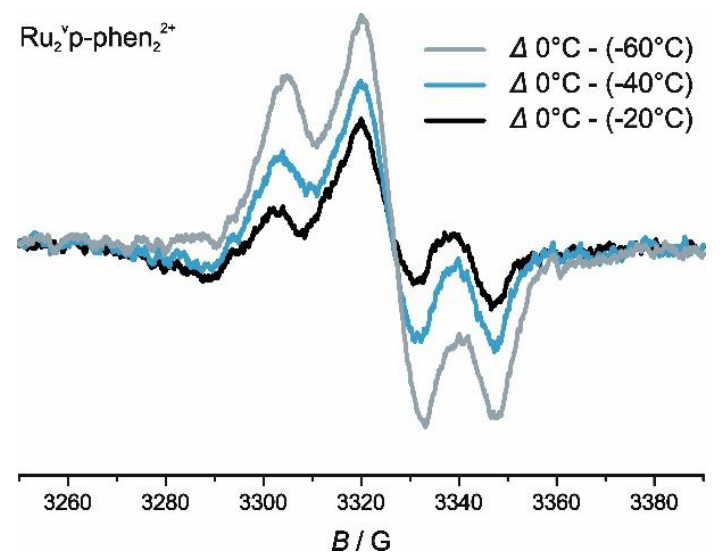

Figure S38. Difference in signal intensities at $T=273 \mathrm{~K}$ and $T=253,233$ and $213 \mathrm{~K}$ for dicationic $\mathbf{R u}_{2}{ }^{\mathbf{v}} \mathbf{p}-\mathbf{p h e n} \mathbf{2}^{2+}$ The dication $^{2}$ was generated by electrolysis in $\mathrm{DCM} / \mathrm{NBu}_{4} \mathrm{PF}_{6}$. 


\section{UV/Vis/NIR Spectroelectrochemistry, Solvatochromism and TD-DFT computed spectra}
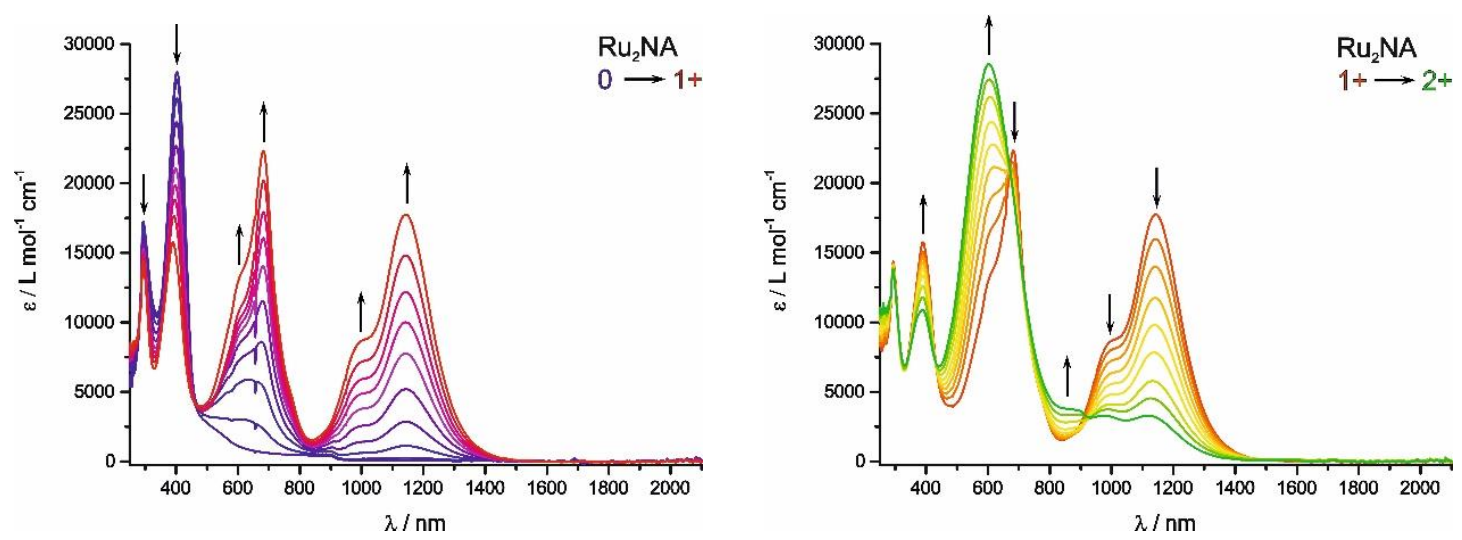

Figure S39. Changes in the UV/Vis/NIR spectrum $\left(\mathrm{CH}_{2} \mathrm{Cl}_{2}, \mathrm{NBu}_{4} \mathrm{PF}_{6}, \mathrm{~T}=293 \mathrm{~K}\right)$ of $\mathbf{R} \mathbf{u}_{2} \mathbf{N A}$ during the first oxidation (left) and the second oxidation (right).
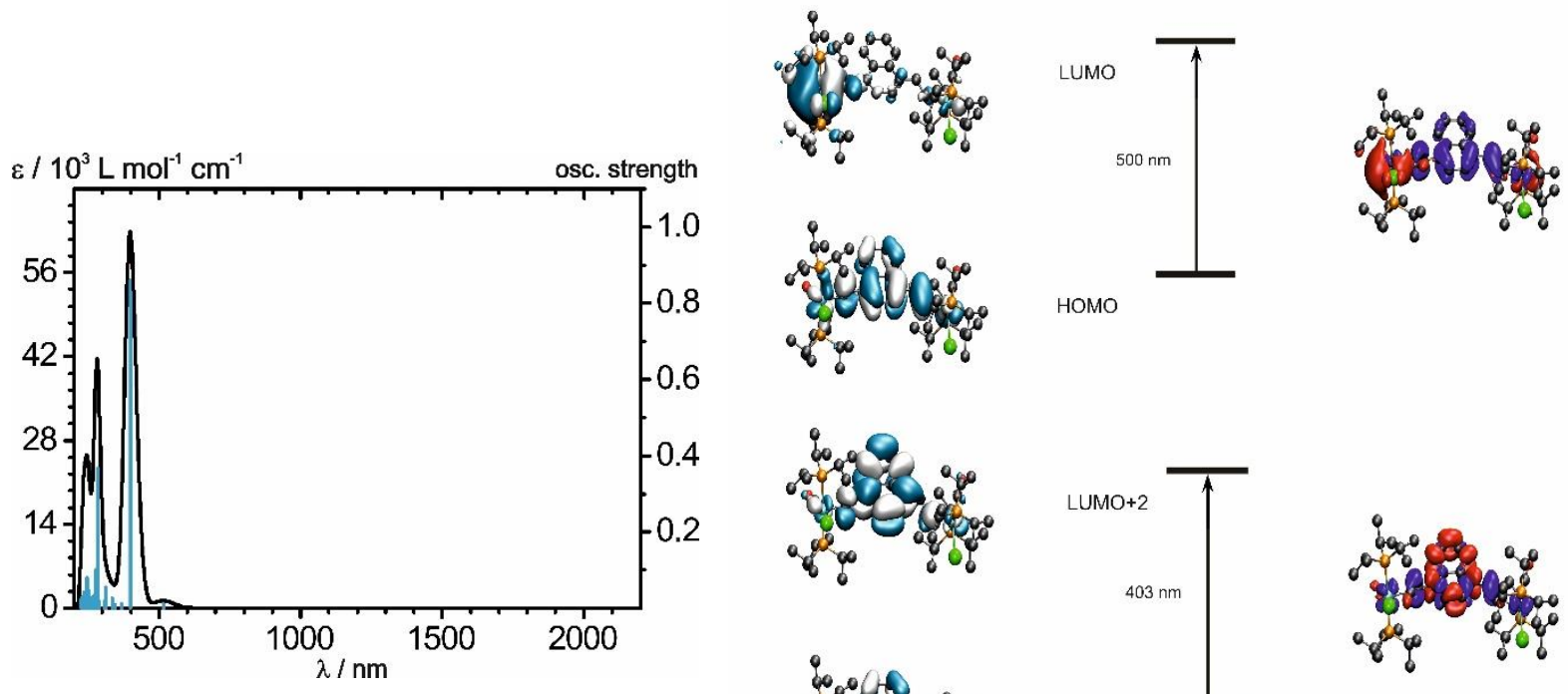

HOMO
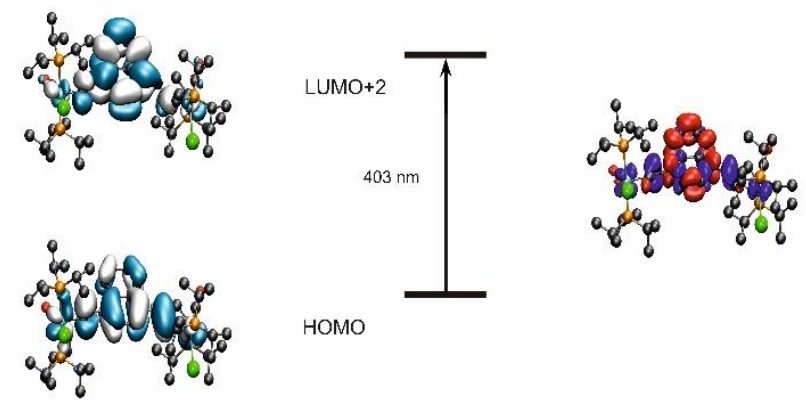

HOMO

Figure S40. TD-DFT calculated UV/Vis/NIR absorption spectrum of neutral Ru2NA and graphical representation of MOs with the largest contribution to the relevant transitions. Color coding for Electron Density Difference Maps (EDDMs); blue: electron density loss, red: electron density gain. 

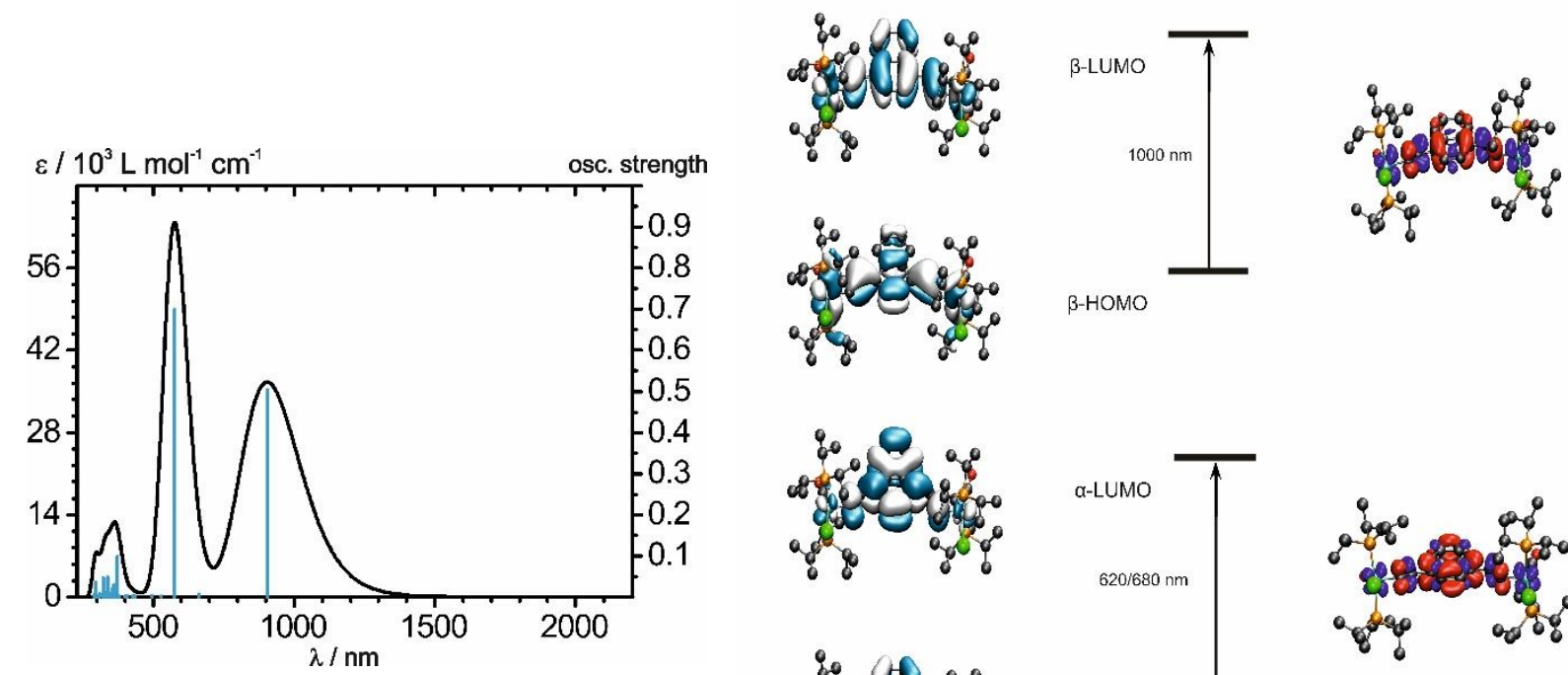

$\beta-\mathrm{HOMO}$
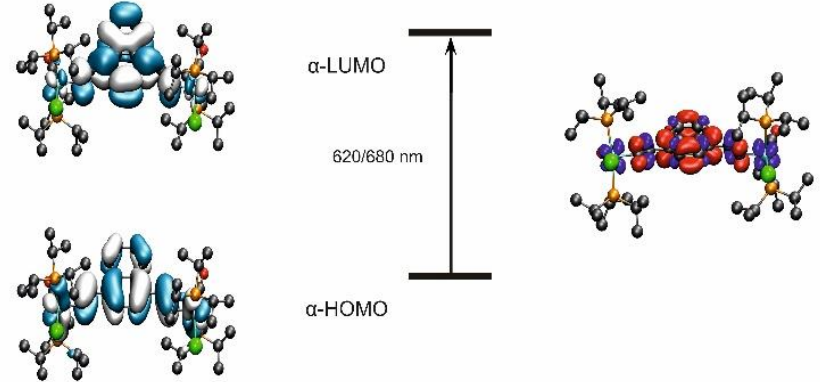

a-HOMO

Figure S41. TD-DFT calculated UV/Vis/NIR absorption spectrum of the radical cation $\mathbf{R} \mathbf{u}_{2} \mathbf{N A}^{+}$and graphical representation of MOs with the largest contribution to the relevant transitions. Color coding for Electron Density Difference Maps (EDDMs); blue: electron density loss, red: electron density gain.
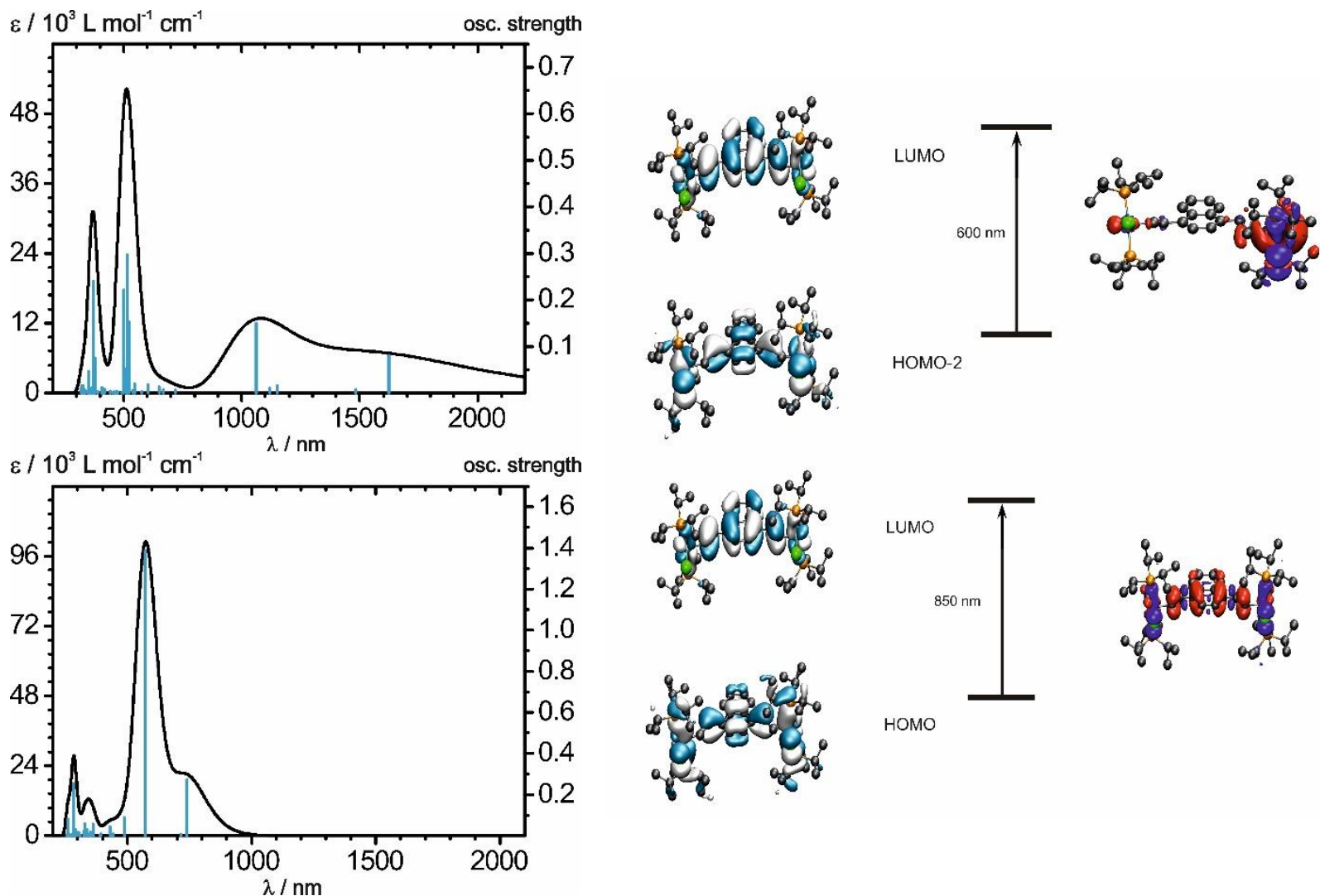

HOMO-2
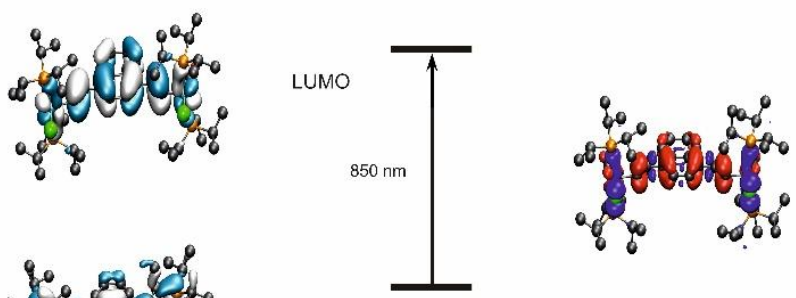

Figure S42. TD-DFT calculated UV/Vis/NIR absorption spectrum of the dication $\mathbf{R} \mathbf{u}_{2} \mathbf{N} \mathbf{A}^{2+}$ in the singlet state (bottom, left) and the triplet state (top, left) and graphical representation of MOs with the largest contribution to the relevant transitions (singlet state assumed). Color coding for Electron Density Difference Maps (EDDMs); blue: electron density loss, red: electron density gain. 

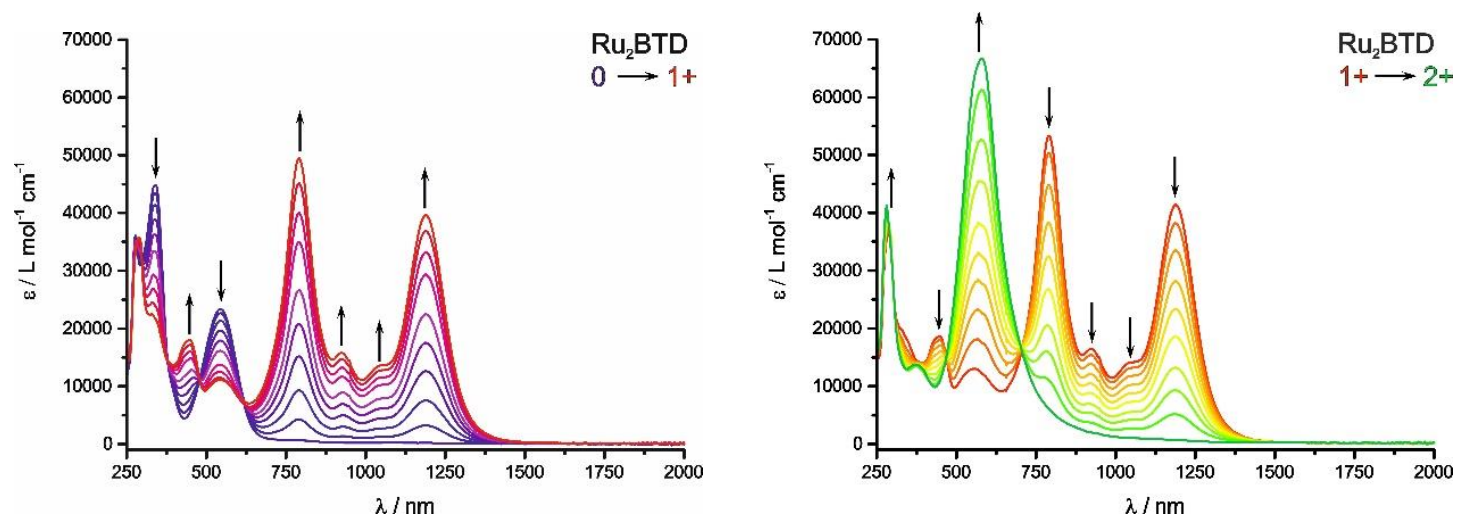

Figure S43. Changes in the UV/Vis/NIR spectrum $\left(\mathrm{CH}_{2} \mathrm{Cl}_{2}, \mathrm{NBu}_{4} \mathrm{PF}_{6}, \mathrm{~T}=293 \mathrm{~K}\right)$ of $\mathbf{R u}_{2} \mathbf{B T D}$ during the first oxidation (left) and the second oxidation (right).
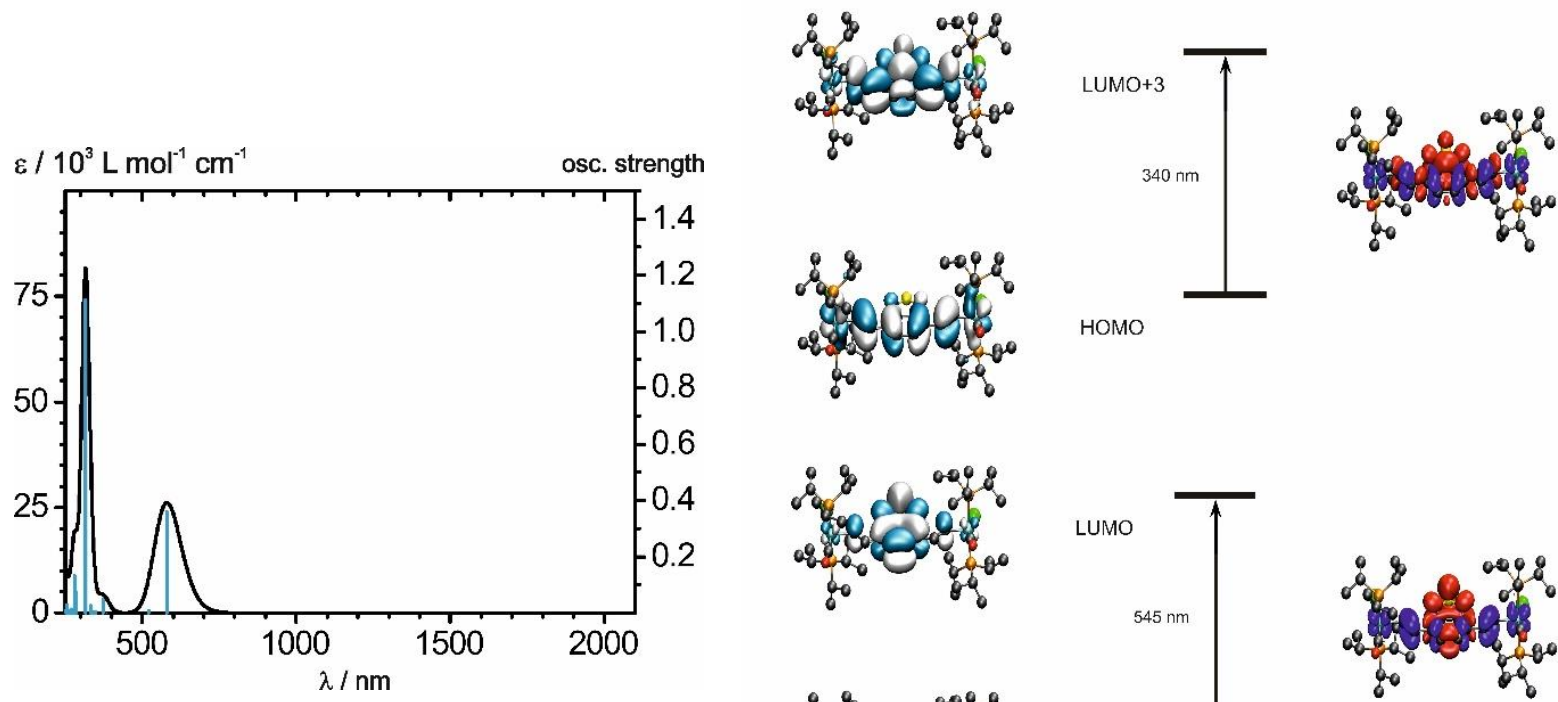

HOMO

$-0.8$

8

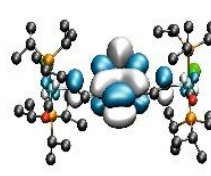

LUMO
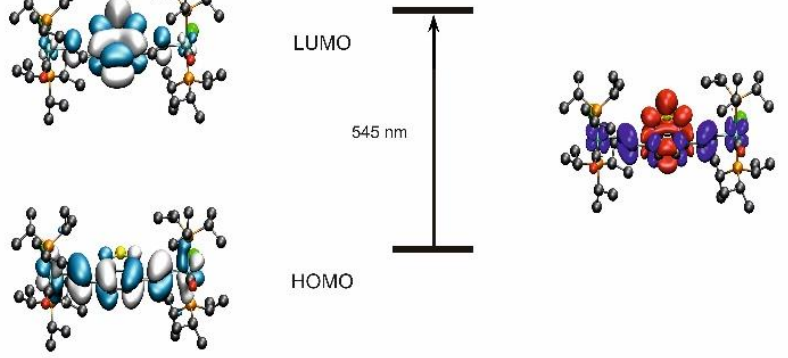

HOMO

Figure S44. TD-DFT calculated UV/Vis/NIR absorption spectrum of neutral Rut $\mathbf{B T D}$ and graphical representation of MOs with the largest contribution to the relevant transitions. Color coding for Electron Density Difference Maps (EDDMs); blue: electron density loss, red: electron density gain. 

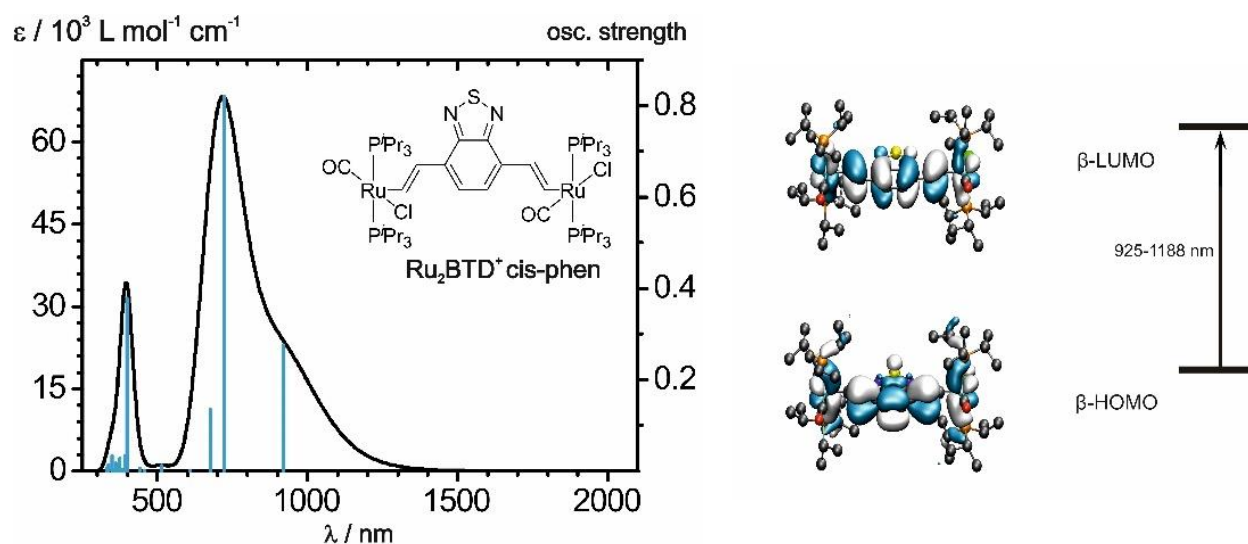

$\varepsilon / 10^{3} \mathrm{~L} \mathrm{~mol}^{-1} \mathrm{~cm}^{-1} \quad \lambda / \mathrm{nm} \quad$ osc. strength
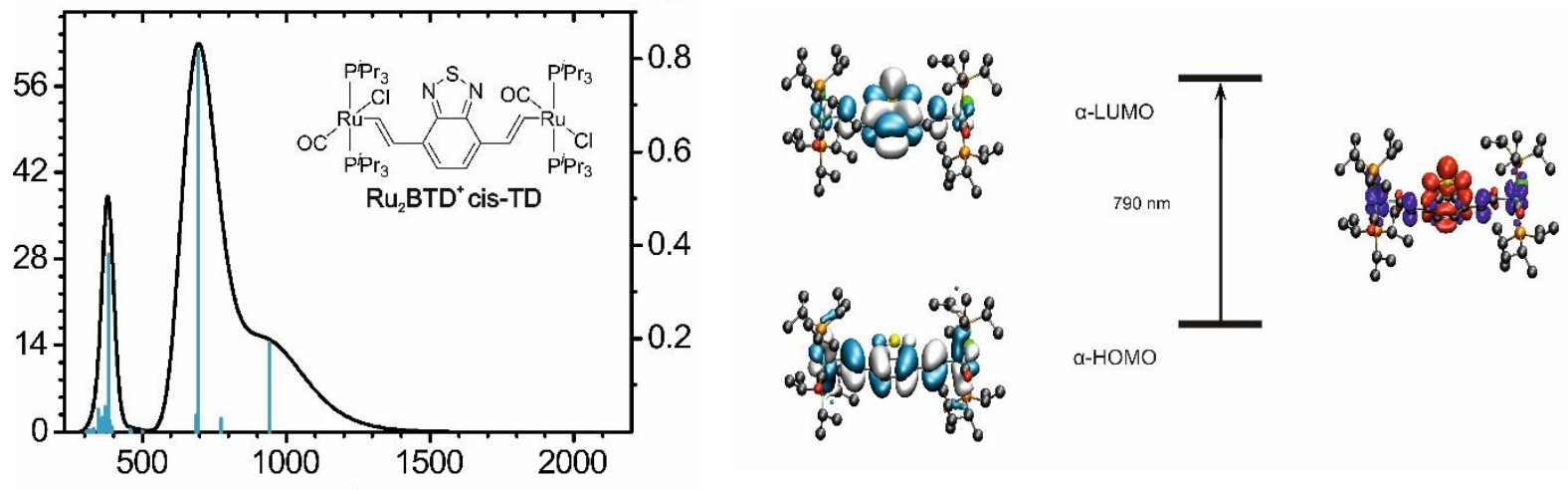

$\varepsilon / 10^{3} \mathrm{~L} \mathrm{~mol}^{-1} \mathrm{~cm}^{-1} \quad \lambda / \mathrm{nm} \quad$ osc. strength
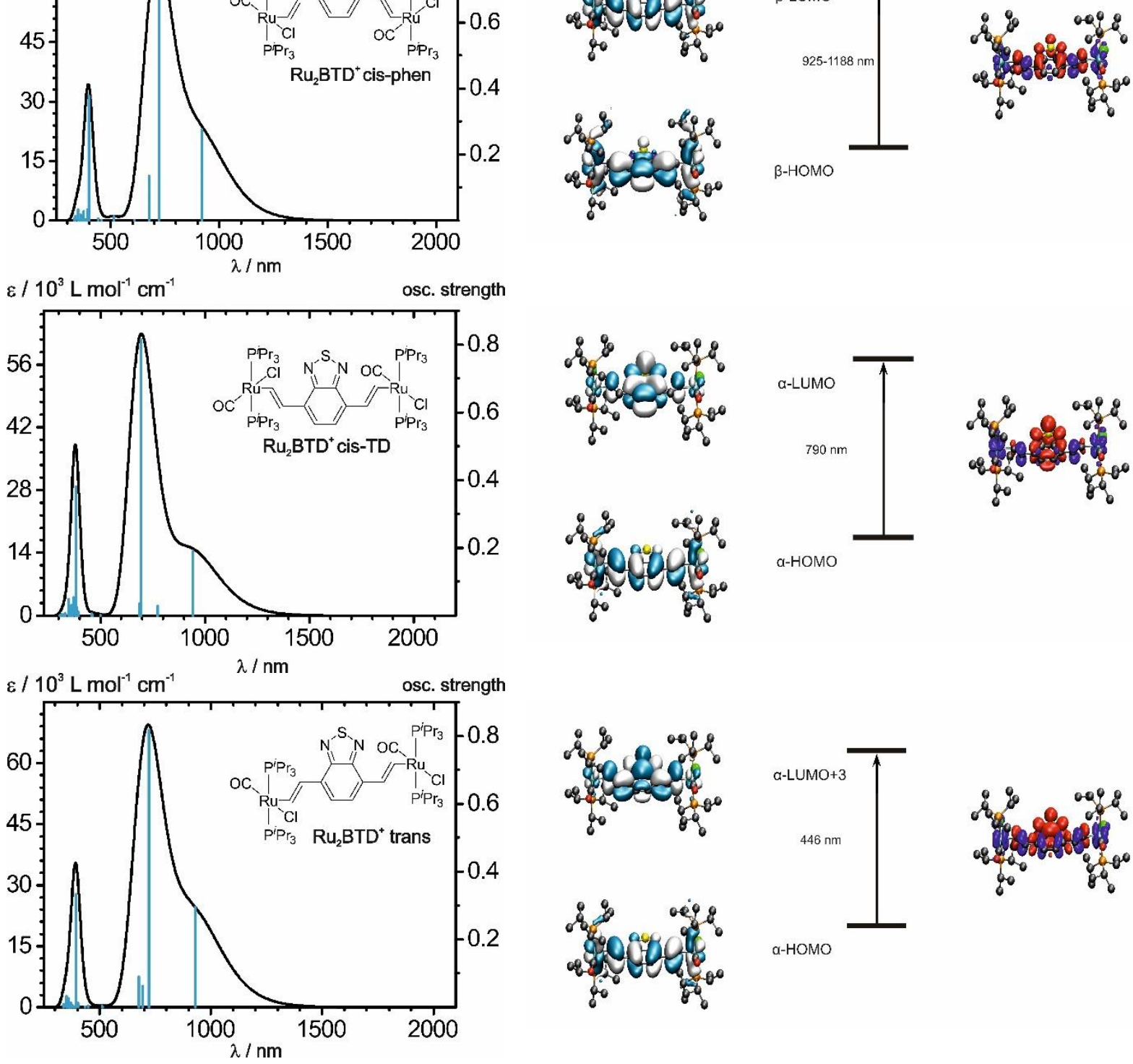$$
\text { go }
$$

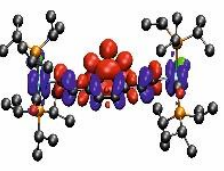

Figure S45. TD-DFT calculated UV/Vis/NIR absorption spectra for different rotamers of the radical cation $\mathbf{R u}_{2} \mathbf{B} \mathbf{T D}^{+}$and graphical representation of MOs with the largest contribution to the relevant transitions (configuration assumed where vinyl ruthenium units are in a cisoid orientation to the thiadiazol heterocycle $\mathbf{R u}_{2} \mathbf{B} \mathbf{T D}^{+}$cis-TD). Color coding for Electron Density Difference Maps (EDDMs); blue: electron density loss, red: electron density gain. 

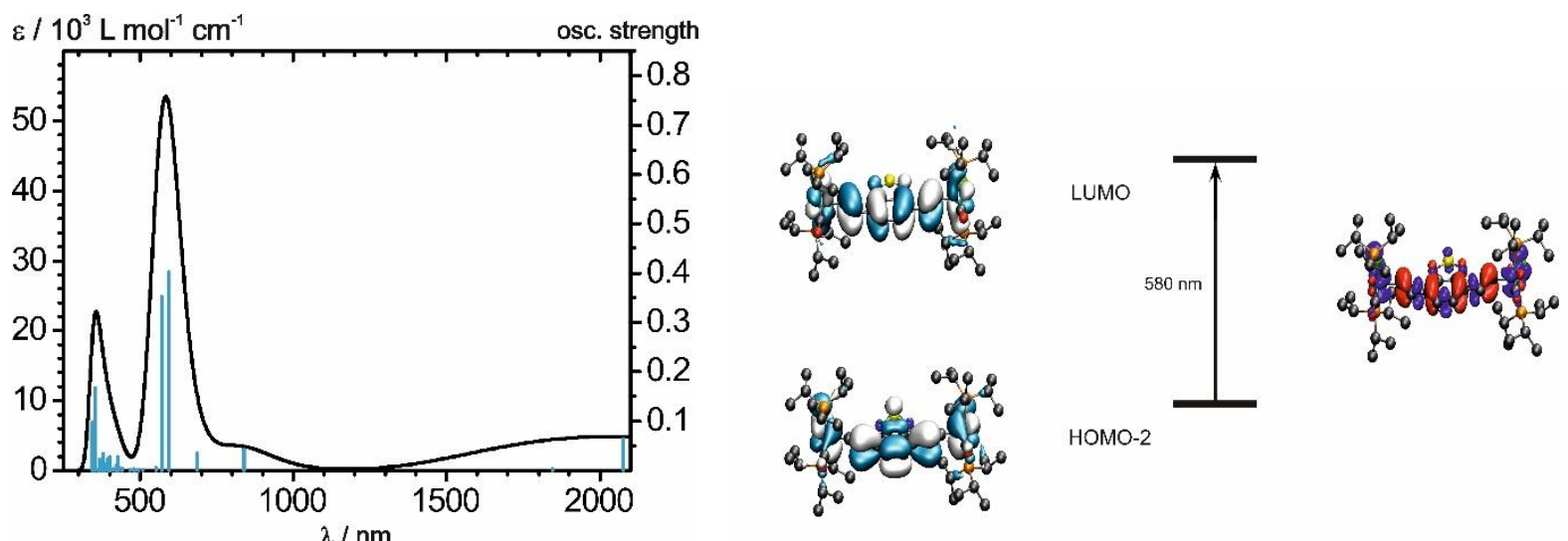

HOMO-2
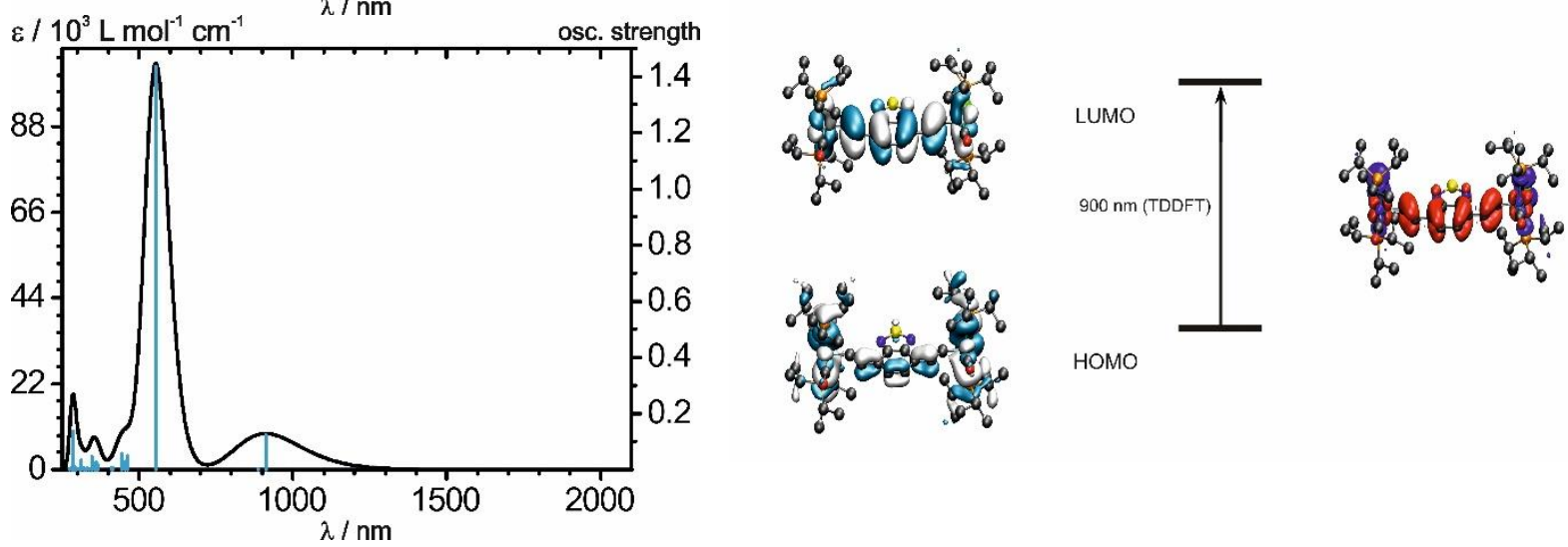

Figure S46. TD-DFT calculated UV/Vis/NIR absorption spectrum of the dication $\mathbf{R u} \mathbf{u}_{2} \mathbf{B T D}^{2+}$ in the singlet state (bottom, left) and the triplet state (top, left) and graphical representation of MOs with the largest contribution to the relevant transitions (singlet state assumed). Color coding for Electron Density Difference Maps (EDDMs); blue: electron density loss, red: electron density gain.
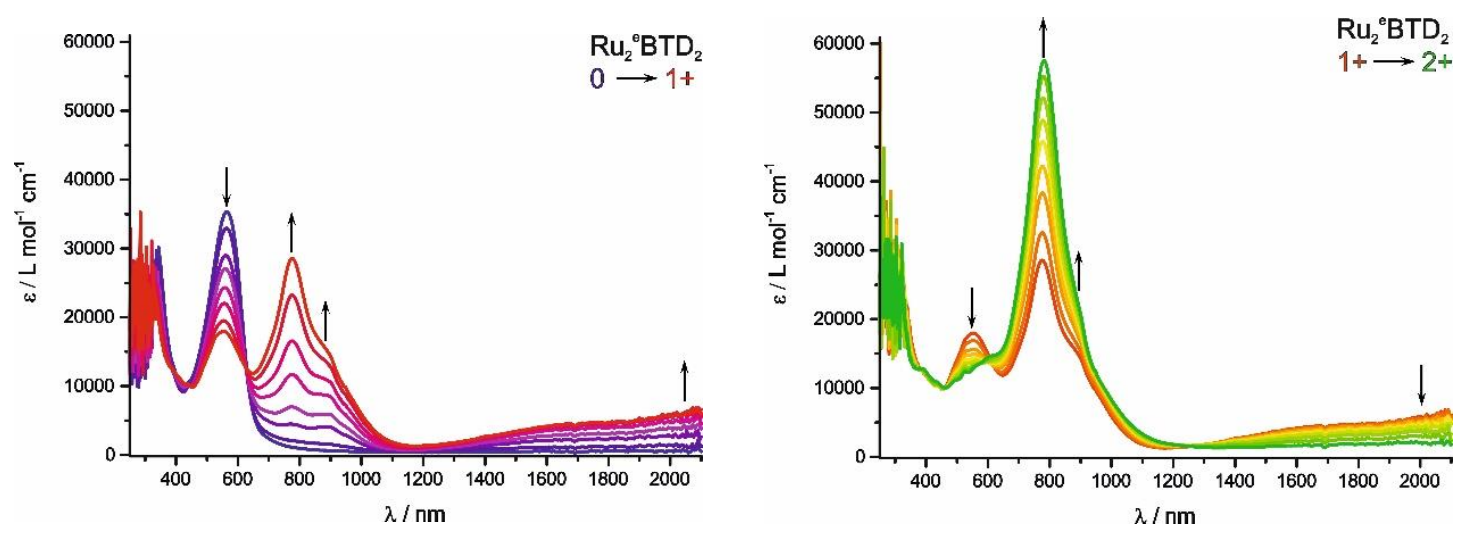

Figure S47. Changes in the UV/Vis/NIR spectrum $\left(\mathrm{CH}_{2} \mathrm{Cl}_{2}, \mathrm{NBu}_{4} \mathrm{BAr}{ }^{\mathrm{F}}, \mathrm{T}=293 \mathrm{~K}\right)$ of $\mathbf{R u}_{2}{ }^{\mathrm{e}} \mathbf{B} \mathbf{T D}_{2}$ during the first oxidation (left) and the second oxidation (right). 

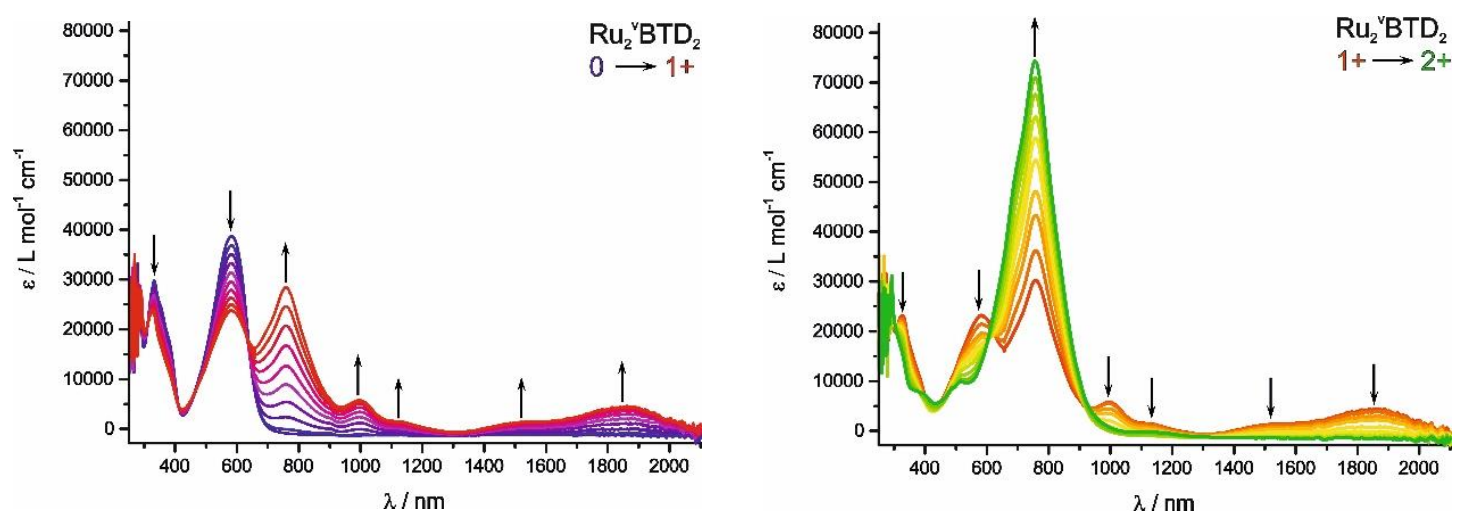

Figure S48. Changes in the UV/Vis/NIR spectrum $\left(\mathrm{CH}_{2} \mathrm{Cl}_{2}, \mathrm{NBu}_{4} \mathrm{BAr}{ }^{\mathrm{F}}, \mathrm{T}=293 \mathrm{~K}\right)$ of $\mathbf{R u}_{2}{ }^{\mathrm{v}} \mathbf{B} \mathbf{T D}_{2}$ during the first oxidation (left) and the second oxidation (right).

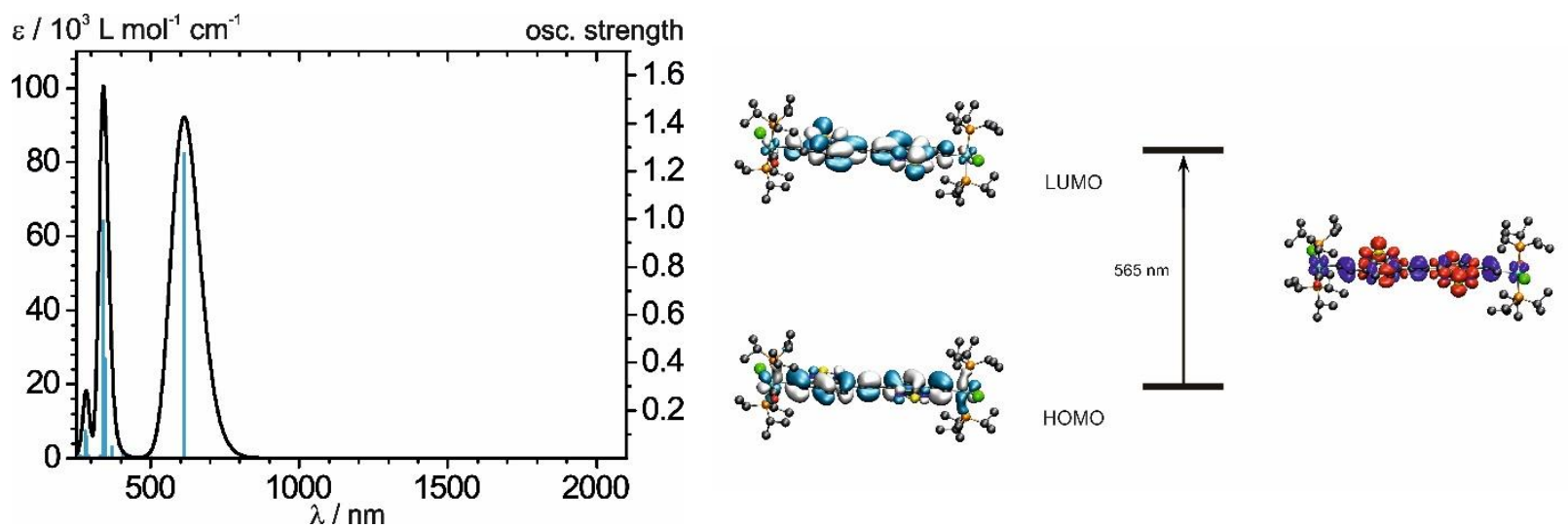

Figure S49. TD-DFT calculated UV/Vis/NIR absorption spectrum of neutral $\mathbf{R u}_{2}{ }^{\mathbf{e}} \mathbf{B} \mathbf{T D}_{2}$ and graphical representation of MOs with the largest contribution to the relevant transitions. Color coding for Electron Density Difference Maps (EDDMs); blue: electron density loss, red: electron density gain. 

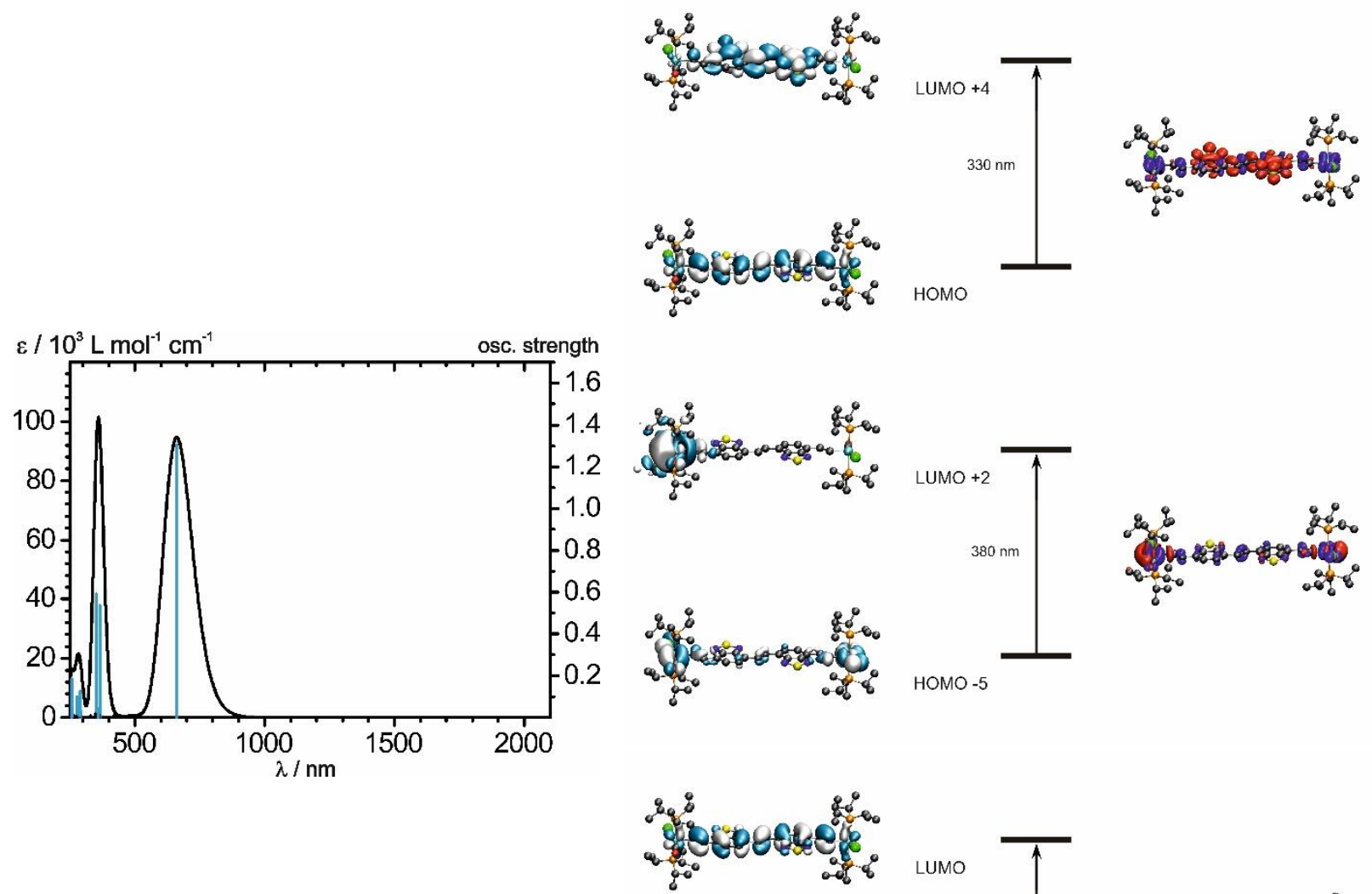

HOMO - 5
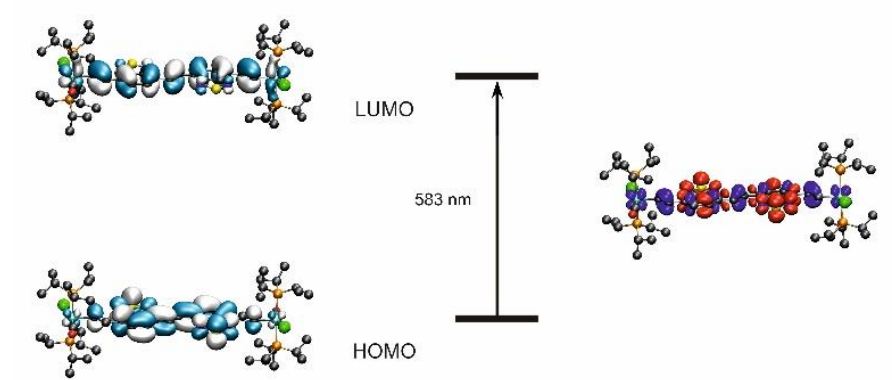

Figure S50. TD-DFT calculated UV/Vis/NIR absorption spectrum of neutral $\mathbf{R u}_{2}{ }^{\mathbf{v}} \mathbf{B T D}_{2}$ and graphical representation of MOs with the largest contribution to the relevant transitions. Color coding for Electron Density Difference Maps (EDDMs); blue: electron density loss, red: electron density gain. 

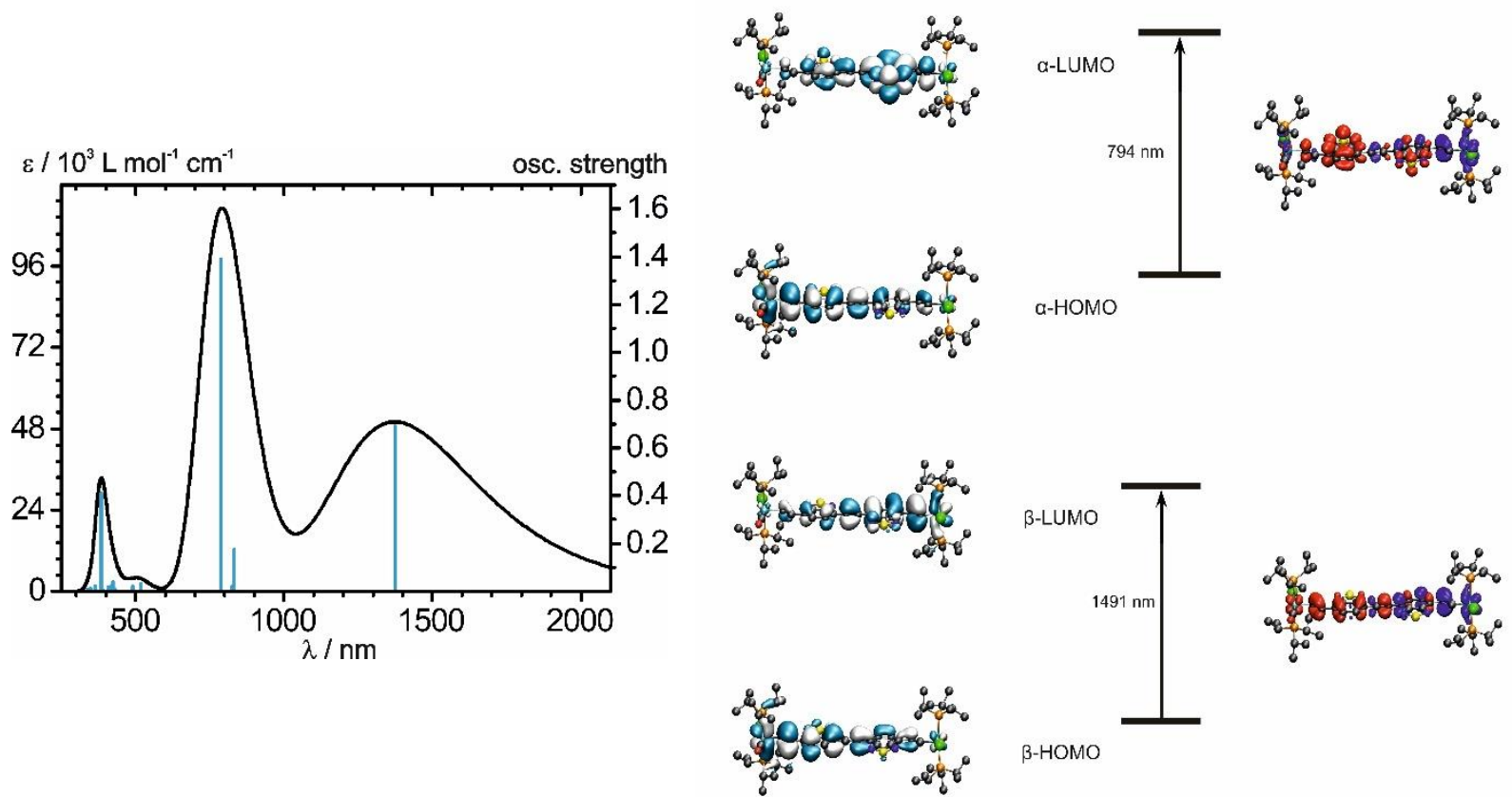

Figure S51. TD-DFT calculated UV/Vis/NIR absorption spectrum of the monocation $\mathbf{R u}_{2}{ }^{\mathrm{e}} \mathbf{B} \mathbf{T D}_{2}{ }^{+}$and graphical representation of MOs with the largest contribution to the relevant transitions. Color coding for Electron Density Difference Maps (EDDMs); blue: electron density loss, red: electron density gain.
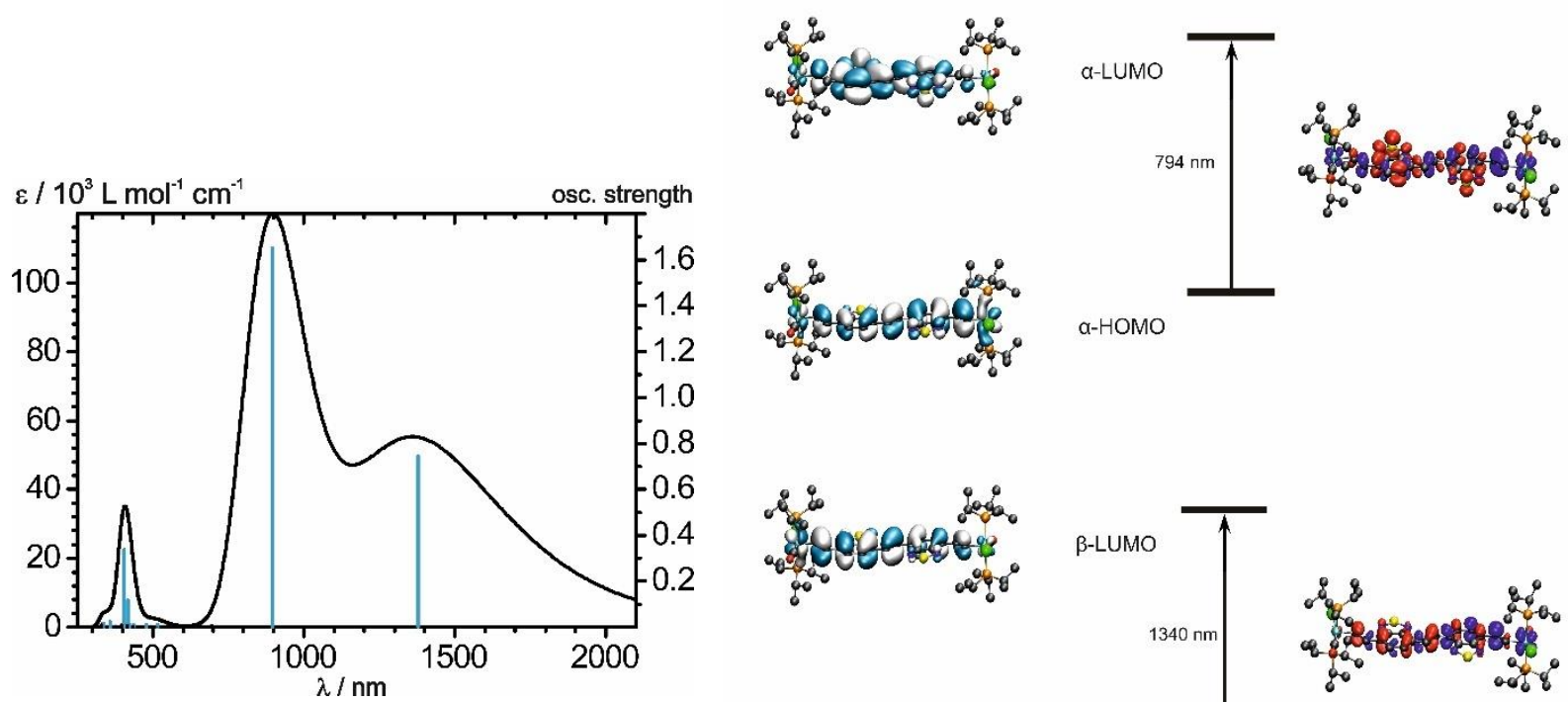

a-HOMO
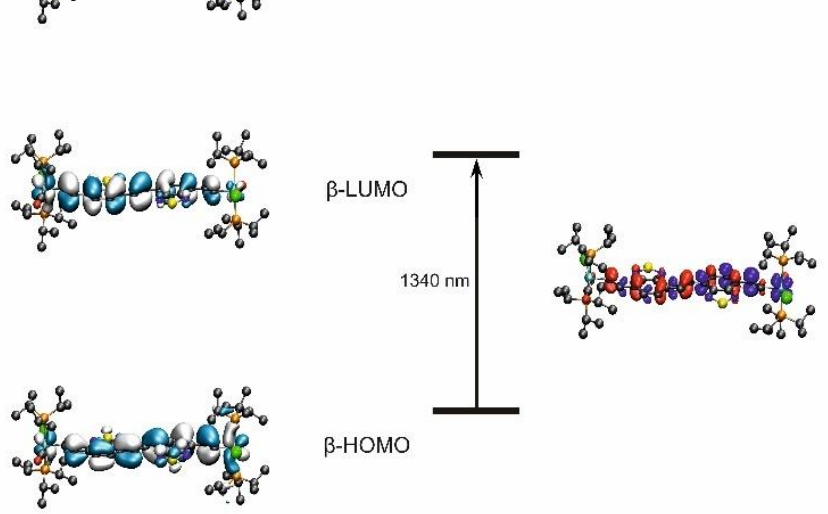

B-HOMO

Figure S52. TD-DFT calculated UV/Vis/NIR absorption spectrum of the monocation $\mathbf{R u}_{2}{ }^{\mathbf{v}} \mathbf{B T D}_{2}{ }^{+}$and graphical representation of MOs with the largest contribution to the relevant transitions. Color coding for Electron Density Difference Maps (EDDMs); blue: electron density loss, red: electron density gain. 

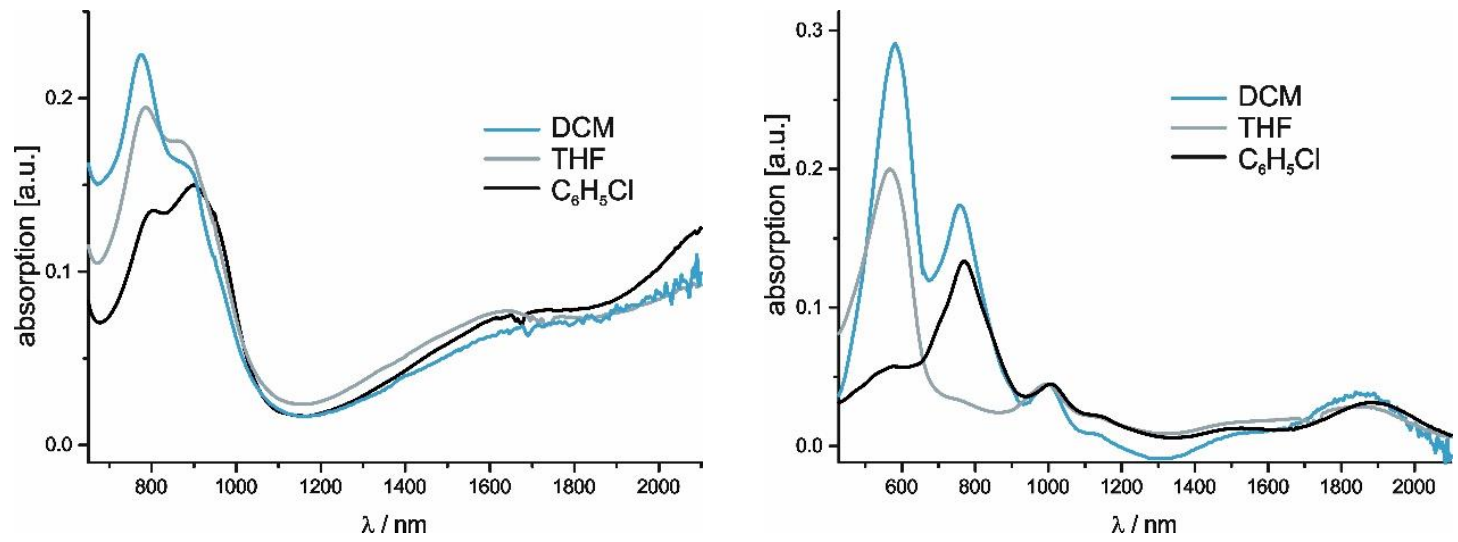

Figure S53. Vis/NIR absorption characteristics of the radical cation $\mathbf{R u}_{2}{ }^{\mathbf{e}} \mathbf{B T D}_{\mathbf{2}}{ }^{+}$(left) and $\mathbf{R u}_{2}{ }^{\mathbf{v}} \mathbf{B T D}_{2}{ }^{+}$(right) in three solvents of different polarity.
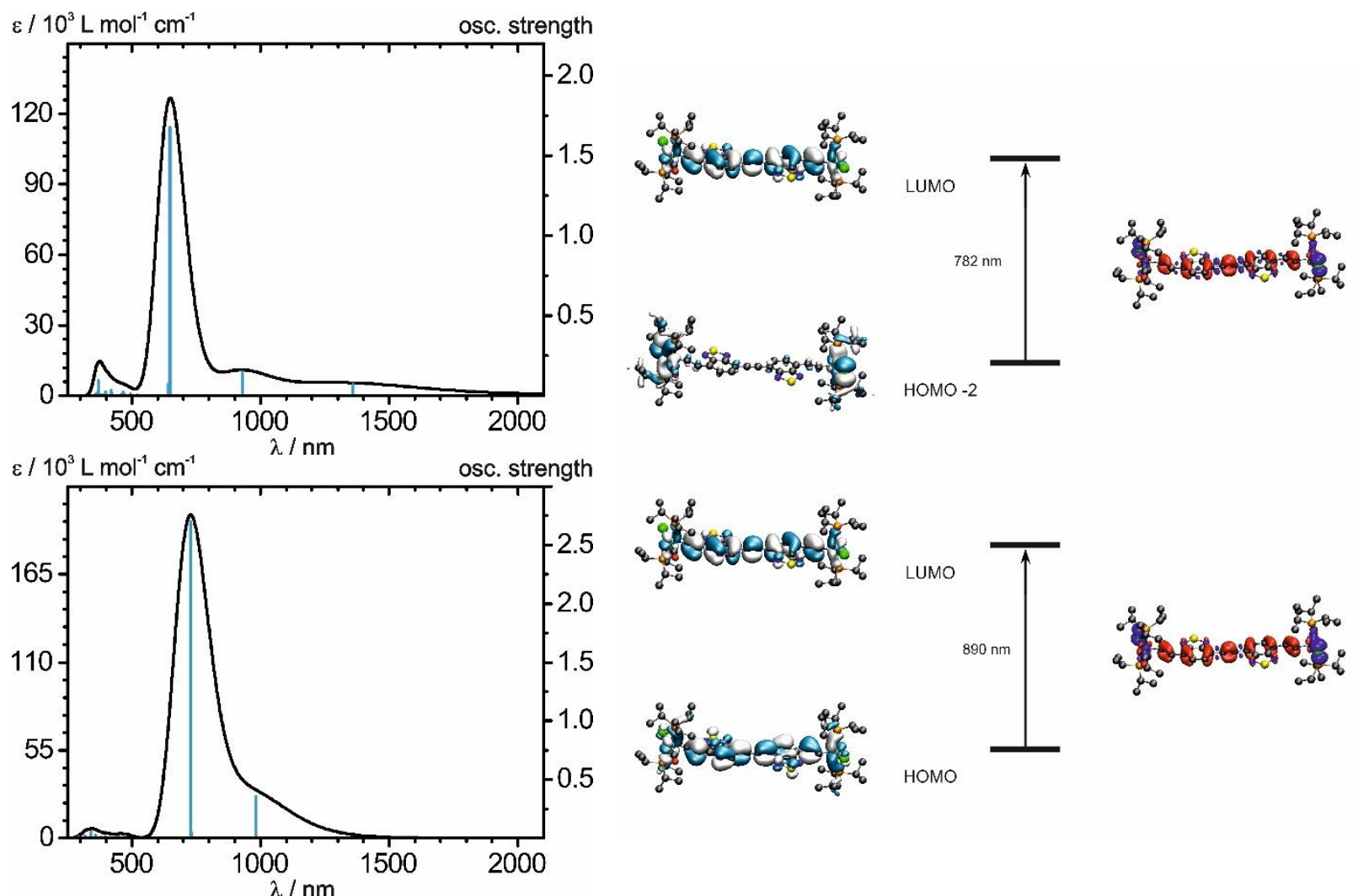

Figure S54. TD-DFT calculated UV/Vis/NIR absorption spectrum of the dication $\mathbf{R u}_{2}{ }^{\mathbf{e}} \mathbf{B} \mathbf{T D}_{2}{ }^{2+}$ in the singlet state (bottom, left) and the triplet state (top, left) and graphical representation of MOs with the largest contribution to the relevant transitions (singlet state assumed). Color coding for Electron Density Difference Maps (EDDMs); blue: electron density loss, red: electron density gain. 


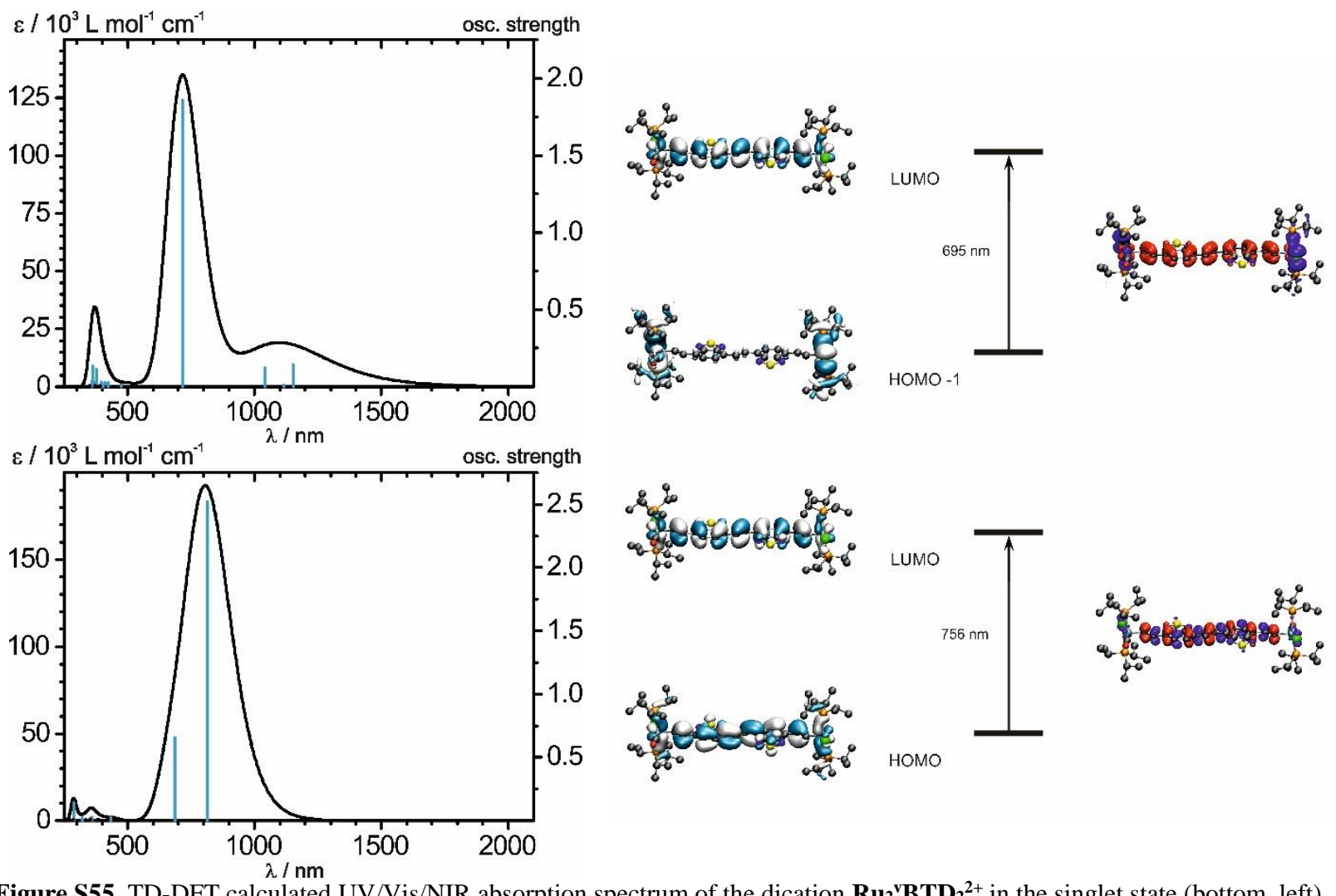

Figure S55. TD-DFT calculated UV/Vis/NIR absorption spectrum of the dication $\mathbf{R u}_{2}{ }^{\mathbf{v}} \mathbf{B} \mathbf{T D}_{2}{ }^{2+}$ in the singlet state (bottom, left) and the triplet state (top, left) and graphical representation of MOs with the largest contribution to the relevant transitions (singlet state assumed). Color coding for Electron Density Difference Maps (EDDMs); blue: electron density loss, red: electron density gain. 